ons

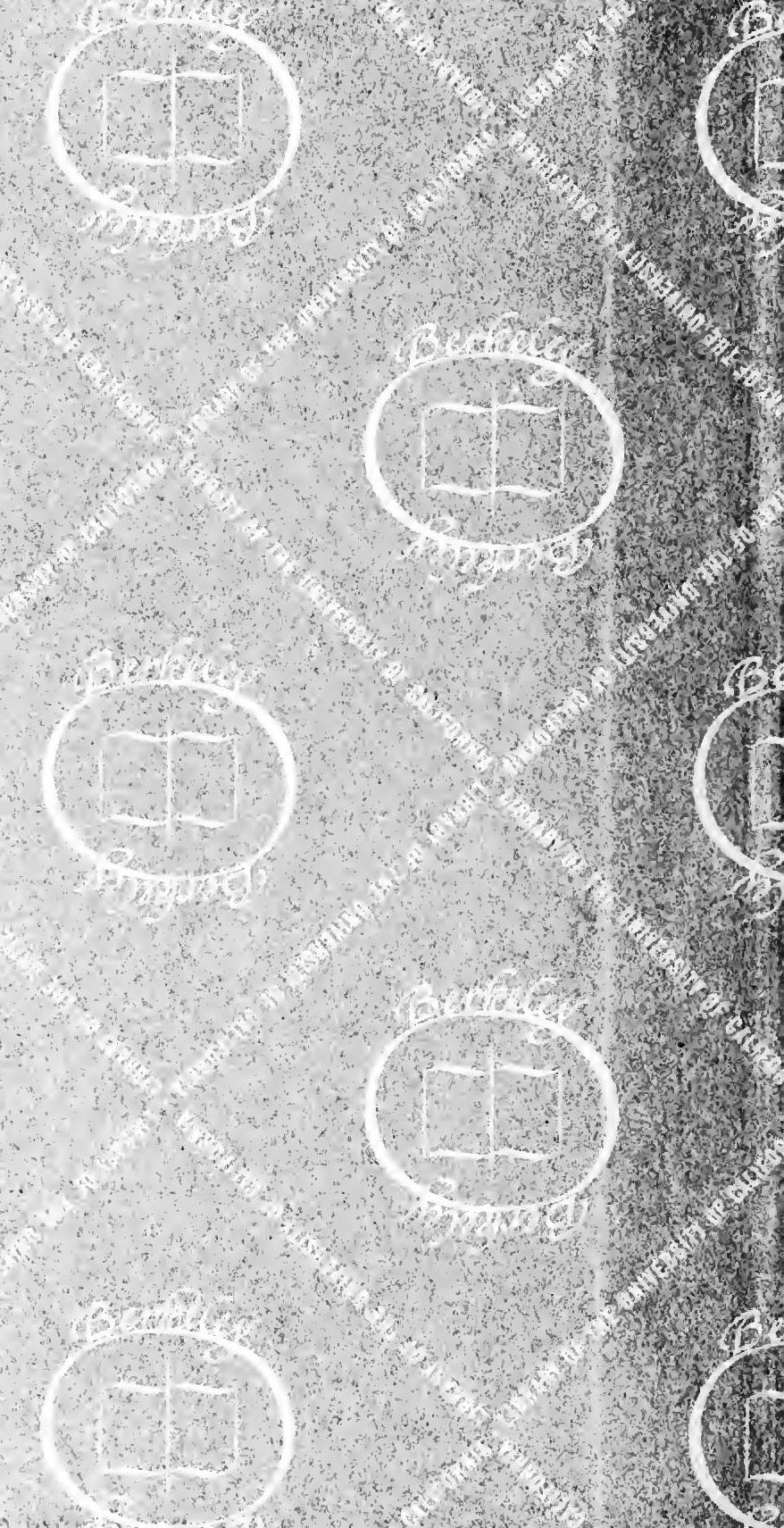




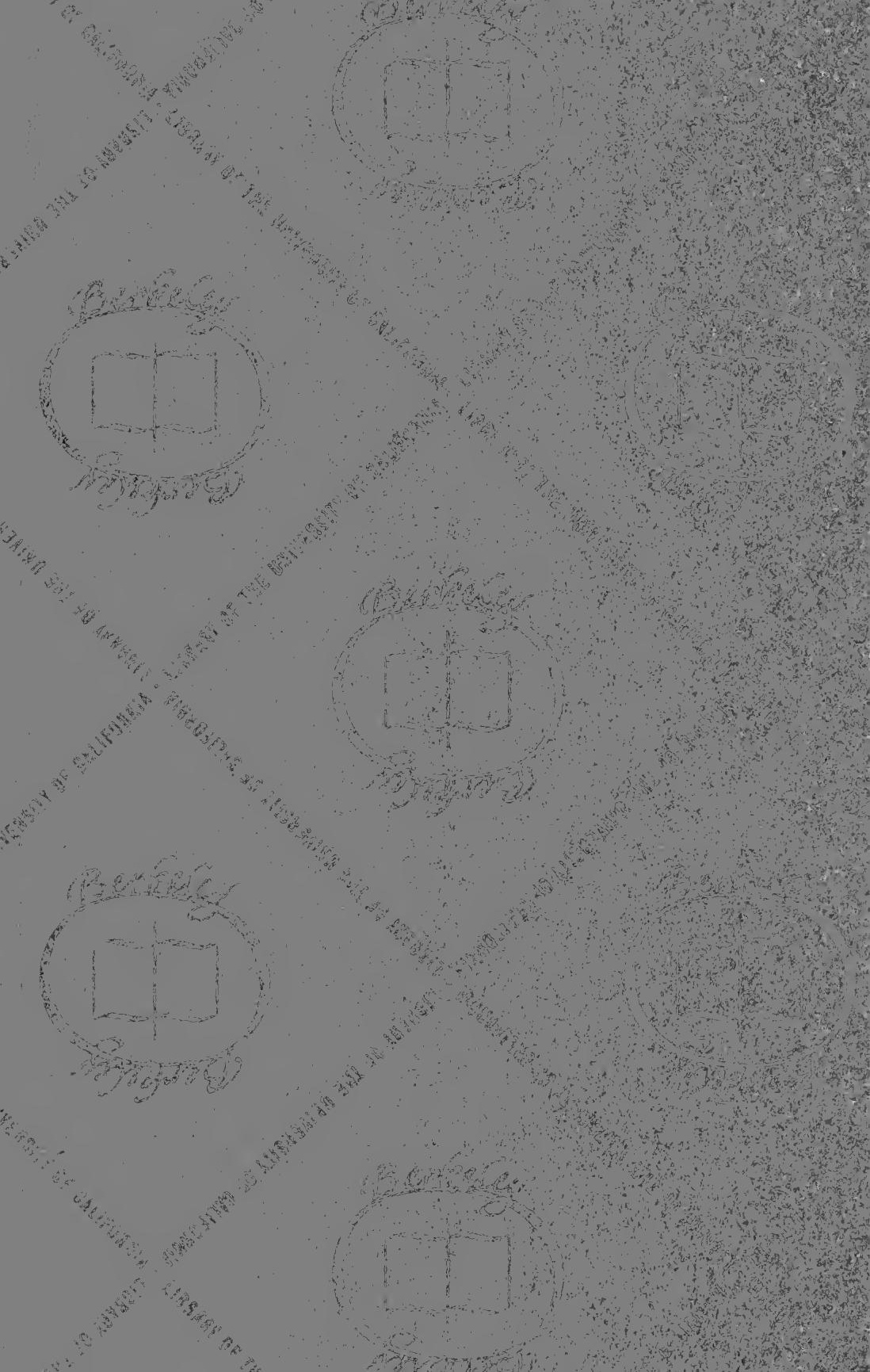



h 
Digitized by the Internet Archive in 2008 with funding from Microsoft Corporation 


\section{THE TEACHING OF GEOGRAPHY IN ELEMENTARY SCHOOLS}




\section{STUDIES IN THE TEACHING OF HISTORY}

By M. W. KEATINGE, M.A. Reader in Education in the University of Oxford

Large crown 8vo. Bound in cloth. Price 4s. 6d. net

Times. - "A book of much suggestion and value." Aberdeen Free Press. - "No teacher of history ought to be without these stimulating studies."

\section{BY THE SAME AUTHOR \\ SUGGESTION IN EDUCATION}

Large crown 8vo. Cloth. Price 4s. 6d. net

Education.-." One of the most valuable contributions to educational science which have been published during recent years."

A. AND C. BLACK, 4 SOHo SQUARE, LONDON, w.

\section{AGENTS}

AMERICA . . THE MACMILLAN COMPANY

64 \& 66 FIFTH AVENUE, NEW YORK

AUSTRALASLA. OXFORD UNIVERSITY PRESS 205 FLINDERS LANE, MELBOURNE

CaNada . . THE MACMIllan COMPANY OF CANADA, LTD. 27 RICHMOND STREET WEST, TORONTO

INDIA . . . MACMILLAN \& COMPANY, LTD. MACMILLAN BUILDING, BOMBAY 309 BOW BAzAar STREeT, CALCUTTA 


\section{THE TEACHING \\ OF GEOGR A PHY IN ELEMENTARY SCHOOLS}

BY R. L. ARCHER, M.A.

PROFESSOR OF EDUCATION IN UNIVERSITY COLLEGE, BANGOR

W. J. LEWIS, B.Sc., AND A. E. CHAPMAN, B.A.

\section{LONDON}

ADAM AND CHARLES BLACK 
LB 1583

A 6

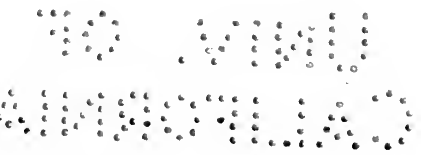




\section{PREFACE}

THIs little book is an attempt to apply the newer conceptions of Geography to teaching in elementary schools. It in no way aims at being original in its treatment of the subject itself: for these we are indebted to the body of geographers who have during the last few years revolutionized the conception of the subject, in particular to Mr. H. J. Mackinder and Dr. A. J. Herbertson, to whose works frequent reference is made in the following pages. We felt, however, that in regard to the teaching of Geography in elementary schools, the central idea for which they are struggling - that Geography is, above all things, the examination of the effect of natural agencies on human affairs-is not yet sufficiently recognized and acted upon, and our aim is to throw out some suggestions as to changes in the teaching which we believe would help the better realization of this idea. In the case of branches of the subject which have only recently come into prominence, we have given some outline of the subject-matter to serve as an introduction of them to readers to whom they may be unfamiliar, and have added information as to sources from which information may be obtained.

In the Index the pages where subjects are treated most fully have been printed in black type. 


\section{CONTENTS}

I. THE AIM IN TEACHING GEOGRAPHY - -

II. SUBJECT-MATTER OF A COURSE OF GEOGRAPHY - I7

III. ARRANGEMENT OF SUBJECT-MATTER IN THE COURSE 33

IV. THE CONCEPTION OF REGIONAL GEOGRAPHY - $\quad$ - 49

V. THE CONCEPTION OF ECONOMIC GEOGRAPHY - - 64

VI. WORK OF THE FIRST STANDARDS - $\quad$ - $\quad$ - 8 I

VII. MAPS AND THE TEACHING OF MAPS - $\quad$ - 96

VIII. PHYSIOGRAPHICAL SIDE OF GEOGRAPHY - $\quad$ - III

IX. BEGINNINGS OF REGIONAL GEOGRAPHY - - I30

X. THE PRINCIPLES OF CLIMATE - $\quad$ - $\quad$ - $\quad$ I49

XI. ASIA AND THE TEACHING OF CLIMATE - $\quad$ - I66

XII. TEACHING OF WHITE MEN'S LANDS - - $\quad$ - I90

XIII. THE TEACHING OF GREAT BRITAIN - $\quad$ - 207

XIV. BOOKS AND APPARATUS - $\quad$ - $\quad$ - $\quad$ - $\quad-\quad 229$

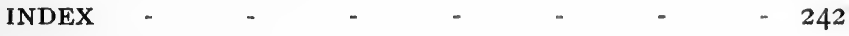




\section{THE TEACHING OF GEOGRAPHY IN ELEMENTARY SCHOOLS}

\section{I}

THE AIM IN TEACHING GEOGRAPHY

I. THE first question which is naturally asked in connection with any subject claiming a place in the curriculum of a school is, What is our object in teaching it? In the case of a subject of obvious practical utility, or with a long-established tradition as to its subjectmatter and methods, the asking and answering of this question is often regarded as a mere matter of form, or a conventional opening for a handbook of method. In the case of Geography, on the contrary, the answer makes a fundamental difference to our whole method of teaching the subject. It will determine what we teach and what we exclude; it will fix our order and our method; it will decide what is essential and what is detail.

Teachers are rapidly becoming discontented with the traditional manner of teaching Geography as a mass of facts, statistics, and names. In fact, while this was the only known method, good teachers usually despised a subject which appeared to be nothing more than a tax on the memory of their pupils. There is consequently 
$\therefore$ generalitendency to lowk round for guidance to a new point of view.

\section{Recent Adyances in the Higher Teaching of} Geography.-It is usually true of all branches of knowledge that the work of schools is ultimately dependent on the stimulus given by the more advanced work which is being done in the outside world and in Universities. Especially is this the case when new conceptions are being rapidly evolved, and the experts are, in fact, pioneers of a new development. And so we find it in the case of Geography. Since chairs have been founded in the Universities it has been given a new character. The lecturers have shown it to be an explanation of the manner in which physical laws affect climate, in which conditions of soil and climate in turn determine the vegetable and animal life of different countries, and in which, finally, all these conditions affect human life. They reveal it as the true meetingpoint of the Natural and the Human Sciences, meaning by the latter Economics, Sociology, and History. Enthusiasts even tell us that, so far from being an unscientific collection of facts in which no principle of cause or law can be found, it is the science of sciences, bringing together the laws which are found in all, and showing their operation as causes in the sphere of human life.

\section{The Effect has not yet been fully felt in Ele-} mentary Schools.-But, stimulating as this conception may be to the student who comes well prepared to the study of the subject, and responsible though it has been for the desire to change the dull routine of past teaching, we cannot help feeling that the very boldness of the claim may paralyze the teacher who has to 
present the subject to young children. Thus we find that, while the influence of the geographical experts has already reconstructed in its main lines the teaching of Geography in secondary schools, the bearing of the new conceptions on the curriculum of elementary schools is still felt to be a matter of uncertainty. Teachers feel that the old system is impossible; they do not feel that they know what to put in its place.

- This little book is a tentative effort to face some of the problems. The ideas which it sets forth are mainly derived from the new school of geographers, but we feel that a solution cannot be found in making the elementary school course a very pale copy of a University course, or even a preliminary to the work of the secondary school. The school education of most pupils ends when they leave the elementary school, and a self-contained course has to be supplied suitable to their age.

\section{Physiographical View of Geography.-A pre-} liminary word of warning has to be uttered. Side by side with the broad view of Geography put forward by the occupants of chairs in the subject there is another tendency, encouraged by experts in Natural Science, to treat Geography only as elementary Geology and Meteorology. The name of "Physiography," under which this kind of teaching used to be known, has lately disappeared from time-tables and syllabuses of examinations; but there is at the present time a marked inclination in some quarters to look for the basis of geographical teaching in the subject-matter included under that name by Huxley and the educational innovators of the "seventies," reinforced with geological material. This movement has gone so far as, 
in the case of some secondary schools, to introduce "geographical laboratories," and to include practical Geography as an alternative to other scientific subjects in schedules of examinations; in fact, it has created a widespread belief that Geography is to be taught by the methods used in teaching Physics and Chemistry, and that, unless it is so taught, it is not worth teaching. Many schoolmasters who have seen the need of reform, and have found in the lines advocated by physiographers the only positive suggestions for a changed syllabus, have come to identify reformed Geography with Physiography. This is not the place to discuss the curriculum of secondary schools, but in regard to elementary schools, we hope that the rest of this chapter will convince the reader that a clear conception of Geography can be found in which the physical is important only from its bearing on the human, and that this kind of Geography is a necessary part of the training of citizens in a democratically governed country. It would be difficult to prove the negative position that the physiographer's idea of Geography, if not used to illustrate the human, has not sufficient value to justify its inclusion in the curriculum of an elementary school ; but no considerations have as yet been put forward which in our opinion constitute even an attempt to justify such a course.

\section{Extent to which we should yield to the} Claims of Conventional Knowledge and to the Demand for "Mental Discipline."-Before putting forward what we consider to be the true reasons for teaching Geography in elementary schools, it will be well to deal with two classes of motives which may influence the treatment of the subject-which are, 
indeed, more likely to do so if they are not definitely faced and limited to their true sphere. These two motives are, first, what Herbert Spencer would have called the "conventional value" attached to a knowledge of certain facts, such as the names of the counties of England and Wales; secondly, the value as "mental discipline," which has long decided every question of curriculum in the eyes of masters in secondary schools.

Seeing that some information of a conventional kind is taught in all schools, and would probably be retained by every teacher who was actually confronted with the task of framing a syllabus, it would be mere affectation to deny all weight to this standard of value. It is much better to look for some canon which would enable us to differentiate between necessary and unnecessary information. A satisfactory canon is to be found by differentiating between knowledge to which value is attached by the outside world and that which derives its professed value only from classroom tradition. Information which the newspapers do not expect their readers to possess, which, in fact, most well-educated people outside the ranks of schoolmasters have either forgotten or else never knew, must show some other ground for inclusion in addition to convention. Knowledge which is generally assumed in adults may be kept in the syllabus, even where its value is conventional. In practice this criterion will sweep away all but a fragment of the lists which till recently have been all that has been meant by Geography. The little that is left can easily be fitted into a syllabus based on more substantial grounds.*

* See Chapter XI., pp. 167-I70, also pp. 212-213, for an application of this principle and those which follow. 
In regard to the considerations of Mental Discipline, it would be impossible to discuss the validity of the conception adequately in a book dealing with the teaching of one particular'subject. We therefore confine ourselves to stating the grounds on which we have dismissed these considerations in the following pages, without attempting to prove our position. We recognize that Mental Discipline is a reality-that is to say, that a careful study of a particular subject may exercise so strong an influence over a pupil's modes of thought that it affects his whole intellectual life, and not merely his further studies in the same field. The prerequisites for such a result appear to us to be-(I) considerable time; (2) such familiarity with the subjectmatter that work involving original manipulation of it occupies the main place. Thus, it is only in the highest form of a secondary school that we find a classical training beginning to give general appreciation of literary form outside Latin literature, which is claimed as one of its chief values, or the study of Mathematics creating its demand for exact proof in all matters of reasoning. In an elementary school the age of our pupils and the time at our disposal make it impossible to reach such a result except in the case of subjects such as Composition and Précis-writing, where the subject-matter is taken from ordinary life, and the whole time can be spent in more or less original manipulation.

The extent of this contention must not be misunderstood. We do not mean to imply that the earlier training does nothing to make the pupils think. It makes them "think" perfectly well if the subject-matter and mode of reasoning present analogies to those which 
they have met in school ; but there is little of the unconscious influence which helps to determine a man's judgment even on questions which lie quite outside the scope of his school or academic studies. In other words, the aim of geographical teaching in elementary schools is limited to giving a sound judgment in matters which are influenced by geographical causes. The succeeding pages hope to show, even with this reservation, how wide a field of thought is covered by the subject.

\section{Statement of the Aim accepted in this} Book.-We are now in a position to state the conception of the purpose of geographical teaching on which this book is based. This may be defined as the acquisition by the pupil of a familiarity with the working of geographical principles in concrete cases, and the creation of a more enlightened outlook on other peoples and on certain classes of public events.

Two important limitations in this definition must be noted. First, it is not proposed to teach abstract principles, only to give a picture of their concrete manifestation. The significance of this distinction is brought out in a later section.* Secondly, we speak of "familiarity" with geographical considerations, not of a power of independent geographical reasoning. Few of our pupils will be able to think out for themselves problems which are ultimately dependent on geographical conditions ; but they will, through this familiarity, be better able to appreciate the arguments of others. The power of the press, of the platform, and of the pulpit towards influencing public opinion depends on the existence of a public which is capable of appreciating their appeals. 
In political matters, for instance, parties always push to the forefront of their programme those issues which are most likely to influence votes; if public opinion is sufficiently educated to be able to appreciate the relative importance of the issues submitted to it, then politicians are bound to cease "dragging red herrings across the trail," and to take their stand on substantial grounds of policy.

In the next section it will be shown by a few instances how great are the bearings of Geography on public questions; then an attempt will be made to show that the subject can be so taught to children as appreciably to influence their attitude to these questions in later life. Readers are warned that at first sight the complexity of the questions will suggest doubts as to the adequacy of any school teaching to achieve this purpose; we only beg them to defer forming a judgment till they have read the entire argument. As far as possible, topics on which political parties in this country have been divided in recent years have not been selected as instances, in order to avoid any appearance of bias.

4. Instances showing the Bearing of Geography on Public Questions.-The first instance . may be taken from the policy of territorial expansion in distant continents which was adopted by most European countries in the "eighties." Germany, France, and Italy all acquired large tracts of land in Africa. It is quite obvious that the productivity of a country depends on its soil and climate; it is also evident that all three Powers acquired territory, the soil and climate of which did not warrant any favourable estimate of their productive power; and we are forced to the conclusion that if the people of these countries had com- 
pelled their Governments to give clear accounts of the grounds on which they considered those annexations desirable, the Governments would have hesitated considerably before attempting to convince the electorate of their desirability.

Again, the foreign policy of a country is influenced considerably by the desire to obtain markets for its own goods, and to receive in exchange the products of other countries. Occasionally such a policy leads to wars. At the present time, fortunately, the foreign policy of this country is not a matter on which parties are acutely divided; but it would not be safe to assume that this state of feeling will be permanent. In case the policy were seen to involve serious risks of a war, it would almost certainly be unable to bear the strain, and then would come the time when there would be needed a public opinion which would appreciate the geographical arguments that ought to be employed.

Or, again, with the greater facilities for communication which have arisen within the last half-century, European nations are brought into much closer touch with the Asiatic peoples, politically and commercially. At any moment some question concerning the Near East, India, or the Far East, might become the burning political question of the hour. It is quite possible, too, that, by the time boys now finishing their schooling are middle-aged men, the Eastern nations, with their great supply of cheap labour, may be our great manufacturing rivals. Is it well that the ordinary Englishman should, as he too often does, interpret the motives of all other nations, even Oriental nations, as if they were Englishmen? Cannot he learn enough about these nations to know at least the need of caution 
in forming his opinions as to their probable actions and feelings?

It was stated above that these instances would not be drawn from present political controversy, and it is well to remember that the school-children of ten will not be the citizens of forty for thirty years. If we look back to 1880 , thirty years ago, we find that no one then could have had any conception what would be the pressing questions of I9ro. But the chief dividingline between parties now, the question of the taxation of imported goods, has arisen from causes arising outside this country and coming within the scope of Geography - that is to say, from the rapid growth of manufactures in Germany and the United States; while the other aspect of the question, Colonial Preference, has arisen from the development of the natural resources of our own Colonies. Even while these pages are being written, the country finds it has to face the entirely new situation of being confronted with a Power which threatens our command of the sea. The significance of this fact again depends on Geography. We may be certain that the questions on which the people must make up its mind in I940 will not be the questions of I9IO; we may be certain that many of them will involve geographical issues; we cannot tell certainly what they will be. This is well for the schoolmaster, who is bound not to be a political partisan. Even if he wished, he knows that it is not of great use to influence his pupils' ideas on the topics of immediate controversy; and it is hard to be a partisan about the events of thirty years hence, much harder than about those of three hundred years ago. 
5. Before passing to consider how far the school can accomplish this work, it will be well to consider a second and somewhat different aspect of our attitude to current events - that of feeling rather than intellect. Mistakes may be made equally well from either. A big nation may deliberately bully a little nation, knowing all the time that it has no just claim on its side; but it is equally possible that a third nation may, from a false sentiment and ignorance of the issues, support a smaller nation which is really in the wrong. The former is a case of bad feeling, the latter of wrong judgment. The tendencies of Englishmen in dealing with any question of foreign relations are well known. One large section, as in most nations, is disposed invariably to think that our own nation is in the right; another -and this is almost peculiar to ourselves-that it is in the wrong. We tend both to dislike and to laugh at foreigners, until they are engaged in a war or a revolution, and then we become strong partisans. Moral questions we tend to judge according to their age. The ordinary man judges slavery by a standard which he would consider pharisaical if applied to the opium traffic, mainly because the views of Pitt and Wilberforce on the former are to be found in the history book. Almost all these errors can be corrected by making ourselves more familiar with other nations. People who render us services and to whom we render services, our tradespeople and our customers, are thought of very differently from those with whom we have no ties. When once it is realized that the world is a commercial unit, that we depend for the food on our breakfasttable on the labours of some black or yellow man in India, China, or the West Indies, then that man is 
brought into a human relation to us. If ever any country needed to have this attitude encouraged, it is our own Imperial democracy. We have assumed the largest share of the "white man's burden." The Englishman's attitude toward his dependent and his beast is sound, and he will naturally extend it to the dependents of his nation, if only their existence and conditions are made alive to him. This, then, is a second demand on the school teaching of Geography.

\section{Effect of School Teaching in giving this} Breadth of Yiew.-Can the school accomplish these two aims? Is it not too much to expect that instruction given before the age of fourteen, and then discontinued, can enable men to judge of questions which do not arise till thirty years later? Is it not unreasonable when we admit that there has been no exact training of any abstract power of reasoning? If it is not so, we see no great benefit from any alternative course of Geography, and cannot tell how any application is to be given to instruction as to the behaviour of rivers, the trade-winds, the formation of coral islands, and the other matters which are now beginning to fill our Geography syllabuses.

The one rule which disposes of the difficulties lying at the root of most objections is that we should teach, not abstract principles, but concrete examples.* The principles are often difficult economic or sociological laws. But we do not suggest teaching a series of propositions such as that intensive agriculture is better fitted to thickly-peopled countries and an extensive

* We are not here referring to purely physical laws, such as those of climate, which are discussed below. 
system to places with a small population, that manufacturers need easy access both to markets and to raw materials, that an established manufacture tends to remain in the same place even after the original reason for its establishment has ceased to be operative, and that the security afforded by a good system of government is necessary to the useful outlay of capital. If we tried to teach in this way, we should spend most of our time in fruitless explanations that apparent exceptions are really exemplifications of a rule, that seaports 2,000 miles away from the place of growth of raw materials may have more "easy access" to them than inland spots Ioo miles distant, or that the word "tend "generally implies that there are often counteracting " tendencies" which make the rule inoperative, though it still remains as true as ever. These are instances of the difficulties which make subjects like Economics hard for older students and impossible for children.

If, however, we give descriptions of particular industries and the chief reasons operating in each case, and that case only, children acquire a certain familiarity with the variety of industries on the globe and the kind of conditions to which they may be attributed, which would not guide them straight to conclusions for themselves, since generally they will overlook some important factor, but would guard them against the more flagrant fallacies. Their minds are broadened by realizing that when "agriculture" is mentioned, it does not always mean the English mixed farming, and that, in different countries of which they have been told, soil, climate, population, and accessibility have all had something to do with the result. If they ever thought of emigrating they would know better what inquiries to make; 
information would mean more to them when it was given. Though no generalization had ever formed itself in their minds, yet the story of the development of a new country must modify their way of looking on capital in later life. The old-fashioned habit of regarding constitutions, not as growths arising out of the needs of particular nations at particular times, but as unaccountable deviations from the one ideally best constitution, could not stand against the variety which Geography exhibits.

If we look back at the instances of public questions which were suggested several pages back, the real factor determining the public attitude will be seen to be breadth of view. The people must have become sufficiently familiar with geographical ideas to make them a part of its working consciousness.

And, after all, does education cease at fourteen ? Is not the intelligent reading of newspapers and magazines a more definite continuation of the study than any which is afforded by most school subjects? The nation already reads the newspapers and takes an interest in politics; we have the easier task of grafting on this habit a true idea of the relative values, not the harder task of rousing a wholly new interest.

If the geographical teaching is actually to influence the attitude in reading the newspapers, it can only be through interest. Whatever is abandoned, interest must be aroused; for the recurrence of the ideas acquired at school and their application in later life depend wholly on the striking and suggestive force of these ideas. Amid all the mass of routine instruction which slipped past without leaving any permanent impress, he is an unfortunate man who cannot remem- 
ber a few ideas, perhaps quite incidental to the set purpose of a lesson, which proved suggestive-that is, which struck the fancy, retained a definite hold, and became a permanent centre of growth in his intellectual life.

In the new geographical teaching we look for an air of reality which will make such ideas far more numerous, a conviction on the part of the teacher that he is handling real problems whenever he is teaching Geography, and an arousing in the mind of the pupil of a feeling that he is not dealing with signs on a map, but the facts of the world in which he will live, the progress of which will affect his welfare, and the welfare of which he himself can influence.

7. Conclusion. - To some this statement of the aims of geographical teaching may appear to be narrowing. They may say that we are basing on utilitarian grounds the claims of a subject which in reality embraces the whole of our physical and human environment. Even if a child were never to grow up to have a voice in forming public opinion, yet the claims of his own nature, they will urge, demand that he should know the story of the mountains and valleys and rivers that surround him, the solar system of which this planet is a part, and the men, with their joys and griefs, their thoughts, feelings, and acts, who along with him form its inhabitants. All this we grant; but the value of this knowledge is that it gives to the individual a sense of his responsibility and a feeling that he is a part of a system of which intelligent life is the centre; and we have but translated this feeling into terms of action and influence. The world is so ordered that a man's character and his influence are the same. Further, 
the mode of treatment that has been adopted affords a direct criterion of what must be taught and the spirit in which it should be taught, while the other would be found to be too vague for real guidance. Every learner should welcome knowledge for knowledge sake, but anyone who adopts this standard as the basis of curriculum will find that it leads to regarding all knowledge as of equal value, an equation which can only be solved in practice by making both its sides equal to nothing.

Before proceeding to deal more fully with the subjectmatter of a Geography course, it may be well to summarize the conclusions of this chapter.

I. The function of Geography is to show the bearing of physical conditions on human life, and in so doing it overlaps Economics, Sociology, and other human sciences which have no definite name.

2. The method of teaching the subject in elementary schools is by examining concrete facts and their relations, without attempting to formulate general laws, except where they are purely physical.

3. The only hope of success rests on interest, a term which will always be used in its higher sense-not for the mere transient attractiveness of a classroom device, but for the permanent interest which arises from a realization of an enlarged outlook, and is always seeking to add to its knowledge within the same sphere.

In the succeeding pages these conclusions will be applied. Any discussion of abstract principles is intended to guide the teacher, not for statement to the class; and if undue space appears to be given to them, it is because it is on this side that outside assistance can most easily be given to a teacher. 


\section{II}

SUBJECT-MATTER OF A COURSE OF GEOGRAPHY

I. Causal Sequence in Geography.-The general sequence of cause and effect in Geography is easily stated. It may be divided into (I) a few preliminary climatic principles, (2) the mode of applying these to particular countries.

The essential principles of climate may be classified as follows :

(I) The daily and yearly movements of the earth explain day and night and the changes in the seasons.

(2) From these changes follow the distribution of heat and the length of days in various latitudes.

(3) The distribution of winds (trade-winds, monsoons, temperate south-westers, etc.), together with the prevailing currents in the oceans, would next be taken; and thus would be explained

(4) The distribution of rainfall and some slight irregularities in the distribution of heat throughout the world.

It remains to apply these principles to particular countries, for, when they are known, a good map of any country gives most of the information that an inquirer needs in order to make a rational attempt to conjecture the rest of its characteristics. The only important facts which he requires to know in addition are the distribution of the minerals and, occasionally, 
the nature of the soil. The application will run as follows :

(I) The map shows the position and physical features of the country.

(2) These determine its climate.

(3) The physical features, climate, and soil determine its vegetation.

(4) The climate and vegetation determine its animal life.

(5) The previous factors, together with its mineral resources, determine all the elements of its human life, such as cultivation, manufactures, commerce, and density of population.

In practice Geography is not so simple as it is here represented, yet this is the rough outline, and it is as true as many provisional half-truths that are stated in all branches of science. Geography itself consists largely of approximately true statements, which are gradually modified by increased knowledge of its complexity. Children in school are, for instance, confidently taught that the earth is round. More precise investigation led men of science to define its shape more accurately - first as an "oblate spheroid," then as an "oblate spheroid tending to assume the shape of a tetrahedron." Experts have now decided that the exact shape of the earth is like that of no other body, actual or geometrical. Sir John Herschell says that we can only call it earth-shaped. Yet the rough approach to accuracy contained in the statement that the earth is round was the first step towards obtaining a true idea of its real shape. Similarly, the rough outline contained above is true in its outlines, though it will need many additions and modifications as we proceed. 
Illustration of the Causal Sequence in the Case of Australia.-The nature of the causal sequence described above will now be shown in a concrete case, by applying it to the condition of Australia, the smallest and simplest of the continents.

Climate-(I) Temperature.-The map shows us that Australia extends equally on both sides of the Tropic of Capricorn. Its temperature, therefore, varies from the tropical heat of equatorial lands to a warmtemperate climate like that of the Mediterranean.

(2) Winds.-A general knowledge of the regular winds of the world tells us that the tropical (northern) part falls within the zone of the north-west monsoon in summer and of the south-east trade-wind in winter, and that the temperate (southern) part falls within the belt of the westerly anti-trade-wind; while the bulk of the continent lies within the "Horse Latitudes," from which winds blow out, but towards which no winds blow in save the south-east trade-wind in the height of summer.

(3) Rainfall.-We again look at the map and find that the interior consists of a cuplike depression, that the western half is a great plateau with its edge close to the coast, and that the only considerable highland uplift runs parallel to the eastern coast. We know that moist winds for the most part discharge their moisture as rain only when they are forced upwards by high ground; $*$ hence we infer that the cuplike depression will be rainless. We then consider to what parts of the continent the winds which have been enumerated will bring rain, with the following results :

* We are not here considering the effect of cyclonic disturbances, on which see p. 153 . 
(a) The north-west monsoon will bring a summer rainfall to the north coast. (b) The westerly temperate winds will supply the two southern protuberances (Victoria and the south-west corner of West Australia). (c) The south-easterly trade-winds will be unable to cross the great belt of upland running parallel to the east coast, and will therefore only bring rain to the north-east coastal strip in winter and the more central belt of the east coast in summer.

The consequent distribution of rain will be: Tropical summer rain in the north-west and east; tropical winter and summer rain in the north-east; temperate rain in the southern protuberances; and little or no rain in the centre and on the western plateau.

Vegetation AND Human Life.-Hence we reach the fact that much of Australia has no economic value, and that even the more valuable part is more fitted for pasture than for arable land, and, in consequence, the population is small.

Complexity of Interaction of Causes in Geography. -It must be remembered that even these statements are only rough generalizations, and that this continent was chosen for its simplicity of structure. Geography is not like chemistry; we cannot pick up continents and put them in test-tubes to see what changes would take place in them if we varied the conditions one by one. If we could do so, we should soon be able to determine the dispute as to the reason why trees will not grow in certain parts of North America, whether it is due to the rainfall being a trifle too small or to the soil not being suitable. As it is, we often find such an intermixture of causes that it is difficult to tell what part each plays in producing the 
result, and consequently impossible to prophesy exactly what would happen under slightly changed conditions. But if prophecy is uncertain, it is none the less useful, as it has frequently passed the test of experience. Analogy suggests that some plant-for instance, tea or coffee-will grow in some new country. A large number of varieties is tried without success, but at length a variety is found which flourishes, and may become the chief product of the district. We do not know all the causes at work, but what we do know has in such cases proved enough to show the right lines for the development of a whole country.

This Complexity emphasizes the Need of Concrete Teaching. - An obvious conclusion suggests itself to teachers from the complexity of Geography. It is this: Though the main physical laws may quite well be taught at some point in the pupil's career, yet no value attaches to them unless he has become familiar by constant instances with the kind of way in which they operate and interact. The human mind does not work after the manner of a scholastic disputation, first enunciating principles and then their application. In actual life we are confronted by situations, and our minds meet them by analogy, and work along grooves already formed. When we find a situation difficult, our thoughts turn to a similar case which we recollect, and not to the law of which that case was an example. If they reach the law, it is through having thought first of the example. "Will such and such an industry thrive?" "Is such and such a country likely to think this point so important as to risk a war for it ?" "Is this town likely to grow, and is it worth settling there?" This is the form in 
which geographical problems present themselves; the situation recalls others, and then we tend to revert to the lines of thought on which we moved in the past when we were engaged in such questions. Then it is that the point which caught our fancy recurs-the flash of illumination with which some unsuspected connection revealed itself-we find ourselves thinking all round the subject; the effects of reiteration, varied illustration, and active inquiry begin to tell, and we feel that this point must be the real root of the matter, and that the other suggestions are irrelevant. Men constantly act on principles, rarely formulate them. This statement is emphasized here, because it is on the physical side of Geography that we actually do formulate principles, and here therefore their limitations are most likely to be forgotten.

- The physical basis, then, is one of the main elements in Geography teaching, and is now left for further consideration in a separate chapter.*

2. Human Sides of Geography: (I) Economic SIDE.-It must be remembered, however, that the physical side of Geography is only taught to illustrate the human. The human side may for convenience be classified under three headings. First, there is the concrete working of certain principles, of which the abstract treatment constitutes the science of Economics. These principles never really operate alone, but Economics treats them as if they so operated for the sake of simplicity. It regards man merely as a producing and consuming animal, whose motive in producing is to acquire wealth for himself, though in "so "doing he also creates it for the community. * See Chapter X. 
Geography also treats of the production of raw material, of its manufacture into useful commodities, and of their distribution by rail, road, or water, to the consumer. Geography and Economics are clearly dealing with the same material, only from a different point of view. Economics attempts to formulate abstract principles which hold good at all times and places; Geography deals now with one place, now with another; now with one industry, now with another, separately. But Geography also tries to explain "why"; and any explanation of the causes is, however little it is realized, an application of the laws of Economics. Were Economics at all a possible subject for schools, there would be no branch of knowledge of which the utility to an industrial community like our own would be more important. The nature, use, and relations of Land, Labour, and Capital; the conditions which regulate the growth and success of industries, and facilitate the interchange of goods-all these affect us as workers, as politicians, as members of trades-unions, and in countless other ways. Economics cannot, however, be taught in schools; it is too abstract and too contentious. Geography, covering in part the same ground in the concrete, can, however, familiarize the pupils with the material, and the teacher should know how to utilize his teaching of productions, manufactures, imports and exports, railways and trade-routes, and the growth of towns, so as duly to emphasize facts which are typical of the commoner ways in which economic laws work. A special chapter will be devoted to this subject.*

(2) Study of Diverse Civilizations.-But Man is * See Chapter V. 
more than an economic animal. Tradition, taste, sentiment, and moral ideas have all their share in determining his action. And these things are very different among different nations. It is true that the nations of the West agree in more points than they differ, since all have based their culture on the Christian religion and the Græco-Roman intellectual and æsthetic civilization. Outside Europe and the countries peopled from Europe, however, are the Chinese, Hindoo, and Mohammedan civilizations, and the nations whom by comparison we call uncivilized. As buyers, sellers, often as their rulers, we are brought into contact with them; some of them may even become our rivals, and all of them we are influencing, whether we intend it or not, with our ideas. School teaching should therefore give such an interest in these races by descriptions that a sympathetic consideration for their differences from us may be a more usual attitude on the part of our pupils; and this kind of impression is the stronger if the descriptive matter is introduced, as it well may be, quite early in the curriculum.

(3) And of Diverse Political Organizations. -Then, again, peoples are ordered into political organizations, and these.differ as much as any of their other institutions. Political ideas in the abstract are as hard to convey as economic ideas; but there is a double advantage in the contrast afforded by our own mode of government and others. The children learn to appreciate the struggle for good and free government shown in their History, when they learn that bad and tyrannical governments are not a nebulous vision of a distant past, but make men living even to-day unhappy, and turn some of the most fertile parts of the world into 
deserts. They also learn an attitude of caution and open-mindedness when they find that some of these countries have good points in their government, and that changes affected by a stroke of the pen have not always the desired results. With younger children, too, the nature of government is much more readily perceived from the patriarchal institutions of less advanced tribes than from the difficult and complex systems of Europe and America.

The points of view from which Geography may be treated are, therefore :

(I) As giving an account of the action of physical facts and laws on the productions required by Man ;

(2) As showing Man using those productions in accordance with economic principles ;

(3) As describing the races of men and their characteristics :

(4) As showing something of their government.

It is necessary next to consider which of these points of view is most capable of emphasis in various classes of countries. These classes are :

(I) Our own country.

(2) Other civilized States.

(3) Countries of civilizations unlike our own, as, for instance, most countries of Asia.

(4) The undeveloped parts of the world.

\section{Conveying of these Ideas by the Geography-} (I) OF OUR OWN COUNTRY.-Our own country naturally gives the first ideas of the physical side and its effect on human life. The use of the Geography of the immediate neighbourhood to give the first conceptions of 
physical Geography to younger children has now become a recognized feature of instruction. It is a small step from the physical to the economic, and we can hardly define the stage at which the one has passed into the other. The contrast of the life of the upland pastures, the lowland farms, the manufacturing towns of the coal-fields, the ports and railway centres distributing the commodities, introduce the child, without leaving his own country, to most types of human activity. Moreover, it is equally important to remember that it is to our own island that we must look for the working out of most detail. This consideration will be found to have an unexpected result when we come to consider at what point in the curriculum various countries should be taught.*

(2) Of Countries of Alien Civilizations.-In the countries with civilizations unlike our own-China, Japan, India, and the Mohammedan countries-the characteristics of the people and their governments afford the greatest contrast to our own. The physical side will here also be important; but a proper emphasis of the human element will be a safeguard against the serious mistake of supposing that physical and economic laws produce their results on the life of Man wholly uninfluenced by his beliefs, aspirations, traditions, and tastes. No child, of course, is sufficiently given to abstraction to think whether they do or not; but, for all that, the teacher's treatment will produce an impression one way or the other. It is to be noted that very much of this material is purely descriptive, and is easier for younger children to understand than the more complex conditions of Europe. 
(3) Of Newly-developed Countries.-The undeveloped countries, or countries which have been developed only in recent times by people of European origin, have distinct advantages for us when we are teaching the physical and economic sides of Geography. In a country like our own, where every inch of soil is utilized, if only for deer-forest or mountain pastureand big towns are found almost everywhere-it is due to some minute advantage-some almost accidental historical chance-that, for example, Reading manufactures biscuits and Northampton boots. In a new country people choose where they settle for much more obvious reasons: a plant is introduced, and in a few years becomes the chief export of the Colony; a town grows from a few log huts to a city of several hundred thousand inhabitants in a few decades, and the reasons stand out with that convincing clearness which is necessary to enable single causes to be grasped at a time. We can see how a geographical attitude of mind has enabled people to anticipate these developments, and we can even try with caution to prophesy ourselves. There are also other countries which never can be developed, which, by their very obvious extremes of heat or cold or drought, bring home to younger children the need of suitable physical conditions for human life.

(4) Of other Civilized Countries.-The other civilized countries present us with the greatest difficulty in finding a point of view. The differences of peoples are less marked; the climatic and economic principles are the same or nearly the same as in our own country. These are not reasons for teaching them immediately after our own country, but quite the reverse. The 
principle of gliding so gradually from like to unlike through so many shades of less and less likeness that the only impression left is one undifferentiated blur, is contrary to all our experience of learning by contrast. A mind that is to be of any intellectual or moral value must learn by strong contradictions: "This is this and not that," must be its first attitude, if it is ever safely to say, "This and that have ninety-nine points out of a hundred in common, and the remaining point doesn't count under most circumstances; but there are circumstances where it counts, and it may become the crucial point of a given situation." We therefore support taking Europe later in the course than is now the custom.

\section{Attitude of Modern Geography to-(I) STRUC-} TURE.-We have now to take the various headings under which countries have commonly been treated to see how much should be retained and what features under each heading should be emphasized.

Physical features are generally taught under the headings of structure, coast-line, and rivers. Structure is important in two ways : first, as determining climate; secondly, as facilitating or hindering human intercourse. Facts should be taught in so far as they are important in either of these ways, and in such a way as to bring out this importance. Modern Geography accordingly takes no account of the names and heights of the highest peaks, while it attaches considerable importance to the general elevation of a range and to the position and height of the passes which are the means of communication. It is not content with the enumeration of mountain-ranges, plateaux, and plains, but insists on a description of them. The ordinary school-child doubtless regards the Alps as a single range; modern 
Geography would describe the main differences between the Eastern and Western Alps, and the way in which the arrangement of ranges and valleys in each, together with the position and direction of passes, drives communication into different routes.

(2) To Coastal Features. - The older Geography revelled in the names of coastal features-capes, bays, and islands. But it is only the larger seas which affect climate, and the minor features are important only where they determine accessibility. According to our canons it is important to know that the coast of Spain has few good harbours; but it is of no importance to know that the "chief capes" are Ortegal, Finisterre, and Tarifa. A considerable saving of time can therefore be effected under this heading.

(3) To RIVERs.-The importance of rivers differs in different parts of the world. Everywhere they are responsible for the minor features of the surface, and, as will be seen later, there is more to be said physiographically about them than about any other characteristics of a country; but, if we do not regard Geography as primarily physiographical, they may sometimes be of little importance. The tributaries of the Mississippi do very little trade, and their absence would not be a serious loss to the country, though it would indicate an absence of rainfall over the North-American continent which would be serious. On the other hand, in dry climates a river may, like the Nile or Euphrates, turn what would otherwise be a desert into a fruitful region; in countries which do not use Artesian wells or bring the water for their cities through conduits from a distance cities may be of necessity built along their banks, and until the advent of the railway they are often 
the only means of trade. The partial acceptance of the modern Geography has often led to the teaching of the river-basins as the unit instead of the political divisions ; and the above account justifies this with rivers like the Nile or Ganges, which dominate the life of the countries through which they flow; but no unity can be found in the basin of the Rhine, whose higher reaches are part of the great mountain region of Europe, while its lower stretch in Holland belongs to the North European Plain. The true unit for teaching is a region with common characteristics.

(4) To Climate. - That Climate should be retained and emphasized goes without question.

(5) To Commercial Geography.-On the side of productions, manufactures, and commerce, the chief need is for a proper perspective. If any idea of causes is to be given, we must confine our attention to a few of the chief commodities and deal with them thoroughly. The teacher should know the conditions of production and distribution of the chief food-supplies; the conditions and distribution of both the production and manufacture of the chief clothing materials; and the distribution, conditions, and places of working of the principal minerals. All these he should study historically, as it is in the growth and spread of industries that he can best see the working of climatic and economic laws. The present distribution is constantly changing; facts true now may have completely changed in twenty years, and, as the knowledge may not be wanted till I930, it is much more important to know what developments had brought about the state of things existing in IgIo than the precise state of affairs in that year. He will find, too, that a study of the changes of the past insensibly 
leads to intelligent forecast of the future. Commercial Geography will naturally not be separated in teaching from other branches, but a thorough account of each product or industry will be introduced in connection with some country with which it is prominently identified.

(6) To Towns. - As regards towns, modern Geography insists that only a few should be taught, but the reasons for their situation and importance should be thoroughly worked out. In England, the large towns, except London, are mostly connected with special industries, and situated near coal-fields. The same lessons, therefore, show the history and importance of the industry and of the town, and discover the causes. It is to be suspected that many persons, without, perhaps, consciously laying down as a principle that all towns are on coal-fields, incline too much towards such a belief. If they will take half a dozen of the biggest towns in America, the Mediterranean countries, or Russia, not to speak of India, China, or Japan, where it does not hold good at all, they may be surprised at the result. It will be found that advantages for communication are a far more general cause, and the tracing of these advantages by means of a physical map is one of the most interesting exercises in Geography, and well within the reach of children. It applies all that has been learned as to the physical features and industries of a country, and brings out the chief routes of commerce, whether by rail, sea, or river.

This paragraph has tried to show what effect the modern conception of Geography has on each of the headings under which countries have commonly been 


\section{THE TEACHING OF GEOGRAPHY}

treated. It must not be supposed, however, that modern Geography sanctions any such order. It rather tries to divide a country into smaller natural units, and to deal with each unit in all its aspects before passing on to another. But, in truth, it will be found that there are many reasonable orders; and that different orders will suit different countries. 


\section{III}

ARRANGEMENT OF SUBJECT-MATTER IN THE COURSE

I. Need of a Progressive Course.-When we have decided what sort of subject-matter we desire to teach by the end of our course, it is time to consider the arrangement and distribution of this matter, as determined by the capacities of our pupils and by its own inherent logical sequence. No one would avowedly teach anything that the pupils would not in the least understand, yet the practical inefficiency of much that is taught in schools is due to the absence of a progressive development of the subject; and this defect in its turn is due to an absence of a definite idea of what work the highest class should be capable of doing, and a suitable adjustment of the work in all the other classes to this end. In subjects where the very nature of the study makes the realization of this end easy the teaching is most effective. Children leave school really able to apply their knowledge of Reading and Writing, and, in consequence, we unconsciously judge the teaching of these subjects by a higher standard. Judged by the absolute standard of the use to which knowledge can be put, most of the past teaching of Geography, even when comparatively good, would fall below the less successful attempts to teach Reading or Writing.

If we take the subject-matter of the preceding 
chapter as our goal, we must lead up to the kind of work which was there outlined under the physical heading by teaching the principles of Climate and the reading of a Map; for at the end we expect the pupil to be able to explain the climatic conditions of a country, and, indeed, in some cases to hazard an anticipation of them from a knowledge of general principles and of the surface of the country as indicated on a Map. Under the human heading we expect him, not, indeed, to formulate economic laws, but to be familiar with their concrete working, and this implies that we must lead him through simpler cases to more complex on a progressive plan. The same applies to government and other human activities.

Early Introduction of Principles of Climate and Map-Reading. - The climatic principles and the reading of a Map are wanted as early as they can be understood by the children. Without the former, geographical facts are a confusing chaos, and the memory is unnecessarily burdened. The same causes are at work to produce the Climate of Great Britain and Vancouver Island; if climatic laws are understood, the trouble of teaching and remembering what is the Climate of Vancouver Island disappears. The world shapes itself into an orderly arrangement of a few main climatic regions, under which countries are arranged according to their position, and the details concerning them are filled in as obvious corollaries from their structure. Thus, the earlier Climate is mastered, the more rapidly, easily, and firmly is the Geography of the world covered, understood, and remembered. The climatic side is a necessary antecedent of the more adequate appreciation of the economic. 
The Map, too, though it can never take the place of description, so far as it goes, can do what description cannot do. Its various shadings state elevation more quickly, exactly, and comprehensively than words can possibly do. Would anyone who has ever used one of Bartholomew's sectional Maps of England and Wales (half-inch to the mile) ever think of ascertaining the physical features of the country through which he was going to cycle from a written description? He would know that the spray of waterfalls, the colours on peaks, the pinewoods, and surprise views were not in the Map -in a word, that scenic effects could be ascertained better from the guide-book. But he would also know that if he wanted to find out the general arrangement, direction, and elevation of ranges, he could see by a glance at the Map what he might only discover from the guide-book by reading twenty pages several times. He would know that, if he wanted to find the shortest and most level route from one place to another, he could in a moment find it on the Map. If, however, he had recourse to the guide-book, he might well find, after hunting in the index for five minutes, that it gave directions as to the routes leading from his startingpoint to a dozen places other than his intended destination, and those leading to his destination from twenty places other than his starting-point, but not the precise information which alone he wanted. This illustration will probably serve to point out the respective uses of descriptions and of Maps, and to show the need of both.

2. Climatic Facts Suitable for Teaching in the Yarious Standards. - These considerations show the need of introducing physical principles and the use 


\section{THE TEACHING OF GEOGRAPHY}

of Maps as early as possible. The present practice is to teach the subject-matter of Physical Geography, often in isolated lessons delivered at intervals, under the name of Object-lessons, Nature-study, or Elementary Science; while concurrently with these lessons there generally runs through Standard I., or Standards I. and II., a course given under the name of Geography, which, with due allowance for alterations introduced under the influence of newer ideas, still too largely consists of "definitions" of geographical features, such as capes, bays, islands, etc. It matters little under what name teaching is given, but it matters much that the whole of the teaching which is really geographical should be given on one systematic plan. All the instruction which is now given under these various names must be gathered together, and any gaps which have been left must be filled up, so as to secure that the teaching leads step by step to an understanding of the principles of Climate. The present teaching, notwithstanding its confusion, shows one thing clearly - that teachers know quite well that some of the principles of physical geography can be taught to the lowest standards, and that others are difficult even for the middle standards. It may be added that it sometimes is possible to give a rough approximation to the younger children, whereas a thoroughly scientific account is possible only at a much later stage.

The matters which have been found by experience to be suitable to younger children are: the Rotundity of the Earth, taught without rigorous proof; the Daily Movement of the Earth as the cause of Day and Night; the Points of the Compass considered merely as marking direction from the place of instruction; 
the existence of an Atmosphere; the recognition, but not the explanation, of the phases of the Moon; the recognition of the brighter Constellations; the formation of Clouds (in very rough outline); the effect of Rain; Springs; the formation and some of the work of Rivers; a little about Snow and Frost; together with descriptive matter, which should be varied according as the locality is on a plain or among hills, by the sea or inland. Rather more advanced is the idea of the Earth as a planet in space, moving round the Sun and forming part of a system of planets, the notion of hot air ascending, of hot air holding more vapour than cold air, etc. In matters of the latter kind the diffculty for the pupils is not so much in realizing each separate principle as in combining them to see the climatic effects, as, for instance, that the two lastnamed principles combined with the coldness of the upper atmosphere constitute the cause of Condensation.

Difficulty of Understanding and Teaching the Seasons. - The changes of the Seasons form a really difficult matter, which, more than anything else, stands in the way of a logical working out of climatic principles in schools, and accounts for the confused notions concerning Climate existing in the minds even of students who are training to be teachers. Most of us know something about the matter, but we should be surprised if many readers could answer off-hand such questions as the following: Is the length of day at the Equator the same when the Sun is directly overhead at noon as when he is at his greatest northern or southern declination? Does the Sun rise due east at the Equator at other times than the Equinox? Will 
the Sun be higher at noon at a place with a longer or at a place with a shorter day? Is there any point where the Sun could be seen on the horizon exactly north? Is the total length of time throughout the year during which the Sun is above the horizon the same all over the World or not? The answers to all the above questions are not necessarily important in themselves, but they are useful tests whether a teacher thoroughly understands the Seasons. It is not very difficult to see that the annual revolution of the Earth round the Sun, combined with the obliquity of the axis to the plane of the movement, must produce an effect both on the length of day and night and on the height of the Sun at noon; and it is easy, if one has heard the results often enough, to remember them as facts; but it needs some thought for the first time to think out the answers to the above questions from the two data of the annual revolution and the obliquity of the axis.

If we were taking climatic considerations in a perfectly logical, deductive order, the full understanding of the Seasons would have to precede the Laws of Climate, as two illustrations will show. First, various products depend on one of the following separate considerations or on several in combination:

(I) High yearly temperature evenly distributede.g., all the so-called "tropical" products.

(2) High summer temperature, whether the winter be cold or not-e.g., tea.

(3) Absence of cold in winter, even if the temperature be not extremely high in summer-e.g., cotton.

(4) Long hours of sunshine in summer, even if not accompanied by great heat-e.g., wheat. 
In other words, average temperature, range of temperature, and length of day are all important. Secondly, the annual migration of the belt of greatest heat, following the sun north and south of the Equator, causes the Trade-Wind belt to migrate seasonally, leads to the "Monsoon" effect, and brings a seasonal rainfall to countries which otherwise would be deficient in this respect.

But the reason for everything need not be taught. At this stage a teacher must think out clearly how many of the facts concerned with the Seasons he intends to explain, how many to teach as pure facts, and how many omit altogether. To teach any part well, however, he should understand the whole matter clearly himself. We believe that this difficulty has not been solved, only because it has not been clearly seen and faced, and we have made suggestions for solving it in later chapters.* We will here anticipate so far as to assume that the children in Standard IV. learn the following principles, at least as facts : $\uparrow$

(I) That variation in length of day and night increases as distance from the Equator increases.

(2) That average temperature normally diminishes as distance from the Equator increases.

(3) That in June the belt of highest temperature lies to the north of the Equator, and in December to the south.

The teaching of the regular Seasonal Winds is needed * Chapters X. and XI.

$\dagger$ These principles are here stated, for the sake of accuracy, in scientific terminology; they would, of course, be taught in very different language to Standard IV. 
to complete the sequence which enables the climate of any country to be understood in outline.

3. Other Work of the Lower Standards. - The allotment of matter to each standard cannot properly be attempted till all the considerations which have a share in determining it have been considered. The teaching of Climate will probably be the most puzzling factor to the majority of those engaged in working out a curriculum, and the discussion of this side has been therefore partly anticipated. The other factors can be passed over much more rapidly.

(I) Maps.-Full understanding of a Map can only come slowly by its use, but the preliminary work can easily be completed in the first two standards.

(2) Descriptions.-Descriptions can be given long before the children can understand the reasons for the occurrences described. It is to the interest aroused in the facts that we trust in order to obtain later the effort to understand the causes. The most striking of the typical regions can be described in very early years, especially in connection with the animals of those regions. The North Pole, bears and reindeer; the desert and the camel; the jungle and the elephant; the tropical forest and the monkeys; the Steppes and the horses: this kind of teaching at the earlier stages is a recognition of the idea which is at the basis of the newer Geography - that the life of a region depends on its Climate.

Refusal to Recognize the "Concentric" Order. -Geography must begin both with what the child knows and what he does not know. Common-sense must not be at the mercy of cant phrases misapplied. "From the known to the unknown" is an attractive 
jingle to express the truism that deductions cannot legitimately be drawn from premises which are not understood; but it does not justify, nor would the unknown author (for it existed long before Herbert Spencer repeated it) have thought that it justified, the arbitrary assumption that the correct order of teaching Geography, after the district of which the pupil has first-hand knowledge has been covered, is to teach first the home county, then the next county, then some larger unit, then England and Wales, then Europe, and after that the World. Why this importance attached to distance in space? Put the question fairly: In which is an ordinary healthy schoolboy more interested-in the market-towns of the next county or in the elephant in the jungles of India? Even granted he had never seen an elephant in his life, we are confident that the elephant, despite his distance in miles, will head the poll by an overwhelming majority. We do not profess to have any secret shibboleth of the "known and unknown" variety by which automatically to classify topics which will or will not interest children of any given age, and we believe the teacher will do well to trust to his common-sense, taking good care, of course, not to confuse therewith any traditional convention, and to do without one.

Postponement of Detailed Study of British Isles. -The preceding paragraph has been introduced at this particular point in order to justify a conclusion already anticipated in an earlier chapter-that the detailed treatment of the British Isles need not be taken immediately after the home district and before distant parts. An introductory treatment of our own islands at an early stage we admit to be essential (I) in order to 
provide a standard of comparison for other countries; (2) because we really, so long as we restrict ourselves to a general treatment without unnecessary details, can use the previous knowledge and interests of our pupils. But we find in practice that the present arrangement of teaching exhaustive details concerning the British Isles in Standards III. and IV. is more largely responsible than anything else for the falling off of geographical interest as the children proceed through the school. Where sand-trays, plasticene, and descriptions are used intelligently, the teaching of Standards I. and II. proceeds smoothly; but few schools have adopted anything for the next two years except the wearisome grind of towns and their manufactures, rivers and the towns on their banks, coal-fields and the towns to which they have given rise, counties and their chief towns. Wherever the lesson starts, it always comes back to the names of towns, and this is through no fault of the teacher who has to prepare the lesson. He feels that he must teach something. He cannot make Standard III. really understand why North Staffordshire should manufacture pottery when the clay has to be brought some hundreds of miles, and that to an inland destination; but he can teach that the names of the pottery towns are Hanley, Stoke, Newcastle-under-Lyme, Longton, Burslem, and Etruria, and he does it. The practical results naturally set us thinking of the grounds for the selection of this detailed treatment of the United Kingdom in these standards, and we find that no really substantial reason can be given. On the other hand, a detailed study, to be properly understood, requires a more advanced knowledge of operative causes and their intermixture than a 
more general treatment. The detailed study of any country must, therefore, come late. But we need to study our own country in greater detail than others; therefore the complete treatment of it must come late in the course. The conclusion, therefore, is that we should retain a brief study of the characteristics of the British Isles which we require at an early stage, followed by a detailed treatment later. The conclusion is revolutionary, but nevertheless it seems to be inevitable. And, when we consider the matter, it seems to be a pity that children should never learn more of their own country than what they learn before reaching the age of eleven. Successful outdoor practical Geography can be done better at the more advanced stage, and physiographical principles can be studied practically by more careful observation than is possible at the bottom of the school.

This arrangement falls in with what was said in the last chapter as to desirability of giving accounts of the countries with different civilizations from our own earlier than is now the case, and of leading up to economic facts from countries where economic conditions are simpler.

The British Empire not a Geographical Unit.One remaining arrangement of the present day must be criticised before we start framing our curriculum. It is a common custom to devote a year's work to the British Empire. This choice has doubtless been prompted by sound motives of rousing interest in the Colonies, but it is nevertheless bad Geography. Ease of teaching demands that we should divide the world into a few natural divisions, to avoid teaching the same thing over and over again. Australia and India are 
such natural regions, but Canada is not. The boundary that divides it from the United States is, for the most part, purely artificial-the two form one climatic, economic, and racial unity-and even the natural subdivisions of the continent take no account of the political frontier. The wheat-growing area embraces Manitoba on the Canadian side, and Minnesota and the eastern half of the Dakotas in the United States; the ranching area includes Alberta to the north of the frontier, the western half of the Dakotas, Kansas, Nebraska, and Western Texas to the south. British Columbia makes a single natural unit with Washington State and Oregon; Maine with New Brunswick and Nova Scotia. By all means lay stress on British possessions when the World has been covered, so far as we can cover it, in natural order. Then revise the British possessions, show the great sea-routes of communication, the coaling-stations, and naval centres. For revision, in a new order and from a new point of view, of facts already treated in the simplest order, is useful from many points of view; but do not sacrifice the central idea that gives any meaning to Geography-the idea that even the British Empire only commands Nature by obeying her laws - to a good intention that has miscalculated the right means for attaining its end. When we come to the minor possessions, the arrangement becomes grotesque. To rush from Mauritius to the Fijis, from Sierra Leone to the Falklands, at the first and only time of treatment, must leave the minds of the pupils in absolute bewilderment.

4. Summary and Proposed Syllabus. - The guiding principles of our curriculum, then, are these: To introduce climatic principles as the pupils are 
able to understand them; to rouse interest from the beginning in the relation of life to its environment by means of description; when the way has thus been prepared, to work out climatic principles in connection with various natural divisions of the Globe ; to introduce economic laws working in the concrete, beginning with the simplest cases, and ending with the complex economic conditions of Western Europe as exemplified by a more detailed knowledge of our own country; to introduce nations unlike ourselves, and with simpler institutions, before describing the European nations who resemble us; and at the end to see that intelligent reflection, and not merely verbal memory, should be the keynote of the work of Standards VI. and VII.

With the view of showing that all these requirements can be satisfied, we venture to suggest a syllabus. Not, indeed, that we believe in any one ideal syllabus, except that which each teacher draws up for himself; but we do believe that no one has a right in educational matters to talk in generalities till he has in his mind an exact idea of what he means, till he has gone into details in many parts, and feels that he could, if called on, justify any part by explicit detail. This should be a kind of intellectual conscience, and does not contradict the sound opinion that no man can do anything well who acts as a machine. The only good organizer in detail is he who has to execute the detail.

Standard I.-Descriptive Geography-(a) of elements in the scenery of our own country not known to the children-e.g., the sea to inland children, and mountains where the school is on the plain; $(b)$ of distinctive parts of the world and their animals-e.g., the Arctic regions, the Desert, the Jungle. 
Physical Geography.-(a) A notion of direction; (b) the shape of the Earth, simply treated, and with constant use of the Globe; Day and Night ; $(c)$ modelling of the neighbourhood in plasticene by the teacher and in sand by the children, leading up to the understanding of a Map.

Standard II.-Physical Geography.-(a) The work of water, illustrated by the local river (or sea) and so associated with the sand-tray work; $(b)$ advance from sand-tray to Map, by way of plan of the school, plan of the immediate neighbourhood, Map of the district, the teacher working the plans and the children doing the same in sand more roughly.

Descriptive Geography of England and Wales -i.e., of upland pasture, agriculture, mining, about three of the chief manufactures, shipping; teaching very few names, but aiming at giving a picture of the various modes of life of the inhabitants.

Standard III. - Physical Geography. - (a) The Atmosphere-i.e., evaporation and condensation, winds, clouds, effect of mountains in forming clouds, etc.; (b) a series of observations through the year of the position of the Sun at noon, showing as far as these islands are concerned the nature of the Seasons; (c) as much idea of the Solar System, the phases of the Moon, etc., as is thought desirable.

Regional Geography.-(a) Outline of the British Isles-i.e., the leading physical features, familiarity with the Map, the importance of London, a selection of about twenty large towns, and the chief railway routes; (b) North America in three aspects, as affording fine illustrations of the work of water (taught in Standard II.), as showing a simple state of Society in the life of the 
Indians, and as tracing the growth of industrial complexity from the backwoodsman to a life much like that of our own country (described in Standard II.). This begins the introduction of economic ideas without the class knowing it.

Standard IV. - The Physical Geography now needed, consisting of the principles of Climate for the World, cannot be taught from direct experience; and, to prevent it becoming too abstract, must be taught by means of some Continent. This Continent should contain as many natural regions as possible, and therefore should stretch from the Equator to the Arctic Circle. Asia best meets these requirements. Similar regions have been described in North America, but without a discussion of causes; cross-references should be frequent. The aims are :

(I) To fix the belts of Climate (heat, variations of heat, length of day, winds, rainfall), made real by teaching the life of the cold region (Siberia), the hot-dry region (Turkey, Persia), the hot-wet region (India).

(2) To proceed from the simplest economic life of hunting (Red Indians as treated in previous Standards) through nomad and pastoral patriarchal life (Arabia, the Steppes) to the simpler agricultural life (India, China).

This latter aim also introduces the development of the State from the nomad band through the patriarchal community to the monarchical State, as well as giving sympathy with peoples of civilizations unlike our own.

Standard V. - (a) Australia, Africa, and South AMERICA, used to fix the ideas already introduced, with 


\section{THE TEACHING OF GEOGRAPHY}

a thorough revision of winds, rainfall, etc., and use of the principles to anticipate climates, productions, etc. The great products will be treated in connection with some country where each grows. (b) The BRITISH IsLES, which can now be treated more fully, in the light of the knowledge of the countries from which they import and to which they export goods, and of the greater maturity of the children's ideas about modes of life and industries. Much use should be made of the construction of Maps illustrating particular points, to fix facts in the memory.

Standard VI.-(a) EUROPE; (b) NORTH AMERICA, treated now more from the industrial standpoint, with a general review of routes of commerce, of the British Empire, and a comparison of the position of the various Great Powers.

As few children reach Standard VII., and it is often not taught separately, we have made the course complete without considering it, and would suggest for this Standard a course based on Lyde's "Man and his Markets," as presenting the facts in a new order. 


\section{IV}

THE CONCEPTION OF REGIONAL GEOGRAPHY

Simplicity is the quality which teachers have most missed in the older Geography. Every fact appeared to stand by itself. Each continent had an innumerable variety of regions, with varying climates, products, industries, peoples, laws, and modes of life, and all that could be done was to work steadily through them from north to south, or from east to west, enumerating them one by one. It is here that the newer Geography has worked its revolution. The methods of teaching are to be changed because the conception of the subject has changed, and it is impossible to write upon the methods of teaching without giving considerable space to the conception of the subject, though such chapters can only convey at second-hand the ideas worked out by the leaders of geographical thought. The first conception which will help the teacher to see order and simplicity in geographical facts is the division of the world into certain large natural regions, each possessing a climatic, and therefore a productive and economic, unity, followed by the division of these large units into the more familiar subdivisions. The reader will find the basis of this division clearly set out in the opening pages of Dr. Herbertson's " Senior Geography," which then proceeds to deal with the various countries 
arranged under these headings, disregarding where necessary the conventional divisions of continents. This conception is so fundamental as a means of introducing clearness and simplicity into our treatment of Geography that we feel compelled to spend a few pages in setting it forth, in the hope that it may induce the reader to read more on the subject.

I. Basis of Classification of Regions.-Briefly, there are three main elements to consider in classifying Climates :

(I) Distance from the Equator, determining average temperature.

(2) Position in the centre, or on the east, or on the west of continents, $t$ as bringing the country within, or keeping it out of, the influence of the regular winds, which are easterly in the tropical regions and westerly in the temperate zones, and thus as determining rainfall.

(3) Altitude, as modifying temperature.

Examples of each Climate may be found both in the Old World and in the New, and in similarly situated regions both north and south of the Equator.

The various combinations of these three factors give us the following regions :

(I) The Equatorial belt of high temperature and great rainfall (Malay Archipelago, Congo and Amazon basins), producing great forests.

(2) Countries lying on each side of this belt, and on

* The reader who finds his knowledge of climatic facts insufficient to follow this summary is recommended to read pp. I49-160.

$\dagger$ Europo and Asia must for this purpose be treated as one continent. 
the eastern sides of continents, being thus exposed to the easterly trade-winds. This region is greatly extended in Asia by the influence of the Monsoons. In the widest sense it comprises many subdivisions, and embraces the most densely populated of those countries whose inhabitants live on the products of the soil. It supplies the world with rice, cotton, sugar, and tea. China, India, and Japan are typical Monsoon lands; and the West Indies, Eastern Brazil, and the SouthEastern United States, occupy other subdivisions of this region.

(3) Countries lying on the western side or in the interior of continents, in the same latitude as those included in the last division, thus having an inadequate rainfall and growing only grass. These merge insensibly into the interior countries of temperate regions, which are also pastoral countries. The Soudan, and Africa south of the Congo basin, are examples of the warmer, the Steppes of the colder, pastoral regions; while in both North and South America there is a continuous belt passing from the warmer to the colder along the eastern foot of the Rockies and Andes.

(4) In the heart of very large land masses, and in the regions situated on the Tropics of Cancer and Capricorn, which feel the influence neither of the easterly tropical trade-winds, nor of the temperate west winds, are the real deserts, with very little or no rainfall. Interspersed among these are tracts which, either through irrigation, or through a rainfall produced by local causes, are of immense fertility. The Sahara and the Kalahari in Africa, the desert of Gobi in Asia, the interior of Australia, and parts of both the Americas, exemplify deserts ; South-Eastern Asia and Egypt illus- 
trate the intermixture of deserts with spots of great fertility.

(5) The Great Uplands, with a wide range of temperature, and supporting small populations, such as Tibet or the Great Basin of the Rockies.

(6) An intermediate region on the west side of continents, situated between the typical region of small rainfall and the region of the marked rainfall brought by the temperate west winds. This is treated separately, because it includes all the countries lying round the Mediterranean. California, the Cape, and Chili are less important examples. This region is characterized by its special fruits.

(7) The temperate region of the west of continents, embracing our own country and other countries of Western Europe, and including, in America, British Columbia and the States of Washington and Oregon. The chief characteristic of these countries is that the prevailing sea-breezes prevent any great extremes of climate.

(8) The corresponding region on the east sides of continents, which is principally exemplified by North America from Chesapeake Bay to the mouth of the St. Lawrence. This type of region differs from the last in the greater extremes between the temperatures of summer and winter. Manchuria is an example in Asia.

(9) The sub-Arctic forest stretching across Russia, Siberia, and Canada. The existence of these forests in the heart of continents is due to the fact that in regions where evaporation is trifling a small rainfall is sufficient to support trees.

(I0) The frozen regions round the Poles. 


\section{Comparative Definiteness of these Regions.}

- Several considerations must be taken into account before these divisions are used as a basis for teaching, though they are invaluable for the teacher himself.

They are, of course, types taken from a series of transitions from one group to another. This, however, will not cause as much difficulty as might be expected. Frequently mountain-ranges, either by cutting off rainfall from their landward sides or by forming the edges of plateaux, present a definite boundary-e.g., the Himalayas, Rockies, Andes, and Alps. But even in perfectly continuous plains of the Mississippi a line drawn from the north-west corner of the Gulf of Mexico, in a direction a little to the west of north, will, for all practical purposes, separate the country into two clearly marked climatic regions. To the east rainfall is sufficient, and agriculture is remunerative; to the west the deficiency of rainfall only permits pastoral pursuits as the regular occupation. The country to the east of this line is therefore considered as lying within our second type of regions (eastern parts of continents) ;* while that to the west, as far as the Rockies, may be included in our third type (central portion of continents), as being outside the influence of the Gulf of Mexico, and cut off from that of the Pacific by the plateaux and ranges of the Rockies. Nevertheless, transition regions exist, and we might hesitate to which of two groups of regions to allot them.

Relation to Regions based on a Classification according to Type of Civilization.-Again, though

* It is, in fact, rather the Gulf of Mexico than the Atlantic which gives it its rainfall, but the Gulf of Mexico is an arm of the Atlantic. 
the preceding classification was based on Climate and consequent productions, it is not surprising to find that various natural regions have given rise to specific types of civilization. But a civilization will often overstep the geographical limits of the region that gave it birth, as that of Western Europe has in the last three hundred years overrun the two American continents and Australia. It is highly convenient, where we can, to teach a characteristic region and a separate civilization together. Suppose, however, that the civilization of one natural region overruns a part of another natural region. This has happened in North Africa. The true frontier of Europe, it has often been said, is not the Mediterranean, but the Sahara. Geographers unhesitatingly classify Morocco, Algeria, and Tunis with Spain and Italy, on the grounds of climate and productions. Moreover, no black race has ever made them its home. Anthropology shows that in prehistoric periods there were the closest affinities of race and civilization between the two shores of the Mediterranean. In ancient historical times Phœnicians and Greeks traded and settled on both sides, and the Romans finally made all the countries into one Empire. If we were framing a scheme for teaching Geography to boys living even as late as A.D. 500, we should unhesitatingly advise the teaching of Northern Africa along with Southern Europe. Then, however, came the Saracen; and to-day, when "East is East and West is West, and never the two shall meet," Morocco and Algiers are of the East, and Spain and Italy of the West. The Mohammedan civilization belongs to our fourth type of region (the deserts and fertile lands between deserts), but the difference be- 
tween our fourth and sixth type is far less than that between the European and Mohammedan civilizations. We therefore suggest that Northern Africa should be taught neither with Africa nor with Southern Europe, but with Western Asia.

But, if we are going to take civilizations into account, the old division of the Old World into three continents returns. Physically, the division between Europe and Asia has no basis; as regards civilization it is all-important. Europe is the land of the Christian Græco-Roman culture ; Africa (leaving out all that part inhabited by white men who speak Arabic) is the land of the black man at a low state of culture; Asia (with the Arabic-speaking countries of Africa) is the land of all the varied civilizations which we Westerners call Oriental.

\section{Division of Continents into Regions for} Teaching Purposes.-On the whole, then, with this one exception in the case of Northern Africa, it seems right to retain the existing practice of arranging our subject-matter under the heading of continents; but the teacher should always keep in mind the climatic divisions, and should bring out the types clearly in his teaching.

It may be of assistance if we divide the continents, as we should in teaching them, in order to show their relation to our ten types of climate regions.

(I) Europe.-The climatic regions correspond fairly satisfactorily with the diffusion of sub-types of the European civilization.

(i.) The Mediterranean countries - Italy, Spain, Turkey, Greece (natural region No. 6), with France as a transition. Rainfall is moderate-i.e., varying 
from good to somewhat deficient, according to local causes. Productions: fruits are characteristic-e.g., orange, vine, mulberry, lemon, fig-but all do not grow in all parts : cereals and pasture exist, as in our own country. The people are of a happy, artistic, volatile, and sometimes rather lazy temperament, in a land of sunshine and moderate warmth; except in the Balkan States, they are Romance-speaking and Roman Catholic.

(ii.) The North-Western countries-Great Britain, Germany, Scandinavia, and the Low Countries (natural region No. 7, which extends far more to the north here than could otherwise be the case, owing to the North Atlantic current). Rainfall is plentiful; the temperature is colder than in the last division, but very equable. Productions: the country is forested in a state of nature; wheat will grow in the southerly parts, otherwise oats and rye are the chief cereals; flax and sugar-beet grow in places. The people are of a sad, energetic, persevering character, and have created the modern industrial system, which renders possible very large populations in a climate less suitable than the last-mentioned to natural products of the soil. They are Teutonic in language, and for the most part Protestants.

(iii.) The continental area, comprising Russia. Throughout, the climate has great extremes; but Steppe, sub-Arctic forests, and frozen Polar regions (Types 3, 9, and Io) succeed in belts running westsouth-west to east-north-east. The "black-soil" area, famous for its wheat, lies between the Steppe proper and the forest region. The people are of a sad, slow, unenterprising character, comparable to the bleak, 
monotonous character of their country. They are mainly of Slavonic race, and of the Greek Church.

Austria-Hungary is merely a political entity, in which races and physical features are so mixed that the only fitting treatment seems to be to leave it to the end, where we can point out in it features which are taken from each of the three divisions.

(2) Asia.-(i.) The enormous plain of the North, forming the Russian Empire. The divisions are the same as those of European Russia, except that there is more real Steppe. Apart from Russian emigrants, the population is made up of the nomad peoples, living by pasture, spending their day on horseback and their night in tents, owning immense flocks and herds, and governed on patriarchal principles. It presents a splendid illustration for young children of the effect of geographical conditions on human life. The teacher should read Dr. Herbertson's "Man and his Work," chapter ii., and his "Descriptive Geography of Asia," pp. 7-II.

(ii.) The Mohammedan hot and dry lands (typically in Division 4-i.e., deserts with breaks of fertile land -but extending into Division 7, the Mediterranean region), comprising Arabia, the Sahara, Mesopotamia, the plateau of Iran, Egypt, Syria, Asia Minor, and Northern Africa. This type is well known to us from the Bible, alike as regards climate, productions, and mode of life. Nomads and cultivators have always lived side by side and have not loved one another (Gen. xlvi. 34). Here patriarchal institutions developed into great monarchies, and we see them side by side in the Arab Sheikh and the Turkish Sultan to-day, as in Abraham and Pharaoh in the Book of Genesis. The 
teacher should read "Man and his Work," chapter ii., and should in teaching make copious use of his own and the children's knowledge of the Bible.

(iii.) The Monsoon countries (Type 2). These we may subdivide into-(a) India, where the population is a mixture of white and black, * and a distinctive civilization and religion were worked out under the impetus of the invasion of the white Aryan-speaking race. The rainfall varies greatly in different parts, but there are well-marked wet and dry seasons : the heat is great. (b) China, Korea, and Japan. These have a yellow population, and a civilization worked out in China, and all the religions are influenced by Buddhism. The prevailing common feature in climate is a warm moist summer, though there is much difference in heat between North and South. Industrially, the chief feature is the careful spade-labour, which makes the best of every foot of soil. The Indo-Chinese peninsula resembles India in climate and China in race and civilization. Rice is the chief article of diet in both these divisions, and the whole of the world's supply of tea comes from them.

Besides these three important divisions of Asia, there are others of less importance, such as the highland plateau (Type 5), illustrated by Tibet, and the Malay Archipelago, representing Type I; but these would not receive much attention.

(3) Africa.-In the ordinary sense-i.e., as extending to the Mediterranean-this continent is noticeable for the parallelism to the north and south of the Equator. It contains a central belt of tropical forests (Congo

* The latest results indicate a larger yellow element than was formerly admitted. 
basin, etc.), fringed on each side by grass-lands (the Soudan on the north, Angola and the Zambesi region on the south) which are unduly extended by local causes to embrace the whole east coast from Somaliland to Natal, these again being bounded by deserts on the Tropics of Cancer and Capricorn (the Sahara on the north, the Kalahari on the south) ; and finally a warmtemperate region at its extreme north (Mediterranean region) and south (round Cape Town)-i.e., from north to south we have Types 6, 4, 3, I, 3, 4, 6 .

As the Mediterranean and Sahara have been taken with Asia, and the Kalahari and Cape Town districts are comparatively small areas, it follows that, though this parallelism should be insisted on as a splendid exemplification of climatic principles, the more regional teaching will be given under the three headings of (I) the Soudan, or land of the pure negroes; (2) the Congo Basin, or land of Tropical Forests; (3) South Pastoral Africa, or land of the Bantus, stress being laid on British South Africa. The life of the Boers shows how climatic conditions have compelled the descendants of an agricultural race to become pastoral.

(4) North America. - If we relegate the West Indies and the Spanish-speaking States to South America, with which they are historically more closely connected, we can treat the rest of the continent as one unit of civilization, subdivisible climatically into:

(i.) The cotton States (a subdivision of Type 2), forming with the tobacco States the Southern side in the Civil War, and the slave-holding States before it, colonized by adventurers, and maintaining the adventurous spirit in the days of the backwoodsman and pioneer.

(ii.) The temperate region from Chesapeake Bay to 
the mouth of the St. Lawrence (Type 8), subdivisible into (a) the original Northern States, the industrial region and chief outlet of the interior, with its great ports; (b) the lumbering region of Canada, Maine, and Michigan, including the whole St. Lawrence basin; (c) the maize States, with their hogs, having Chicago as their great outlet; $(d)$ the wheat region of Minnesota, the Dakotas, and Manitoba.

(iii.) The ranching country from Texas to Alberta, giving us the counterpart of the Steppe life, except that it is lived by the Anglo-Saxon and not by the Tartar (Type 4).

(iv.) The thinly-peopled plateau belt of the Rockies (Type 5), rainless, and subject to violent extremes. Its cañons and "parks" illustrate physiographical principles better than economic principles.

(v.) California, the solitary representative of the Mediterranean States (Type 6). Stevenson's “Across the Plains" is well calculated to give the spirit of the three last-mentioned divisions.

(vi.) British Columbia, Washington, and Oregon, representing a land like Great Britain, with the difference that it is only now beginning to be opened up (Type 7).

(vii.) The poorer Canadian pine-forest, stretching from Labrador to Alaska, and economically valueless (Type 9). (viii.) The Frozen North (Type ro), the land of the Eskimos, suitable chiefly for descriptions to very young children.

North America, with its Niagara Falls, its mammoth caves, its grand cañons, its great lakes, its raised coasts and sunken coasts, exhibits the most striking examples of the work of water, and American writers have paid 
great attention to the physiographical side of Geography. From this point of view, Regions 3 and 4 of the above are of great interest, as little or no rain falls, but great streams flow from the mountains. Consequently denudation is confined to the actual bed of the streams, which thus make immense cañons in the mountains, and plough their way in courses deep below the plains. Instead of hill and dale we thus find plain and sudden deep ravine, succeeded by unending plain at the same level as before. Such a contrast will make a teacher realize how entirely our own scenery has been moulded by the slow, imperceptible work, not only of the rushing stream, but of every little rivulet which has carried away its share from the sides of the valley. If no rain had fallen on the hills on each side, the Vale of Llangollen would have been a trench 30 or 40 feet wide, and 700 or 800 feet in height.

North America gives us two contributions for the human side. In the Old World the hunting life is found either at the dawn of history, or in countries where no facilities exist for any more complex mode of living - that is, in the least fertile spots. The American Indian, as he was when the white man found him, consequently presents to us the hunter at his best, with the widest scope for his activities. As representing the simplest economic conditions, we have allotted him to Standard III. in our suggested scheme. The second advantage is that we see the operation of geographical causes in the development of a country with a purely Anglo-Saxon civilization. This is equally important in the higher classes. North America is a continent almost as varied as Asia, but one race dominates it, so that the contrast of Colorado and New York, Carolina and 
Manitoba, cannot be assigned to racial differences like those existing between the Arab and the Chinaman, the Hindoo and the Tartar. And with children, Economic Geography gains by being historical. A tendency, which, although it acts amid countless other causes, inevitably conquers by inclining the balance in a million unnoticed cases, is the most common factor in evolution; but no child will appreciate such tendencies till he has seen some similar motives influencing a real live Jacques Cartier or Walter Raleigh, or causing substantial movements of distinctive classes, such as the Pilgrim Fathers, or the backwoodsmen, or the gold-hunters. For this reason it is an advantage that America has only 300 years of history.

(5) South America.-This is the least important of the continents, and only a few typical regions need be taken-e.g., the Amazon forest, the West Indies, the Savannahs, and the coffee regions of Brazil. Though this continent contains parts representative of most of our types, yet owing to its tapering off in the south, Types I, 2, and 3 are the most extensive and important.

(6) Australia.-The climatic conditions were discussed in Chapter II. Both Australia and South America serve to revise Climate, at the time when the class is able to reason it out deductively by the principles which they have been taught in connection with the larger northern continents. Australia necessarily receives attention as a British Colony, and there is enough that is curious in its native fauna and flora to keep interest. The natives need not be considered at all. They are, in the world of savages, what the slums of our own cities are in the world of civilized man-a proof to how low a level a bad environment can reduce men; but the 
fact that men will, after generations of having nothing else to eat, come to eating one another is not an attractive circumstance in Economic Geography. Australia is mainly desert (Type 4), or " bush " and grassland (Type 3 ), with small portions of country similar to the Mediterranean region (Type 6), and of subtropical regions (Type 2).

The Oceanic Islands, especially New Zealand and the Coral Islands, are interesting regions.

4. Need of Subdivision.-It is beyond the scope of this chapter to illustrate by examples how a region can be worked out by showing, first, in general, the effect of the physical characteristics on climate, then of these two elements on products, and finally of all these factors on the life of man, and how its subdivisions may be treated similarly, but in greater detail. Indeed, it is only by reading a good work on some one region written by an author who fully appreciates the spirit of Regional Geography that the spirit can be caught. Mr. Mackinder conceived the idea of editing a series for the world which should do this, and we heartily advise teachers to read his own contribution, "Britain and the British Seas," which gives to students who have already caught the idea a model of the way in which it can be carried out. For, though, in teaching children, to introduce notions in advance of their powers of comprehension would lead directly to failure, the teacher who has himself realized what the new Geography signifies is in a far better position to convey even the elements to young children. 


\section{V}

THE CONCEPTION OF ECONOMIC GEOGRAPHY

I. THE examples of the Red Man and the European in North America will have brought before the mind of our readers the truth that the effect of geographical conditions on the life of Man will vary according to the stage of development to which Man has attained when he is first exposed to them. Slowly and gradually a set of conditions will lead a race to develop its civilization, till perhaps it reaches a point where it hardly seems to progress at all; again, a race will emigrate to a new country, where in a few generations the new conditions will lead it entirely to change its mode of life. Perhaps the change can hardly be called an advance; sometimes it is even a retrogression; but occasionally the change breaks the barriers of some conventions that stood in the way of advance, and we have one of those extraordinary ages of progress which in the last 500 years have made "fifty years of Europe" better than "a cycle of Cathay." The study of the history of the development of human institutions under the influence of geographical conditions has consequently come to be pursued by a separate body of experts from those who consider the effect of present geographical conditions on Man at his present standard of culture in Western Europe. Neither body of men started with stating 
their problem in this form, and it would be unfair to call either science merely geographical. By the second body are meant the Economists, who were led to examine the subject of Political Economy by the changes which were seen to be making rapid progress in the sphere of industrial life in the eighteenth century; by the first body are meant the Sociologists, who were led to the subject by a scientific and historical desire for knowledge as a means of satisfying enlightened curiosity.

Geography, as soon as it becomes scientific, and as long as it resists the temptation to become a mere branch of Geology and Meteorology, must in a large measure cover the same ground as these two sciences, and must accept or, it may be, sometimes modify their conclusions. The aim of this chapter is to introduce to the teacher in a brief outline some of these principles, of which an appreciation will colour geographical teaching.

\section{Historical or Sociological Economics-} Progress to Yarious Levels of Civilization effected in Separate Regions. - The progress of civilization has consisted in the discovery of easier means of satisfying the elementary needs of human life, such as food, clothing, and a dwelling, and in the development of fresh needs, which sometimes may be of the nature of mere bodily luxuries, but, as we may well hope if we believe in higher desires in human nature, are commonly found in the long run to be demands for a higher intellectual, æsthetic, and social life. Comparatively speaking, man was more the servant of Nature before he had invented many of the means for using the products of the soil, and is more its 
master as he learns to modify natural conditions rather than adjust himself to them; but in all cases he is becoming the master of Nature by becoming her servant.

(I) Primitive Man.-Different natural regions have been instrumental in leading to different stages of Man's advance. Imagine Man with no needs beyond those which enable him to live, as near an animal as he can be conceived, and the Tropics will be the most suitable region for him. He can live on bananas or bread-fruit and other natural products which need little or no tillage; the climate renders clothing and houses almost superfluous; and Man can live. But if he needs anything higher, the climate, which up to this point has been so lavish, is now against him. The heat is too intense for hard work, and the rapid growth of forests and undergrowth makes clearing, for the savage, a matter of great difficulty. Thus, the ease with which he can obtain absolute necessities and the difficulty of obtaining more has kept the Tropics in a state of savagery.

The removal of the ease of obtaining food compels Man to advance. Only the inventive survive. The efforts by which he devises new means to secure food show the way to other inventions as well. As Virgil put the truth in the form of a fable, the gods put an end to the Golden Age when the earth yielded all things of itself in order that man by experience and unrelenting hard work might "hammer out" the arts of civilization.

(2) Hunting Life.-The first step was the hunting life. It is unnecessary to dwell on the power of observation, the skill of hand and eye, the courage and endurance, and the amount of practical reason, to which 


\section{CONCEPTION OF ECONOMIC GEOGRAPHY 67}

this life gave rise, the extent to which it enabled men to live in all parts of the world; or yet on its limitations, the uncertainty of securing a livelihood, the small population which can thrive on large stretches of land, and the constant migrations which it renders necessary. It belongs to no one climate, and fishing may be considered as one of its modifications.

(3) Pastoral Life.-Another step was taken when Man learned that, instead of chasing animals, he might keep them domesticated and kill them as required. The American Indian never learned this in the case of any very useful animal. The pastoral stage was specially suited to our third type of regions, the great grass-lands, being hindered by the forests which covered the tropical regions and all those parts of the temperate zones which have an abundant rainfall. It flourished, too, on all the outskirts of the desert regions. Food and clothing were both furnished by the flocks and herds, but the deficient rainfall of unforested regions made a migratory life still essential; and, as long as pastoral Man represented the highest stage of culture in the world, he must have been without most of the requisites for the higher needs of life. But he was receiving a training in corporate life, as the co-operation of numbers was more essential than at the hunting stage, and the patriarchal government was the ancestor of the State. The more rigorous virtues were being trained even better than at the agricultural level, which is, in many respects, higher ; and many of the tribes who remained pastoral afterwards founded great Empires among their agricultural neighbours-in fact, South-Western Asia has generally been ruled by the Arab of the desert or the Turkoman of the Steppe. It has already been 
pointed out how the lives of the patriarchs, as described in the Book of Genesis, can be used to illustrate this mode of life.

(4) Agricultural Life.-The transition to agriculture, from which arose the one great civilization of which all others are branches, from China to the Atlantic, almost certainly arose on the outskirts of the deserts, where rivers deposited alluvial soil of great fertility. On the banks of the Nile, indeed, the dropping of the seed on the soil is almost the only preliminary operation necessary for agriculture. Not that agriculture, or, perhaps better, gardening, was unknown in the Tropics; but it is real agriculture, the growing of cereals on a large scale, which renders large populations possible. China is forty times more densely populated than a pastoral country of the same size, Russian Turkestan. We must suppose that such agriculture originated in one spot, since it spread to all suitable parts of the Old World in prehistoric times, while it was unknown in America and Australia till the inhabitants of the Old World discovered those continents. Just as the treeless stretches of Asia were the geographical conditions which originated the pastoral life, so probably were the alluvial basins of the Nile and Euphrates the origin of agriculture, though to-day the basins of the Ganges, Yangtse, and Hoangho have far greater agricultural populations.

The characteristics of these three stages of civilization are brought out in a very interesting way in Dr. Herbertson's "Man and His Work."

\section{Effect of the Change in Occupation on} Social and Political Institutions.-It will be well to pause here and notice that the countries which are 
now the scene of most advanced civilization were then not the most suitable. The instruments of tillage were not yet able to break the hard soil ; the cold stupefied rather than braced men who had no tools to build houses. Agriculture must have proceeded from easier to harder soils as the use of metals was discovered and advanced. A stationary life must have introduced social changes far greater than those which were brought about on the material side. The patriarch became the king of a large community. Property was no longer confined to goods which could be carried about ; in particular, property in land became possible. The division of labour came into existence with the increase of arts, then the sale of one man's work to another, and thus shops and towns. The idea of beauty had its first chance of expression on any large scale in the adornment of houses. Social relations became more complex, and the hardship of agricultural work made slavery very prominent. So many, in fact, were the advances in prehistoric and historic times in agricultural communities at the time when the Nile and Euphrates still led the world (including the invention of writing, which makes history possible), that it will be found easier to state what yet remained for other regions of the world to effect than to enumerate these advances.

Of course, in a sense, we are still in the agricultural stage, and likely to remain so. But what we mean by the agricultural stage is that condition of society in which each community tills for itself, and only individuals in each community specialize.

4. Specialization of Industries in Different Localities and Interchange of Products.-We 
pass to a fresh stage when communities themselves specialize, as the Phœnicians did in commerce. During the greater part of historical times there have been certain communities engaged in production, and others in manufacturing the productions by hand, and in passing those of one community to another. A further stage was reached in the eighteenth century, when machinery largely took the place of hand manufacture, and thus coal-fields became the densest centres of population. Modern Political Economy is engaged in working out the principles which govern the relations of communities in this last stage.

What forms of social advance, then, were left to the later stages to bring to pass? First, many of the moral virtues; secondly, and in close relation, the idea of political freedom. Agriculture greatly increased the drudgery of life; it gave birth to the great Oriental monarchies, in which luxury and injustice became the vices of the rulers, fear and loss of initiative those of the ruled. The European, who is the product of the Mediterranean, and still more of the North Sea, civilization, differs from the Oriental, who represents the civilization of the agricultural river-valleys, in his virtues and in his vices. Lord Cromer's book on Egypt illustrates in detail what everyone realizes in general. The geographical significance of this divergence has not been so commonly realized. The reader will, perhaps, now understand more clearly what is the motive which has prompted us to pass from the Red Indian huntsman, through the nomad of the Steppe and the desert, to the typical Oriental, and then back to the European, even in cases where he is, as in North America, a rancher or a farmer. In the one case we have the historical effect 
of environment on the development of civilization, and in the other the effect on man when he has reached our present stage of development.

\section{Contributions to Civilization of-(I) MEDI-} TERRANEAN REgIONS.-The last two acts in the drama of progress have been played each in a particular geographical region-the first in the Mediterranean countries, the second in the westerly temperate regions. It is still possible to believe, as the whole of this conception of progress compels us to believe, that the Mediterranean originally derived its culture from the agricultural regions of the desert frontiers, though the discovery of the Mycenæan, and still more that of the Minoan, civilization takes back the date of its origin far farther than used to be supposed, and greatly diminishes the extent of the debt. Nevertheless, the main conceptions remain the same. Seafaring kept alive the hardihood, resource, and inventiveness of the maritime peoples. Small natural areas of valleys and islands preserved political independence and the virtues which it keeps alive. If the race that gave Greece its vigour really came from the bracing North, it may add to the Englishman's pride of race to know that Achilles and Agamemnon were his kinsmen, but it cannot alter the fact that it was by means of the geographical conditions of Greece that they were provided with a suitable field for their activities. Love of freedom, daring originality, and inventiveness were the characteristics of this race of mountain and sea, while their joyfulness and love of beauty were due to the Mediterranean climate. The Roman seems to give us a foretaste of the sterner Northern virtues; perhaps the character of the race had been formed before it entered Italy. The medieval 
Italian once more has the Mediterranean characteristics. By the time the Mediterranean ceased to be the centre of the world it had developed, on the material side, maritime commerce, coinage, and specialized industries; on the spiritual side, art, literature, and a love of knowledge.

(2) North Sea Basin.-The Northerners, too, were men of the sea, and even to a greater extent than the peoples of the Mediterranean. To the Greek it was his place of business, to the Viking his home. The chief quality which the latter discovered was discipline. Freedom he took as a matter of course, but in the stress of life in his Northern climate he learned that success in the struggle depended on voluntary subordination for the purpose of co-operation. Though these qualities have often been only latent in his descendants under agricultural and oppressive conditions, they have always been ready to revive, and the more fortunate classes have generally exhibited them. From the Tudor epoch, when our countrymen first obtained conditions favourable for their exercise, these virtues have secured the position of this country; while the Dutch and Scandinavians have exhibited them with equal persistence. But naval supremacy and our favourable position for the control of the Atlantic, which since the discovery of America has been the centre of commerce, might not have secured the increase of population which was indispensable for supremacy had not the coal-fields provided a means by which the strenuousness, inventiveness, and commercial honesty of the people could obtain a marketable value. Sweden, Norway, Denmark, Holland, and Switzerland are morally great; but Germany, Great Britain, and 
the United States are the countries which are naturally thought of as representing the dominance of that type of civilization which has been developed by the nations of the Western Temperate regions.

Summary.-Each civilization, therefore, has depended-

(I) On certain moral qualities, in the formation of which its geographical conditions have had a great share;

(2) On the application of the material progress borrowed from a neighbouring civilization; and

(3) On the use of these qualities and the borrowed habits in the development of some new elements of civilization out of the possibilities created by its own geographical conditions.

We can depict the qualities of each race; we can clearly show the dependence of its new advance on its geographical conditions; but we must also keep in mind the necessity of a previous state of culture in order to allow the geographical conditions to become operative. Though the theories expounded in this chapter are not suitable for teaching to children, yet, by describing the nations which are typical of each stage of civilization, by depicting their environment and their character, and, finally, by showing the effect of environment on modern economic situations, much may be done to develop the attitude of mind which will be capable at a later age of appreciating reasoning of this kind.

6. Economics Proper-Land, Labour, and Capital-(I) In Agricultural Communities.-The 
appreciation of the more elementary stages in economic organization is, however, primarily useful in order to enable the pupil to realize more easily our own more complex system. There is no subject with which working men are more directly concerned, whether as producers or as politicians, than Economics. It is no part of the function of our schools to combat Socialism by special pleading, as is done in Germany. It is our duty to show the origin and working of our present economic system. If Socialism is good, this will make for Socialism; if Socialism is bad, it will make against it. Everyone admits that there are three factors in production, whatever views may be held as to the best system of ownership-Natural Agents, Capital, and Labour. This conception can be given just as well in the teaching of Geography as in the first chapter of a primer of Political Economy.

(a) "Land" or Natural Agents.-In the first place, every country, properly taught, shows the children that countries differ in the natural possibilities of wealth, in fertility of soil, in sunshine and rainfall, and in minerals. These are things of which ownership of "land," whether private, family, tribal, or communal, gives the use.

(b) Capital. - But, secondly, every civilized country shows that the action of man in the past has rendered it easier to turn the natural facilities to advantage, though the pioneer work of emigrants in a new country, where this work has not been done, shows most clearly the true origin of advantages which we are too apt to take for granted, or to attribute to Nature along with the real natural agents. The hardships of emigrant life experienced by the first settlers in the undeveloped countries should be turned to account by pointing out 
that all this clearing of forests, draining, clearing away of rocks, fencing, killing off of wild beasts, etc., has been done by our ancestors long ago, and that we have entered into their labours. But striking instances of modern improvements can also be utilized in order to create the notion of Capital. The enormous addition to the agricultural possibilities of Egypt which has been brought about by the construction of the great dam of Assouan illustrates the deliberate expenditure of money in order to secure an increase of production. So we introduce the idea of Capital in relation to agriculture.

(c) Labour.-Lastly, there is Labour. The existence of labourers, of course, needs no teaching; but Geography can give plentiful instances to show thatgiven similar natural resources-skill, industry, and knowledge, possessed by the people, will produce very different results from those which will result from ignorance and laziness. Spain has long been used as an example; the Mohammedan world shows the evil of popular ignorance on the subject of good methods of agriculture, while the United States give an example for imitation. We should show how the brain of the inventor, as well as the hand of the workman, is part of Labour.

Chapters in books dealing with Political Economy are always devoted to the effect of systems of government on production. A discussion of the more complex effects would involve a consideration of the whole theory of government; but the connection itself is shown quite simply by the obvious need of security and of confidence that the Government will not seize a man's earnings by arbitrary taxation. The saying 
that "the grass never grows where the hoof of the Turk's horse has trodden " suggests how this need may be made clear to a class by concrete instances: and the work of our own nation in India and Egypt has promoted the well-being of the inhabitants as much by the introduction of good government as by means of any direct expenditure of capital by the Government.

(2) In Manufacturing and Commercial ComMUNITIES. - The production of raw materials, however, would be of little service unless they could be manufactured into useful commodities and could be transported to those who desire them. The three factors which have been brought out in the case of raw materials must now therefore be applied to the processes of manufactures and transport.

(a) Land or Natural Agents.-Corresponding to the natural agents which make production possible, we have, in the case of manufactures, natural facilities, such as nearness to raw material or to markets, presence of coal or water, or other sources of mechanical power, and suitable Climate;* and in the case of transport, conveniently situated rivers, seas, and passes. These needs are suggested to a class, if we teach the advantages which have brought about the existence in their present situations of manufactures, towns, and trade-routes.

(b) Capital. - Capital as regards manufactures is shown in the form of "plant," and its importance is one of the reasons, along with the existence of skilled labour and the growth of subsidiary industries, why places where an industry has long been established are

* E.g., the moist Climate of Lancashire, which is good for manufactures. 
able to compete successfully with places where the industry is new, even if the latter possess superior natural facilities in dealing with transport. Railways and canals will, perhaps, be more obvious instances of capital to children than any which can be found in the case of manufactures, because in the course of teaching so many instances occur of districts which have become inhabited, and towns which have grown up, because of the construction of such means of communication.

(c) Labour.-The need of skilled labour is the most obvious point to emphasize. How far it can be brought home to a class is a matter for the teacher to think out in relation to the circumstances of the district in which the school is situated. The mention of this point suggests an important problem-namely, how far in the future the school can be used to prevent boys drifting into the ranks of casual labour and unemployment cwing to the demand for a type of boy-labour which is for a time fairly remunerative, but does not lead to permanent adult employment: but a book on the teaching of Geography is not the place to discuss the means that should be taken to organize Labour.

7. Other Economic Ideas which can be taught through Geography. - Illustration of the three fundamentals of production by means of examples, which, by the very nature of the subject, are constantly occurring, is the chief contribution which Geography can give to the popular knowledge, which is greatly needed, of some of the elementary conceptions of Political Economy. The duty of spreading such knowledge must be shared by other subjects. The teaching of the history of the eighteenth century, when the transition to the modern industrial system took place, 
should give some idea of its temporary evils and its permanent elements of good. Arithmetic should certainly, in the upper standards, give some notion of the nature of investment. It is impossible to say how much of the unequal distribution of wealth is due to the fact that the vast bulk of our population have never considered themselves as potential capitalists. As long as the terms Capital, Investment, Interest, are considered to belong to a different world-that of people who wear "top hats" on Sunday-so long will facts correspond to the belief. With this particular problem Geography can do little.

(I) Increasing and Diminishing Returns.-There are, however, a few other economic points which Geography can illustrate. The "law of increasing and diminishing returns "- that is, the principle that, up to a certain point, additional outlay and trouble will bring in greater proportional returns, that beyond this point they will give less proportional returns, and that this point differs under different conditions-is often supposed to be a principle of some difficulty. The teacher need, however, never refer to the principle as such; it is enough to describe a particular industry in which, under one set of conditions, people find it profitable to take more trouble than they can profitably take under others. In England, for instance, where land is scarce in proportion to the population, more manuring and tillage are employed, and the product per acre is greater, than in the United States, where land is so plentiful that, instead of trying to get more per acre from existing farms, farmers bring new land into cultivation. This fact is easily illustrated by the rapid increase of the wheat lands of Manitoba, and the 
emigration of farmers from the United States into that province of Canada.

(2) Money not Wealth.-Geography, likewise, will contradict the popular error which identifies wealth with coined money. Teachers can always ask of a country which they have been describing why it is "rich," and show that it has large facilities for producing goods of particular kinds, and that it exports the surplus to other countries, and is thereby able to buy the goods of other countries. The same law holds good even if, in the case of a large country like the United States, we substitute parts of the country itself for different countries. That wealth consists in commodities, not in money, which is a symbol of their value, is only another way of saying that the wealthy country is the country which provides all that men need, either directly or by exchange.

(3) Little Permanent Use of Gold and Silver Mines.-Another point which might well be illustrated is the failure of gold and silver mines to give any safe economic basis for the prosperity of a country, though they may attract a population to a country which is afterwards found to have other industrial possibilities. California is an instance of the exceptional case ; among the numerous examples of the general rule the State of Nevada stands out conspicuously. The rapid increase of population led to its being admitted a State of the Union in 1876 ; then the mines were exhausted, the population drifted away, and Nevada, returning as many Senators as New York, is left a desert with 42,000 inhabitants-one person in three square miles! If such a result is compared with the effect of sinking coal-mines, which has made barren counties like Lanca- 
shire into permanent centres of population, no abstract proposition is needed to distinguish between the expenditure of Capital and Labour which has permanent value and that which has not.

The principles determining Wages and Prices and the Theory of International Trade cannot be illustrated in the concrete form in which alone economic teaching can be understood by children. The former, it is true, is the economic question which most naturally interests the labouring population, and the latter is at the basis of all fiscal issues. For these very reasons there is no danger that they will be lost sight of in later life. The teaching which has been already suggested will, however, have given the children some idea of those facts which are at once the bed-rock of sound Economics and a preventive both of most fallacious economic arguments and of the confusions which make any argument meaningless. A knowledge will have been gained of facts which writers and speakers can use as illustrations, and a higher level of argument will be possible when speakers can assume that these preliminary ideas already exist in the minds of their hearers. 


\section{VI}

\section{WORK OF THE FIRST STANDARDS}

I. ENough has now been said of the aim which we have in view and the conceptions which guide our teaching to enable us profitably to consider the teaching at various stages. The first necessity with Standard I. is to make a clean sweep of the old teaching of definitions. Pictures, plasticene, and relief-maps will not put new wine into old bottles. A syllabus cannot be made up of nothing; and we feel sure that the difficulty of teachers has been to find a content for these lifeless lessons. If a child knew rivers, mountains, etc., by actual experience, he could learn all the names of these physical features in a few days; our duty is to tell him something about those physical features which he can see for himself, and to give him as good a mental picture as possible of those which are not to be seen in his own district. What a pupil realizes he can describe; and his own descriptions are better than a "definition" in a textbook. The words which were "defined" under the old system are words of everyday use, not technical terms; indeed, scientific Physical Geography has coined quite a different technical terminology of its own, which no one would dream of introducing into schools. Definition is only possible where terms have an exact meaning, and only desirable when that mean- 
ing is to be employed in careful scientific reasoning. If an attempt is made to use definition outside this, its proper sphere, it is apt to mislead; for instance, children frequently have an absurd notion of the flatness of tablelands and plains, which they have acquired from "definitions." It is safe to act on the maxim : Describe the scenery and the names will take care of themselves. The children will learn to use them just as they learn to use other words, by hearing them properly applied. We do not begin History by teaching definitions of king, laws, army, general, fleet, archbishop, tax, but explain the words as they occur.

Material for Descriptive Geography. - The substitute for the old "definitions" consists of mental pictures given to the children of the various kinds of scenery which exist in the world. No hard-and-fast line need be drawn between the scenery of our own land and that of other countries; nor have the features which used to be the subject of "definition" any exclusive claim to inclusion in this course. Waterfalls, icebergs, frozen seas, the aurora borealis, the midnight sun, palm-trees, sand, mirages, are as much geographical facts as bays, gulfs, channels, sounds, and firths, of which the real or imaginary distinctions have hitherto been treated as important. In the case of types of scenery which are only found outside these islands all schools are in the same position; but with those of which examples occur in our own country everything must be varied to suit the locality of the school. With Midland children the difficulty may be to give a picture of the Sea; with Fen Country children the appreciation of mountainous country is probably even harder. In Bangor, which presents an ideal view of sea and 
mountain, we have the more unusual disadvantage of not having a satisfactory stream within thoroughly convenient access. These three-sea, mountains, streams -practically constitute the scenery of our islands for children of this age. There are other types-the chalkhills of the South, the well-timbered parks of the Midlands; but quiet beauty is not so attractive to children as is awe-inspiring grandeur, while it is a rarer gift to be able to describe it. The plains of East Anglia have the majesty of vastness; to the eye they might be as boundless as the Prairies; the Sky seems to share in the extension of the Earth, for the spectator feels that he never sees where Sky and Earth meet; but this grandeur of the plains is only for those who can see it, and we believe that no child of the mountains sees it as the child of the plains sees the majesty of the mountains. Outside our islands, we have a wide area of choice, and it is not necessary that all should choose alike. The Frozen North, the Steppe, the Desert, the Jungle, and the Tropical Forest, may be suggested as particularly well-marked regions.

2. Essentials of Good Description.-Is the describer born or can he be made? To some extent he is born-if, indeed, we should say "he," since women are usually better describers than men. Description needs imagination; and imagination is partly a gift of Nature. Frequently imagination suffers from too much learning by rote, and teachers enter on their profession fresh from six or more years of preparing for examinations. It is well that Standard I. should be generally taught by women; and no one should be allotted either to Infant Schools or to Standard I. who is not imaginative. But it is equally important that nowhere should 
a great break be allowed; and description, though it has less exclusive possession, is needed all the way through the school. No teacher need, however, despair; imagination can be cultivated, and expression can be acquired even more easily.

\section{Comparison of the Use of Descriptions and of} Pictures.-Let us be clear about the respective pro* vinces of pictures and descriptions. Pictures cannot take the place of description. There are two reasons for this. First, a picture cannot represent everything we see in Nature. A really fine sunset is a spectacle some of us have seen and others have not. We mean a sunset where the whole sky, from the western horizon to the zenith, is coloured with all the colours of the rainbow, the series varying in intensity from the bright bands of red and yellow, where the Sun has set, to the pale broad tract of violet overhead, in which, as time passes, the lower bands decrease in intensity and die away, one by one, while the others extend and become paler. During the quarter of an hour while the sight lasts there is a constant change, and the spectator is affected, not only by what he sees, but by what he has seen, and by what he is watching to see. A picture can only seize one moment of the spectacle; and gives the same emotions as the sight itself only to him who has seen it.

This leads us to the second limitation of pictures. Even if they represent all that is to be seen in Nature, they do not represent what is heard or felt except to the spectator who can interpret them. To the trained eye Art can suggest even more than Nature; but we are here dealing with the use of pictures to give to children, who are very literal beings, an idea of what 
they have never seen. Take some very simple picture of a harvest scene in the evening. Any emotional effect which it has on us is due to our appreciation of the feelings which we should experience in the circumstances which are depicted. The hard work and the heat of the day are contrasted with the restfulness and satisfaction of the evening. To the child's literal gaze the picture resolves itself into a catalogue-item, one waggon and two horses; item, two men, one with a fork; and so on. The difficulty is increased when the scene which is depicted is absolutely new to the child.

A common picture on the walls of schools is rightly a desert scene, representing a waste of sand, with a caravan of laden camels and riders. This is all that could be seen in the desert itself, but much more could be felt. The oppressive heat, the blinding glare, the sand-storms filling eyes and mouth, the thirst and weariness, and then the oasis, the shade of the palmtree, the water, and the well-earned rest-these things can only be told, and not seen.

Again, take the Frozen North. A picture can represent ice and snow: but ice and snow dimly seen in every direction, a grey indistinctness fading into a grey nothingness, without definite boundary between what we see and the distance into which we look, without seeing anything ; the varying flicker of the aurora, and the sudden cracks of distant ice, emphasizing silencethis is not painted or printed.

A painted forest consists of trees and undergrowth. The Amazon forest is described by travellers as a solitude of dark, green, subdued light. They know that hundreds of feet above them the Sun is shining 
straight down upon the tops of the trees, but not a single ray finds its way to them. Absolute silence, obtrusive silence, is in this scene, as in many, an element which cannot be represented. The grandeur of intensity, of sameness, and of noonday twilight, can only be expressed in words.

As pictures need to be supplemented by description, so description needs to be supplemented by pictures. The impression which we wish to create in children's minds is a picture presented to the mind's eye. The other elements are mere accessories, and the sight of a picture keeps before them the scene which they are trying to imagine. A picture, too, presents all parts of a scene simultaneously, and, as the teacher proceeds with the description, the children read more and more into the picture, till finally the picture and his description fuse. The school should therefore contain a picture of a scene in each of the typical foreign regions which is to be described.

\section{Suggestions as to Power of Description.-}

How can a teacher who feels himself to be a poor describer set to work to prepare a good description? Not by enumerating items in the scene. A string of headings perfectly memorized may be of use, if the only object is to get facts remembered by the class, but it always lacks reality. The first requisite is to imagine the scene as clearly as possible. To sit back in a chair with one's eyes shut is a more valuable preparation than vigorously to write out notes of points that must be introduced. Further, the describer must not only see, but feel. The descriptions must not only be clear, but must convey the peculiar spirit of the scene. The question is not merely what there is to see, but how 
it strikes the beholder. Clearness is not vividness. Clearness is a perfectly intellectual quality ; vividness is clearness enlivened by emotion. If the teacher during his preparation tries to put the scene in words as he would before the class, let it be from the picture in his mind, by reading it off, as it were, not by recollection of facts about it. Any such cues must be used as signals for the formation of new images, not for the utterance of words describing things which are not seen or felt in the mind. Before the class itself the teacher should keep to the picture in his mind as much as possible. See and feel, and the class will unconsciously imitate. But clearness is essential to the right effect of feeling. There are teachers who try to make up for clearness of the mental vision by tone and gesture, who seem to be aiming at working up enthusiasm for an idea which they have not got, losing themselves in the superlative degree, and unable to think what is the quality which is to be expressed in that degree, communicating their own restlessness to the class to the subversion of discipline, and unable, after all their effort, to convey an idea more precise than "big," or " nice," or "grand." Quietness and control are outward signs of the teacher who sees and feels what he describes.

Sources for Description. - The publication by Dr. Herbertson of the series of Descriptive Geographies, one for each continent, gives the teacher access in books of small compass to selected descriptions from travellers who have seen the scenes which they describe, and often describe them with great literary power. Often, however, a greater extent of reading is necessary before the spirit is caught. A further use, therefore, of the Descriptive Geographies is to enable the teacher 
to judge from the extracts what books are likely to appeal to him; he can then read the originals. It is, of course, useless to do this in view of a lesson which is immediately to be given. But a teacher who anticipates making teaching his life-work, and contemplates taking the same class for at least a year, will wish to equip himself with all that makes him really a good teacher, as well as with those paper "qualifications" which make people think he must be a good teacher; and a course of interesting reading will do more to facilitate good teaching of Geography to younger standards than a mastery of many textbooks. The spirit of a country can often be obtained better from novels than even from the works of travellers. A few suggestions as to the use of novelists are contained in the last chapter.

Children have a special fascination in living creatures. Kipling has seized and united the two aspects of love of animals and love of story in the two "Jungle Books," and teachers can find in them much that is suggestive as to the method of introducing into a story the peculiar touch of a particular region.

\section{Sand-Tray Modelling as an Introduction} to Maps.-Descriptions are the first element in Geography for the lowest standard; the introduction to Maps is the second. The lessons which should lead to an understanding of Maps have often been described; the difficulty which is sometimes overlooked is that of obtaining anything like accurate drawing to scale with such young children. If children began Geography at eleven, accurate drawing might be a very suitable introduction; but they begin at seven or eight.

We believe that, on the whole, it will be found best 
to postpone to Standard II. lessons of the type usually suggested, in which we begin with the plan of the classroom and work up to the Map of the district, and adopt in its place the following method:

Where the country is hilly, by the sea, in a valley, or in any spot where a sand-tray model would show some prominent features of relief or water, it is suggested that the teacher should model the striking features of the landscape before any idea of measurement is introduced. Accuracy is a demand of a mature mind; a child naturally begins any kind of representation freehand. The necessary adjuncts are plasticene, sand, and a really large sand-tray ( 6 feet by 3 feet) for the teacher, and possibly small sand-trays for the children. Simple features can be imitated by all the children in their small sand-trays, and a model of a much more complicated character may be made by the teacher in the large tray.*

A few instances selected from different kinds of localities will suffice. If the school is on a hill or at the foot of a hill, the teacher will model the hill in plasticene or sand, marking the school. A stream will be represented by a slight trench, and water may, if plasticene be used, be allowed to trickle down it. A child's sense of "make-believe" is enough to make any very accurate representation unnecessary: the trench and school may be out of all proportion to their real size, and the gradient of the hill will be what it looks, not what it is. Schoolmasters will probably agree, though geographers may be pained. A simple example

Sand-trays are regularly in the possession of all children in good infant schools, and we see no reason why this should not be the case with Standard I. also. 


\section{THE TEACHING OF GEOGRAPHY}

like this may be imitated simultaneously step by step by the children in their smaller sand-trays.

A sea-coast has so many features that many can be modelled separately and then combinations made. The near view of beach, with details, the more distant view of some capes and mountains rising above the coast, and the whole circle of a bay are examples. At Bangor we can see the Menai Straits opening out into Beaumaris Bay, the coast-line of Anglesey opposite us and ending in Puffin Island, the winding coast of the mainland stretching away along the edge of a coastal plain to the round mountain of Penmaenmawr, which is the termination of a long range of mountains, and rises abruptly from the sea; then, after another interval, we see the lesser hill of Penmaenbach rising similarly; while the view out to sea is finally interrupted by the long egg-shaped mountain of the Great Orme rising almost like an island from the sea, and connected with the mainland by a long flat isthmus. Of course, few districts have such a scope for modelling as this, but few are without some distinctive features.

It will usually be necessary to take the class to some point from which a better view can be obtained than from the playground, as it is hard even for an adult to recall the arrangement of the features in the most familiar view from memory, unless he has observed it for a definite purpose. The view would afterwards be modelled in the large sand-tray, as the school would not possess enough plasticene. It would also be too large for the children to imitate in small trays, but they should be encouraged to take an active part in suggesting the steps in building up the large model.

Another example may be taken from a view of. 
distant mountains, whose peaks and passes can be similarly modelled stage by stage. The model can be extended beyond what is seen, so long as the features which are to be represented have had parallels in the instances which have already been taken from the children's experience; then modelling becomes an integral part of our descriptive Geography. Scenes are modelled from pictures; scenes are modelled to use instead of pictures; the class learn incidentally the names of the things which are modelled: thus at the end the children will know the appearance of various types of coast and mountain scenery.

Then, too, if there is any stream near the school, the teacher models parts of its course which the children have seen; he gradually extends the modelling to parts which they have not seen. At the end he can represent a considerable area of a river-basin. Where much is visible, it is all the better. The mountains on each side of a valley, the main stream in the middle, the tributaries coming from the adjoining hills, and the valley opening up into a plain, form such an area. This instance is suggested by the Vale of Llangollen. Gradually the teacher's plasticene and sand work becomes more true to fact. From the beginning, indeed, the mountains must always look like mountains, and not be knobs bulging like a door-handle, or protuberances like those which children on the seashore turn out of an inverted bucket, or, still worse, lofty cones, with their altitude several times as great as their diameter. As time goes on, however, they become still less elevated, the coating of sand or plasticene becomes thinner, the lines representing roads and railways more marked, and the model has become 
almost a relief-map. In the case of a plasticene model, by seeing it suspended in an upright position the children learn the nature of a Map. Thus, provided that enough work of this kind is done, the children acquire an idea of a Map previous to any idea of exact measurement.

\section{Apparatus-Disuse of Imaginary Pictures} to teach Definitions.-Some criticism of appliances commonly used in schools for the earlier work is here in place. Wall-sheets, representing respectively a bird's-eye view and a Map of an imaginary country, are frequently to be found. These often show great ingenuity, but the majority are actually bad, because they attempt to crowd in one picture examples of all the "definitions." Impossible scenery is the result. A convenient volcano stands by itself on a coastal plain, situated in a peninsula, which contains mountain chains and mountain groups, with perhaps a lake visible from the coast, and various inlets, harbours, and islands, for which no structural reason could be found, and rivers with mouths and deltas out of all proportion to their few miles of length. The reason for this wonderful patchwork is clearly a desire to save the expense of multiplying pictures, while showing the correspondence between a country as seen and the same country drawn to scale. If teachers use for their landscapes views which are actually within the children's sight, or any pictures of real scenery which are kept for other purposes in any of the classrooms, and if for their drawing to scale they substitute modelling, then there is no longer any need for the former impossible combinations. The attempt to use the same picture and Map for schools situated in dissimilar sur- 
roundings is as absurd as if we tried to clothe the whole population with garments of identical dimensions.

Disuse of Relief-Maps.-Another common appliance is the relief-map. This is usually a very expensive luxury, and often quite useless. A hilly country becomes a mass of bumps. If the smaller mountains are to appear at all, the larger become precipitous cones rising to heights six or seven times as great as their diameter. All river-valleys are gorges, and railway travelling in such a country would put to shame the Scenic Railway of the Franco-British Exhibition and all switchbacks ever invented. Some such Maps are even coloured according to counties, increasing the bewilderment, since, though the eye is too well aware of the general unevenness, comparison of heights is very puzzling when the top of a mountain may be bright blue and its lower part in another county dark red, the two colours being separated by a spiral line.

Parallel Bird's-Eye Views and Maps.-For a really good attempt to illustrate the meaning of a Map covering a small district to children rather older than those of whom we are speaking, we can refer to a series of pictures and Maps at the beginning of the Welsh edition of Philip's "Shilling Atlas for Schools," in which the middle portions of the larger Map and picture are enlarged in the next, and similarly a second time in the third. The difficulty is that such illustrations are not likely to be inserted in atlases for each particular district, and that their use is largely confined to schools in the district represented.

Physical Geography of Standard I.-Two main elements in the syllabus of Standard I.-Description 
and Modelling-have now been discussed. There are a few matters about the World as a whole which can be taught in this standard, although they lie outside the general scheme. They are best taught at this stage because the conception of the Earth as a planet is so contrary to the appearances of sense that it requires several years from its first introduction for its complete understanding.

The Roundness of the Earth is clearly the first point. The Globe should be familiar for some time-a year or more-before Maps of the World are shown. The only attempt at "proof" should be that people have sailed all round it. With older children the fact which brings its roundness most closely home is that allowance has to be made for the curvature in cutting canals. Clearly a "lesson" of half an hour cannot be made out of this material, and this is the reason why the other "proofs" are frequently introduced at an early stage ; but our aim is not to give "lessons," but to teach.

The cause of Day and Night is already taught on the right plan. Elaborate instruments for explaining it are unnecessary and expensive. An orange, a knittingneedle, and a candle are enough.

A knowledge of the Points of the Compass is necessary to prepare the way for Maps. They should in the first instance be taught merely as a means of indicating direction from the school, not in relation to the Globe. This lesson can be taught by bringing out certain children in front of the class to impersonate the points of the compass by pointing in the required direction, while the rest of the class follow their example. Intersecting chalk-lines can be drawn on the floor. There will be a tendency at first for the children to point towards some object at 
which the teacher (or the child who is representing that point of the compass) appears to be pointing ; but they learn very quickly what is expected. The idea of direction is much easier than one might have supposed. In addition to the four children, we might have a fifth in the middle as "weathercock," to point in whichever direction the teacher says the wind is blowing. This instance has been given to show how the Kindergarten and infant-school spirit can be introduced in Standard I., not only in the matter of modelling, but also in teaching through action and play. When the Frozen North is taught, the children will, of course, be asked to point in the direction they would have to take to reach it, and they should name the directions in the models.

Finally, if children become acquainted with the Globe, there is no reason why, before the end of the year, they should not learn the names of the six Continents and five Oceans, even though they cannot attach to them much idea of size, and though they only know that the former are land and the latter water. It is the only teaching of mere names which has been introduced into a year's work. 


\section{VII}

\section{MAPS AND THE TEACHING OF MAPS}

I. IN the last chapter reference was made to the method generally suggested in books on the principles of instruction for teaching the meaning and use of Maps, and the subject was then postponed. The following pages will contain-first, a slight account of the features of a good physical Map; next, a discussion on the teaching which is to familiarize children with its use; and, finally, remarks on some special points which call for notice in connection with Maps.

\section{Choice of Salient Facts about the British}

Isles.-We will take as a type of a good physical Map Bartholomew's sheets of England and Wales (two miles to the inch). The chief feature is the clear way in which elevations are marked by shading. Teachers will probably follow the accepted convention by which higher ground is coloured brown and lower green, the darkness of the brown increasing as we ascend, and the darkness of the green as we descend; but they will begin with only one or two shades of each, and increase the number of shades as the greater complexity of the region or our greater desire of accuracy requires. We must assume that the reader knows Bartholomew's or some other good physical Map. 


\section{Knowledge of Methods of Surveying not} Essential.-It is often assumed that the use of a Map presupposes that the reader knows how it has been made. Some writers even hold that children as well as teachers should be given this knowledge. Explanations as to the way in which such teaching should be given have appeared; but we may state at once our belief that the fourth form of a secondary school is the earliest point at which the elements of surveying can profitably be given.*

Use of Contour Lines.-As regards the method of locating positions on the flat, it does not seem to be necessary to know what measurements are taken if we are confident that some distances really have been measured, and that the whole Map has been drawn to scale. Similarly as regards altitude, most people know that the exact altitude of certain spots has been carefully ascertained and "bench-marks" placed there; but it does not seem to matter how the altitude was ascertained so much as that we should know that on an Ordnance Survey Map " B.M. 362" means that a bench-mark of 362 feet above mean sea-level exists on that spot, and that if we went there we could find it in the form $\uparrow$. We must know that a contour line means a line every point along which is of equal altitude, and that it consequently separates the country above that altitude from that below it; but it is not material to know whether, after ascertaining the height of several spots, the surveyor draws in the contour lines freehand or whether a more delicate method is used. On an

* The teacher who is interested in the subject can find the methods clearly explained in Frederick Mort's "Practical Geography"; Blackie and Sons. 
Ordnance Map the contour lines should be carefully distinguished from other lines marking parish or county boundaries. It is clear that where it is required to give height in detail-the Ordnance Survey Maps mark a contour line for every hundred additional feet of elevation-contour lines have a great advantage over shadings, as the number of contour lines on a single sheet can easily reach twenty, while twenty shades of colour would become hard to distinguish. In other words, colouring gives a general impression, contour lines give accuracy. One of the great uses of accuracy in this matter is that it enables us not only to know the altitude of the top of a hill, but also, by means of the distance of the contour lines from one another, to see what is the slope of the hill on various sides. For if we find the distance between two contour lines of 500 and 600 feet to be only roo yards (300 feet), we know that we have ascended roo feet in traversing 300 feet-that is, that it is a steep slope of $I$ in 3 ; whereas if the distance between the contour lines is 300 yards ( 900 feet), the slope is only I in 9 .

Ordnance Survey Maps.-The Ordnance Survey Maps are: (I) Town plans, 25 inches to the mile; (2) the larger scale sheets, 6 inches to the mile, and I 8 by $\mathrm{I} 2$ inches in dimensions (i.e., 3 by 2 miles); (3) the smaller scale sheets, I inch to the mile, and 27 by 18 inches in dimensions (i.e., 27 by 18 miles).* Every school should possess the sheet or sheets of the second, taking in the neighbourhood of the village, and every town school should have the town plan.

* The newer I-inch sheets are of these dimensions. Some districts can still be obtained only in sheets of 18 by 12 inches. 
Maps are ordered from the Ordnance Survey Office, Southampton, who send them carriage free on receipt of a postal order. The prices are as follows: Town plans, 2s. 6d. (large scale), "quarter sheets" (four of what would ordinarily be termed sheets are together called a "sheet" officially, and numbered the same, so that if you want a sheet numbered 32 you must order 32 north-east, north-west, south-east, or south-west, as required), Is. each; smaller scale, Is. each.

2. Early Lessons in Drawing to Scale.-The last chapter described a way of reaching a rough idea of a Map, the flat representation, from the model, the raised representation. It is assumed that in the following standard the second method of giving the idea of a Map will be introduced-first, because it introduces the idea of scale; secondly, because repetition in a new form is a sure mode of fixing knowledge. Some teachers may elect to use it from the very first, especially in flat districts, where a flat representation causes no difficulty. Even then we hold that all the accurate work must be done by the teacher on the blackboard, and only rough work by the children in sand-trays. The idea of measurement by means of a fixed unit is quite easy; it is the complexity of yards, feet, and inches which makes children unable to use a tapemeasure. If we use a yard-measure or a piece of string a yard long, and if we are content with half and a quarter and a "bit" (the child's convenient description of a fractional distance which he realizes but cannot name) to express smaller parts, the length and breadth of the room and other distances in it can easily be ascertained, the children helping vigorously. Each yard of reality is to be represented by "the piece up to 
this mark" (a mark clearly drawn by the teacher on a ruler) on the board. Eight yards are represented by eight "pieces," and so on. All that the teacher draws is drawn at the suggestion of the children, and afterwards the children imitate the plan roughly in sandtrays. The classroom, which can be measured before the children's eyes and in which all can take part in measuring, either actually or at least in spirit, is, of course, the first area to be treated. The class will probably insist on the insertion in this plan of a very considerable amount of detail, and the teacher's ingenuity and his coloured chalks must suffice for the ordeal. The use of coloured chalks to represent various classes of objects in the room is the way to lead the children to expect the use of various colours in maps for the same purpose. Such exercises as making one child walk round the room and another draw his course on the Map will lend animation to the work, and may possibly prepare the way for those "imaginary lines" which appear on Maps. Rougher representation of the ground-plan of parts of the school, the whole school, and school and playground follows. At first it may be desirable that the measurement should be a solemn function performed during the break, but soon the class will recognize what is expected if the teacher. supplies the measurements. The children should also be given practice in drawing these plans roughly in sand at some time when the work has not been done for them immediately before, as well as directly after a demonstration. Each step must be grasped well, and we must not try to get results too quickly. Then follows the immediate neighbourhood, the children selecting the buildings, roads, or other objects to be inserted. 
Use of Colours to express Altitude. - The idea of colours as representing heights should be introduced quite early-how soon depends on the hilly or level character of the immediate neighbourhood. Usually the need of a means for marking hills is not felt in dealing with a plan of a district a quarter or half a mile square; but sometimes a school is built at the very foot of a hill or on its summit, and in such cases representation on the flat, with no means of giving an impression of height, will, even in the minds of the children, seem deceptive.

It is almost unnecessary to state that the use of colours to express height should precede the drawing of uncoloured contour lines or any attempt to explain how heights are ascertained or contour lines drawn. The ordinary convention, by which low ground is coloured green and high ground brown, should be adopted as soon as colours are introduced at all for the purpose, but only one or two shades of each should be used at the beginning.

3. The child has now in two ways attained an idea of a Map; the one method gives him the idea of a Map as a representation of the scenery of the country-side, the other as a drawing to scale. The shadings for height are as natural a corollary of the former point of view as the flat representation of the latter. Care should be taken, though it is always known that green is to represent comparatively low ground and brown comparatively high ground, that children should realize that we have sometimes to use brown to denote much greater heights than at other times, that the colours are relative to the particular kind of Map, and that what is brown in one Map may be green in another. No care can avoid this 
necessity. An Atlas should use the same scheme of colouring for all continents and for all countries; but we cannot use the same colouring for a Map of Asia and for a Map of a parish, as it would reduce the parish to a uniform green or introduce several hundred colours in Asia. As our teaching progresses, certain standards of height should be introduced and developed out of one another-local heights in the beginning; standard heights, such as Snowdon, later on. When a new scheme of colouring is introduced, the class should be asked to suggest suitable colours, and the scheme should be compared with the standard heights.

Introduction to Real Maps.-Very soon after the completion of the work of modelling described in the last chapter, and that of local plans described in the last section, children should be introduced to the Ordnance Map. The teacher should first draw the district roughly on the board with the help of the children, and then present the Ordnance Map. The work of the children will consist in the identification of the objects which are marked on it, beginning either with hills or with rivers, roads, and railways. Should the district be hilly, it will be necessary for the teacher to colour the parts between certain contours according to the scheme on which he has been working for his own blackboard Maps. The children's attention will not be called to contour lines till much later. The primary ideas are the representation of hills and lowlands by brown and green, and the method of indicating rivers, roads, lakes, railways, buildings, etc.

In the scheme of work given in Chapter III. it is contemplated that this kind of work should proceed parallel with the physiographical instruction in the 
work of water during the first part of the year; and that, when the idea of a Map has been extended by means of the Ordnance Map, followed by Bartholomew's coloured Maps, then the class are ready to be confronted with a good physical.Wall-Map of England and Wales or of the British Isles, and to begin regional work on the country.

4. Wall-Maps.-In the opening paragraph of this chapter it was stated that, after the discussion of the work of familiarizing Standard II. with Maps was completed, there would follow some remarks on Maps in connection with the work of other parts of the school.

The essential feature of a good physical Wall-Map is that it should be so shaded as to give a good general impression of elevation at a distance. Purchasers should stand at the same distances from it as those at which the nearest and farthest parts of the class are likely to be, and should consider the general effect. No real advantage is gained from the existence of names, as the bulk are illegible at a distance, and we do not always desire that they should be read. If they are not too numerous, they are, however, harmless, and it is hard to secure Maps without them. It is probably best that important towns should be marked, whether named or not; many Maps insert only the mark and the initial letter of the name. In the case of Europe, the idea which is conveyed of the great plain of Russia and the extent and breadth of the Alpine system are points to be particularly observed. In Asia, the great plains of Siberia, the plateau of Tibet and the other lesser plateaux, and the clearness with which the great ranges are distinguished from the plateaux, are important. No Map should be obtained 
till it has been seen by someone who has an adequate knowledge of the physical features of the country which is represented.

A school needs to be supplied with several Globes, varying in number according as Geography is or is not taken simultaneously through the school, a physical Wall-Map of each of the six continents, of the British Islands, and probably of England and Wales. The only political Wall-Map which is at all desirable is that of England and Wales, and this should never be used without the corresponding physical Map (or, at least, the physical Map of the British Isles).

Now that suitable Atlases can be obtained for a shilling, all children should have them as soon as they begin to study the separate countries of Europe. Up to that point, the only country for which they are required is India, and an additional physical Wall-Map, or the purchase of penny "Diagram Maps" for each child, will get over this difficulty. We wish that a good physical Wall-Map of South-Western Asia and Egypt, extended to take in all the countries in Scripture, were published, to be used both for Geography and Scripture teaching. We do not abandon geographical principles when we are not in Geography hours, and so we would have our Map of Palestine physical. It might be so far political as to contain a red line marking the boundaries of Judæa, Samaria, and Galilee; but the locality of the twelve tribes, except that of Judah, is practically without mention in the Bible after they have once been located in the Book of Joshua.

Map-Making by Class.-In many schools Mapdrawing by the children has occupied considerable time. The substitution of physical for political Maps 
does away with the drawing of political frontiers and the painting with gorgeous colours that used to be understood by "mapping"; and the use of colours by the children to represent altitude will not be found to render an adequate return for the time expended. In England and Wales, however, where the names of the counties have enough value as a matter of general knowledge to justify their retention, the old plan can still be followed; indeed, it is the only way of making the children thoroughly familiar with the relative positions of the counties, and their use in locating the position of the towns within them is their only service in later life. The main railway routes can be taught in the same way, though here the physical reasons which determine their course must be emphasized in cases where the courses really are influenced by physical reasons.

5. Map Projections. - Before the problems of Map-making in relation to large countries or continents can be properly understood, teachers must have some notion of projections. It is obvious that the Globe is the only true representation of the Earth, seeing that the actual shape of the Earth is globular. If we attempted to flatten a globular piece of paper we should crumple it, and all flat representations of large pieces of the curved surface of the earth are distortions. The scheme of distortion varies. If we looked at the Earth from a distance, the middle portions of the hemisphere turned towards us would be fairly accurately shown, while the extremities would be enormously distorted. No ordinary "projection" follows this plan, since we wish, by spreading the error over the whole surface proportionately, to minimize its effect. 


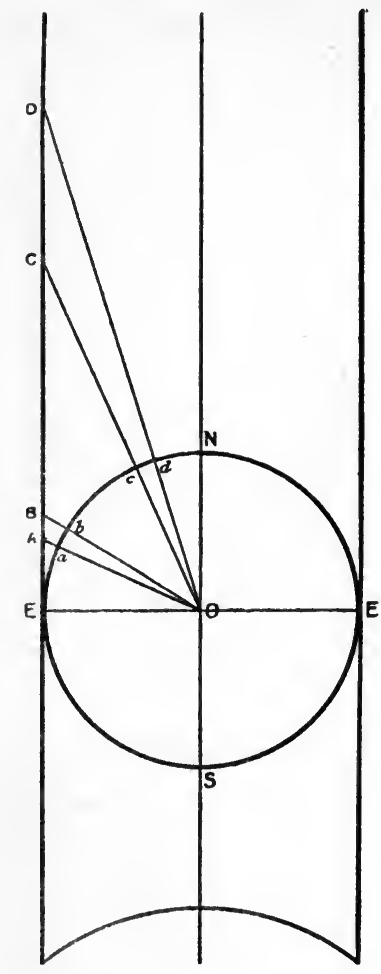

Section throdgh GLObE, AND Cylinder of PAPER.

$\mathrm{N}$, North Pole; O, centre of Globe; E, E, plane of Equator ; $a, b, c, d$, four points in the same longitude, but in different latitudes; the distances between $a, b$ and $c, d$ are equal. A, B, C, D, the projections of $a, b, c, d$, on the paper cylinder. The exaggeration of distances in the higher latitudes is easily observed.
Of actual projections used, it is necessary first to distinguish Mercator's from all the rest, as it differs from all others in its aim and the kind of error involved.

\section{Mercator's Projection.}

- The purpose of Mercator is to represent direction with perfect accuracy, and for that purpose to sacrifice accuracy in all other respects, such as those of shape and size. It is intended for use by sailors.

This purpose is achieved by making all lines running north and south cross all lines running east and west at right angles, so that direction can be seen at a glance without looking at those curves which represent latitude and longitude on ordinary Maps.

On the Globe lines of latitude are really parallel, but lines of longitude intersect at the poles. On Mercator Maps both have to be represented as parallel.

The method of producing this projection is to 
imagine the Globe made exactly to fit inside a hollow cylinder. The Globe must touch it on all sides at the Equator, as represented in the accompanying diagram. The surface of the Globe is then projected on the cylinder by means of a series of lines drawn from its centre through the surface to the cylinder, as shown in the diagram. When the cylinder is removed and unfolded, the lines of latitude and longitude, which were circles on the Globe, will be found to be represented by straight lines.

But in securing this end other startling consequences have been produced. The diagram shows one such. Every degree of latitude as we recede from the Equator is represented by a larger interval on the unfolded cylinder, till finally the line drawn from the centre through the poles is not projected on the cylinder at all, because parallel lines only meet at infinity!

Danger of Use of Mercator in Schools.-This account has been introduced to show that the difference between projections is not, as is often supposed by persons who have not thought about the matter, a difference of detail. Used for any other purpose than to ascertain direction, Mercator is a hideous distortion; and children are not thinking of direction, but of size and shape. The Polar Regions are so much exaggerated that Greenland appears the same size as South America, whereas the latter is twelve times as great. To use a Mercator's Map for five minutes gives a class more false impressions than can be corrected by weeks of teaching. This warning is particularly needed when we find an eminently patriotic society, the Empire League, disseminating maps which suggest that threequarters of the British Empire is situated amid ice and 
snow, and that India * is no larger than the Arctic island of Baffinland. It may be said that this can be explained to children, but when a teacher can explain the matter of the last few pages to Standard II., then the Maps may be brought out of their locked cupboard.

The projections most commonly used are attempts to preserve some approach to truth both as to shape and area, though some preserve accuracy as to area by making a greater sacrifice in shape. In all cases the middle portions of a Map are preserved as accurately as possible and the outlying parts are more distorted. This may easily be noticed when the shape of the parts of Europe which appear at the edge of a Map of Asia or Africa are observed. The smaller the country and the nearer to the Equator, the less is the distortion. The great difficulty in Map-making is that in ordinary projections the lines of latitude and longitude are curved, and the principles of the curvature are too intricate to be explained to children. The question may be raised whether the class should use the lines of latitude and longitude as the means of drawing Maps.

\section{Should the Class draw Maps by Means of} Latitude and Longitude?-In such a complicated subject it will, perhaps, be best to put forward the opposing views rather than to adopt any without demur. Some authorities believe that Map-making is of little value unless the lines of latitude and longitude form its basis. Mr. Yule Oldham, reader in Geography in the University of Cambridge, suggests a method for drawing such a framework of lines with a very fair

* The actual area of India (without Burmah or Baluchistan), I,377,000 square miles; that of Baffinland, about 50,000 square miles. 
approach to accuracy and the least possible amount of trouble in an article in Spencer's "Aims and Principles of Teaching." The chief arguments on this side are that position is the fundamental fact which Map-making sets out to teach, and that position as regards latitude is the fundamental fact determining Climate. On the other side, it may be urged that with the limited time at our disposal the time taken in teaching any method of drawing lines of latitude and longitude is not repaid by the benefit obtained.

\section{Use of Map-Making by Class to illustrate} Particular Points.-The upholders of this view affirm that every exercise in Map-making should have the definite object of fixing some particular fact which can be better taught in this way than merely by pointing it out on a Wall-Map or in an Atlas. For instance, in teaching the reasons for the greatness of New York, the dominant factor in determining its importance is the unique position which it holds on the coast of North America for affording access to the Lakes. The coast from the mouth of the St. Lawrence to Chesapeake Bay is very complicated; it is usually seen on a small scale as part of a Map of a much larger area. Consequently, few people realize how much farther west New York is than the mouth of the St. Lawrence, and how much farther south Lakes Erie and Ontario are than the mouth of that river. Most people, if they were called on to draw a memory Map without having received good teaching of this region, would represent New York as entirely out of reach of the Lakes. In point of fact, the railways and canals of the MohawkHudson valley from Buffalo to New York are the great outlet for the Lake traffic-that is, they form the last 


\section{THE TEACHING OF GEOGRAPHY}

stage of the great through route from the wheat and maize country of the interior, from Chicago, Milwaukee, Detroit, and Cleveland, to the coast. What this means can be seen from the statement that more traffic passes from Lake Superior alone to Lake Huron, before any of these towns have contributed their quota of traffic, than through the Suez Canal. A carefully-made Map of the coast, marking the Catskill Plateau, the Adirondack Group, and the southern spurs of the Green Mountain Range, impresses on children the meaning of the position of New York better than anything else. We incline to this latter view, feeling that Map-making should, above all things, be an integral part of the teaching of some definite point, that the teacher should tell the children exactly what is to be put in it, that its value consists in finding out these facts in the Atlas and copying them in, that it then contains just what is needed to bring out the point and nothing more, and that tracing or any other method of getting the outline is quite permissible. Instead, therefore, of setting a Map of a country we should set Maps which bring out routes of communication, Maps showing distribution of particular products, Maps of temperature and rainfall, and in each case include any factors which help to determine these results. If this view is accepted, a separate discussion of the choice of work in Map-drawing becomes impossible. 


\section{VIII}

PHYSIOGRAPHICAL SIDE OF GEOGRAPHY

I. Scope of Chapter.-This chapter is intended to give an account of another aspect of Geography, which is practically begun in Standard II.-namely, the Physiographical Side. It is true that this side has been touched in the previous Standard; but it is intended that a new feature should be introduced at this stagethat is, the direct observation by the children of physical phenomena, which necessitates out-of-door work. The beginnings of such work must necessarily be elementary; but teachers who are interested in this side of Nature-Study can develop it from these beginnings at a higher stage of the school, where quantitative work becomes possible. It will be convenient, however, to collect all that has to be said on this topic in a single chapter. We propose, therefore, first to give certain information, especially as to the work of moving water, which may be of assistance to teachers to whom this branch of Physiography is new, and may lead to a further study of the subject; secondly, to discuss the elementary treatment of the matter which is possible in Standard II.; thirdly, to outline what may be done in the higher standards in schools where the teacher elects to make this kind of work a special feature of his Nature-teaching.

2. Changes constantly proceeding on Surface of the Earth. - The surface of the land seems identi- 
cally the same from year to year, and we are apt to regard the present surface as permanent. A little consideration of the work done by water in modifying the topography will show clearly that great changes are taking place; the alteration may be very slow, but nevertheless it is always proceeding. In lands which have greater variation in the weather than our own the change is more rapid. There are several agencies at work in producing changes in the surface of the land, some resulting from subterranean, others from subaerial causes. Among the latter are diurnal changes in temperature, wind, water, and ice. These forces are acting in conjunction with one another, and it is difficult to separate the work done by each. To illustrate the way in which changes, constructive as well as destructive, are continually taking place, we propose to deal briefly with the life-history of a river.

Life-History of a River.-Though the two processes of denudation and deposition by water take place at the same time, it will be convenient to separate the account of them; and, as they in turn are largely the result of the rate at which the water is flowing, a preliminary consideration is necessary of the causes which determine the rate of flow.

Yariations in Rate of Flow.-The two main factors which determine the swiftness of a stream are its gradient and its volume. Except in the case of a few rivers which rise in marshy plains, it is possible to divide the course of every river into two more or less marked divisions, the upper and the lower. In the former the slope of the land is considerable, and consequently the current is swift, but the volume of water is less than in the lower course, after several tributaries 
have poured their contents into the main current. In the lower course the slope is gentle and the path winding.

Further, the rate of flow varies in different parts of the same cross-section. The surface waters move faster than the water near the bottom, which is impeded by friction against the bed of the stream; and the water in the middle moves faster than that near the side, which is impeded by friction against the bank. When a river flows round a bend, further complications arise. The water which is moving faster tends to continue in a straight course, and so moves towards the concave bank, and hence causes a temporary heaping up of the waters on that side. The level is restored by surface currents flowing towards the convex side, and these have the effect of further decreasing the velocity of the current on this side. These intricate movements give rise to a whirling of the water. There is no suitable word in English to describe this, but the Welsh term "trobwll" (literally a turn-pool) expresses the idea. Deep pools are by no means uncommon at these points, and it is interesting to note that the bed of the stream slants gently on the convex side and rises abruptly on the concave side.

Denudation-(I) Chemical Action.-We are now in a position to consider denudation and deposition. As regards the former, there are two ways in which water can carry down solid matter-in solution and in suspension. Rain water, on account of the atmospheric oxygen and carbon dioxide which are held in solution, is a powerful rock solvent. Its solvent power is further increased by organic acids resulting from plant decomposition ;* consequently it is able to carry away much

* Humus acids. 
material in an invisible form. Different rocks are affected to different degrees. For instance, limestone is easily dissolved, and in limestone areas river water is very hard in consequence of the carbonate of lime which it contains. On boiling this water, a white incrustation is obtained, which proves the presence of soluble material. Caves and underground streams also are most common in limestone districts, and they owe their origin to the dissolving power of the water. Sandstones are likewise attacked by rain water. The cementing matter which binds the sand grains together is dissolved, and the rock is given a looseness, which enables the water easily to carry it away. Harder rocks are affected, though to a less degree. Even igneous rocks, such as granite, are unable to resist the action of rain water. The amount of matter carried in solution by a river depends on the nature of the rocks in its drainage area. The Thames, which drains a large limestone and chalk area, is particularly rich in soluble material. It has been estimated that this river carries I,502 tons of material every day in an invisible form past Kingston Bridge, and allowing for tributaries which join it below this point we can increase the amount to 2,000 tons. From the data available for other rivers, Mr. T. Mellard Reade has calculated that the rivers of England and Wales are annually removing over $8,000,000$ tons of solid matter in solution.

(2) Mechanical Action.-The mechanical work accomplished by rivers is even greater than the chemical, and is more variable. On account of the high speed in the mountain track, the river moves large boulders, which are broken up and assume a rounded appearance. The larger boulders are only moved in flood time, but the 
constant friction between them and the small stones leads to a decrease in the size of both kinds. This process further tends to reduce the stream-bed to a uniform gradient. In addition to this material which is rolled along the bed, there is a steady flow of fine sediment, and the finer material finds its resting-place in the sea or in a lake. The amount of sand thus carried out to sea varies considerably. The Mississippi has been estimated to take enough sediment past New Orleans each year to cover a square mile to a height of $26 \mathrm{~g}$ feet. Even this is not a fair estimate of the carrying power of a river. When there is a marked difference in gradient between the upper and lower course, it is found that deposits of material are formed at the point at which the change takes place. Such deposits are termed alluvial cones, or fans. The position of these cones is interesting, apart from their physiographic significance, from the fact that many towns have sprung up on them, such as Philadelphia and Baltimore.

\section{Effect of Rate of Flow on Cutting and Carry-} ing Power.-It has been previously stated that rate of flow is an important factor in determining the cutting and carrying power of a river. Sir Archibald Geikie quotes the following table "of the power of transport of different velocities of river currents":

$$
\begin{aligned}
& \begin{array}{c}
\text { Inches } \\
\text { Miles } \\
\text { per Hour. }
\end{array} \\
& 3={ }^{\prime} 7 \text { will just begin to work on fine clay. } \\
& 6=34 \text { will lift fine sand. } \\
& 8=45 \text { will lift sand as coarse as linseed. } \\
& \mathrm{r} 2=.68 \text { will sweep along fine gravel. } \\
& 24=r^{\cdot} 3^{6} \text { will roll along rounded pebbles one inch } \\
& \text { in diameter. } \\
& 3^{6}=2^{\circ} 04 \text { will sweep along slippery angular stones } \\
& \text { of the size of an egg. }
\end{aligned}
$$


An examination of this table clearly shows that, if the rate of flow is doubled, the carrying power is more than doubled. It can be proved that, if the speed is doubled, the power of transport is increased by two , degrees, or sixty-four times the original capacity. The obvious deduction from this is, that in regions where the rainfall is very variable the changes produced on the land surface are much greater than in places in which the same rainfall is uniformly distributed. The energy of the stream is divided between the task of carrying material down its course and that of cutting its channel deeper and deeper.

\section{Tendency to Grade Stream; Special Cases-} (I) Waterfalls.-All streams are therefore tending to reduce their course to a uniform gradient, but this task is rendered more difficult by variation in the rock structure. When hard and soft rocks exist side by side, the softer yield to the destructive agent more readily, and a waterfall results. The Aber Falls of North Wales are an example of this phenomenon. Even in such cases the fact that the river is cutting back into the hard rock is clearly seen by the rounded nature of the upper part of the fall. The weight of the falling water produces a deep pool at the foot, and this is further deepened by the circular motion given to the pebbles which are contained in it. Falls also arise when the course of the stream is crossed by a band of hard, compact rock resting upon a more incoherent layer. The classic instance of this is Niagara. Here a band of limestone rests on a thick layer of shale, or mudstone. The back-wash of the fall removes the shale, leaving an overhanging ledge of the harder rock. In time the weight of the water is sufficient to 
cause a fracture of the protruding ledge, which yields and falls into the pool below, where it is ground into fine pebbles. Hence the fall is travelling upstream. In the case of Niagara this is about 4 feet per annum at the present day, but in all probability this rate has varied from time to time. The gorge of the Niagara River owes its origin to the retrogression of the fall. As we know the length of the gorge, a rough estimate may be formed of the time taken to produce it. Numerous instances of falls of this kind may be seen in our own country-for instance, the numerous streams forming the Neath River, in South Wales, furnish examples of both kinds of falls.

(2) RAPIDS.-Rapids in the course of a stream may be due to a variety of causes. Some consist of a series of partially graded falls; others are produced where a band of rock with peculiar jointing crosses the path, as is the case with the Wye above Builth Wells.

(3) Potholes. - In limestone districts, where the rocks are approximately horizontal and the river runs over their surface, we often find circular holes, which are termed potholes. In every case a number of pebbles are found inside, and the smooth surface of the holes clearly points to the fact that they have originated as the result of the rotation of the pebbles produced by the action of the water. Some excellent examples may be seen at Pontsarn, near Merthyr Tydvil.

Formation of Yalleys.-In lowering its bed the river is indirectly forming a valley. As the river cuts vertically downwards, the sides are gradually brought down by rain and the other subaerial agencies, and the loose material on the slopes steadily gravitates to a lower level. In this way we can therefore speak of a 
river as carving out its own valley. The width of the valley depends on the nature of the rocks. When these are hard, the river is able to work faster than the other agencies, and a narrow valley, or in some cases a gorge, is formed, such as Taff's Watt Gorge, near Cardiff. Through continual erosion of its bed, the stream must ultimately reach a level where the rate of flow is such that all the energy is spent merely in transporting, and no further erosion is possible. The process of widening the valley can still continue, and thus a broad valley is gradually produced. Broad valleys are usually associated with soft strata, as, for example, the valley of the Thames. If the trend of the rocks is at right angles to the direction of the stream, both sides of the valley will be similar in slope, since the conditions on both sides are alike; but if the trend of the rocks is in the direction of flow, the two slopes will differ considerably. The Dee, in the Vale of Llangollen, forms an example of the first case, while the Taff and its tributaries, in South Wales, will illustrate the latter. When a river flows for part of its course over soft rock, and then passes on to hard rock, we find a change in the width of the valley, and consequently in the angle of slope.

Cañons and Gorges.-The cañons of Colorado illustrate the special case in which the sides of a valley are perpendicular. This peculiarity is due to three causes: (I) The horizontal nature of the rocks, which makes both banks of the stream alike; (2) the absence of rain in the cañon area, which makes the production of an ordinary valley impossible; (3) the steady upheaval of the source of the river in recent geological time. If this last cause were not at work, the river would long ago have reached the level at which no 
further erosion is possible. The upheaval of the source has, so to speak, put new life into the river.

A stream which has so nearly reached its base level could not be expected to have any waterfalls in its course, and their absence was noted by a party who travelled through the Great Cañon in small boats.

Deposition: Terraces.-As long as the river water is moving, it will carry with it its load of sediment; but as soon as the motion is arrested, some deposition takes place. A river flowing over low-lying ground is apt to overflow its banks in times of flood. The side waters become still, and their load is deposited. A good example of this is the flooding of the Nile. The deposit slowly raises the level of the country, and if the source is raised so as to give the water more speed, erosion will again take place, and later a second plain will be formed. On the outer rim of this some of the original plain produced by the river-deposit-covered plain may remain as a flat terrace. Repetitions of this process will give rise to a series of terraces, of which the highest is the oldest, and the lowest is the last formed.

Bends.-Streams moving slowly across plains invariably follow a very winding path. All the energy of the stream is utilized in transportation, and thus any obstruction is sufficient to deflect the stream. Since retardation occurs on the convex side, deposition will result, and similarly the faster portion of the water will be directed towards the concave side. Some deposition having taken place, the stream will possess some energy available for eroding the bank, and the curvature will increase. Two complementary bends 
will approach the shape of the letter $S$ until they meet, when the river resumes a straight course, leaving two stagnant pools of crescent shape. Examples of meandering are very common. The curving of the Dee round the Chester racecourse, of the Wye at Symond's Yat, of the Ely between Cardiff and Penarth, and of the streams seen from the train a few miles south-east of Crewe, may be cited as instances.

Deltas.-The sea is the final resting-place of the sediment which is carried by the river, and the way in which it is disposed of depends largely on the force of the current and the movements of the sea water near the mouth. In every case a portion of the material is deposited at the mouth, but this may be regularly washed away by tidal currents. A big fraction of the land-waste brought down by the rivers of North Wales finds its destination along the north-west coast of England. The detritus carried away by the Devonshire rivers, together with the products resulting from the destruction of the coast by the sea, is piled up on Chesil Bank. Where the sea is comparatively still and the river current is fully loaded we have deltas, such as those of the Nile and the Indus. Borings made at the mouth of the Nile have proved that at one time that river possessed an estuary. Size seems to be the chief factor in determining the arrangement of the detritus, the coarse materials settling down first. The water on emerging into the sea spreads out like a fan, and the delta takes that shape. Similarly we find fanshaped deltas in lakes-for instance, at Geneva. The rate of growth of deltas varies with the volume of the river. The Mississippi extends its delta seaward at the rate of about 200 feet every year. The Po and Adige have 
regained from the sea about fourteen miles of land since the town of Adria was built on the coast. Where the flow of the current is strong, the coarser material is deposited, and forms a track curving seaward across the mouth.

\section{Observational Work in Lower Standards.-} Our object in teaching this side of Geography by observational work is to form a clear and living picture by means of the changes which are effected on a small scale in the immediate neighbourhood of the greater changes of the same kind, which in other countries may produce effects of great importance to human life. The small depositions of soil by the local brook are the same in nature as those which have made Egypt a fertile land in the midst of a desert, which make the mouths of many large streams inaccessible to commerce, and which make the Hoangho "China's sorrow" instead of its fertilizing agent. The matters in which local instances can frequently illustrate principles which, on the larger scale, affect human Geography are: deposition and its correlate, denudation; bends in streams, which often determine the sites of towns; rapids and other obstructions, which render rivers unsuitable for navigation; rate of flow, and its relation to the breadth and depth of a stream, which distinguish the mountain torrent from the broad commercial river of the plains.

In considering how far and in what manner any of these topics can profitably be presented to Standard II., it is necessary first to form some impression of the ideas which children at that stage usually have of a river. Few of them, indeed, have not seen at least a small brook; but many vague and often erroneous 
notions have probably found their way into their minds through lack of guidance in observing. They have probably an exaggerated notion of the permanence, not only of its general form, but even of details, such as the pebbles in its course and the soil on its banks. They assume uniformity where there is really diversity, as, for instance, they imagine its course to be normally straight, whereas bends are the rule, and straightness the exception; they suppose the rate of flow to be uniform, both as regards various parts of its course, and as regards the cross-section at any point; and they project the width and depth of the point at which they are most familiar with it, both to its higher and its lower reaches. These wrong impressions concerning the local stream will naturally be transferred to their idea of the larger rivers of which they hear in the Geography lesson. The work of Standard II. will be devoted to correcting these false impressions by sight of the actual facts, and by such guidance in their observations as will lead them to notice what might otherwise pass unobserved. Work of a quantitative kind is obviously beyond the reach of children of this age.

The practical difficulties which a teacher must overcome consist in the large numbers of an ordinary class, the amount of time spent in reaching the stream and returning from it, and the need of a very definite notion of the kind of facts which he desires the children to observe, and the manner in which they are illustrated by the actual stream which he is able to use.

Where possible, the first difficulty should be met by dividing the class into two portions for this kind of work, which would either be taken by the same teacher 
at different times, or, if two teachers are available, each portion under one of these teachers at the same time. As soon as the point is reached at which observations are to begin, the class must be drawn up in some regular formation, and must observe either simultaneously and drawn up in file, or, in other cases, by marching past and observing in turn. The second difficulty may be met by combining the expeditions for geographical with those for botanical or other purposes. The third necessitates that the teacher shall have explored every portion of the ground over which he intends to take the class, and have decided exactly what he intends to do at each point-that is, what he wishes the children to see, and the best way of making them see it.

It is clearly impossible to attempt to state any sequence of lessons, or even to determine the number of visits that should be paid to the stream, as both depend partly on the nature of the stream, partly on the conditions of the weather, partly on the distance of the stream from school, and, finally, on the extent to which these expeditions can be made to serve several purposes. In most streams, * however, the following observations can be made:

(I) Differences in Depth and Width.-These are specially noticeable in the case of streams in hilly districts. They are frequently so obvious as to need no demonstration, otherwise a walking-stick should suffice for the purpose of showing these differences. If more is needed, the work is probably too advanced for this standard.

(2) Differences in Rate of Flow.-The difference

* A small stream or brook is better for this purpose than a larger river. 


\section{I24 THE TEACHING OF GEOGRAPHY}

between the middle and the sides at the same place, provided the course is straight, can readily be shown by throwing light objects of about equal size, such as small twigs, simultaneously across the steam. The class will observe the "race" which follows, in which the middle twigs invariably win. The difference between the rate of flow at various portions of the course is most striking in streams which have rapids and deep pools near together. If "timing" is needed, the work is too technical.

(3) Bends.-In the case of bends, the greater swiftness of the water on the outer side can again be observed by means of twigs, and the comparatively greater depth of this side by means of a walking-stick. The steepness of the outer bank should be compared with the shallowness of the inner bank, and the collection of fine material on the sloping inner side should be pointed out. In the lesson which follows in school the question can then be raised, Where did this fine material come from?

(4) Matter held in Suspension.-The difference between the appearance of a stream in fine weather and after a storm can be observed on suitable occasions. In both cases a sample of the water may be taken away in a jar, and the sediment which is deposited may be observed and, if the two visits are close together, compared. The children can now be led to conclude that moving water can carry fine material. A further illustration of the carrying power of water may be introduced from the street gutters. At a more advanced stage, evaporation of a sample of clear stream-water will reveal the matter held in solution.

These observations should be gathered together in the course of the ordinary lessons, and will be sufficient 
to form the basis for teaching the main principles concerning rivers. The last section brings out the work of rivers in denudation : the comparison of the inner and outer sides of bends shows that swiftly-moving water denudes, whereas slow water deposits what has previously been carried; and the other features mentioned in the early part of this section, such as the existence of bends, rapids, and variations in depth and width, only need to be impressed.

\section{Observational Work in Upper Standards.-}

If the geographical side of Nature-Study be adopted in any of the higher standards, more advanced work is possible. Quantitative methods will now be in place. The following pages of this chapter are intended to suggest work of this character which would be suitable for Standard V. or VI.

As a starting exercise the class may be set to determine the rate of flow in feet per second. By means of a 66 foot tape a distance of about 44 or 88 yards should be measured, and twigs floated down this stretch. At first the teacher might note the times, one boy shouting when the twig starts and another when it reaches the end of the course. Very little difficulty will be experienced by the pupils in expressing the result in miles per hour. This should be done both with a comparatively rapid and a comparatively slow portion of the stream, and the results compared with the slope in the bed, which will be found to vary concomitantly. The same exercise may be repeated, the twigs being floated down the sides. These experiments should be done at two different times-first when the stream is at its normal state, and again shortly after heavy rains. Some surprising results will be found. 
Another interesting exercise which can be done indoors is the determination of the amount of material per gallon which is carried down in suspension and in solution. The result may be expressed in grains per gallon. The water is passed through a filter-paper, which is finally dried and weighed. If the school has suitable material, the same exercise might be repeated, using the metric system. This latter method has a distinct advantage, for, knowing that the number of grains per litre is equivalent to that of pounds per Ioo gallons, we can easily change the result into our ordinary system of weights and measures.

A suitable exercise at this stage is to set the pupils to ascertain whether the increase in the amount of sediment per gallon is proportional to the increase in speed of the river.

The determination of processes going on at the bed of the stream is more difficult; but the teacher can, with very little trouble, show that surface waters move faster than deeper waters. If a few crystals of permanganate of potash are dropped into the water, they will sink and gradually dissolve, forming a slowly-rising coloured streak. The top of this streak will gain on the lower parts.*

Before we leave the straight course, it will be convenient to study the nature of the river-bed, and obtain a graphical representation of the cross-section. This may be found by stretching a tape tightly across the river, and noting the depth at intervals along the tape by holding a flat ruler edgeways towards the current. The data collected will be used indoors. While this is

* A better substance to use would be a piece of sugar soaked in an alcoholic solution of magenta. 
going on, a number of pupils may be set to collect data to determine the rate of flow past this point. By means of squared paper, a diagrammatic representation of the cross-section may be made. Knowing the scale chosen and counting the squares (making due allowance for fractions of squares), we get the area. Multiplying the area by the velocity of the current gives us the volume of water passing down each hour. If the amount of sediment per gallon carried down at the time is found, we can calculate the amount of sediment taken down each day under the same conditions. Some corrections are required to reduce this result to an approximately true figure. By taking the greatest velocity we exaggerate the result, but if we take two-thirds of this figure we approximate more closely to the truth.

The question of the size of the material carried down may be again studied. A good experiment is to take a number of stones of different weights, to make suitable marks on them with a piece of flint or a chisel, and then to place them in the river-bed at known places. They are then left until a flood has occurred, and their positions are again noted. It will help the children to accept the results if the stones are weighed by a spring balance while they are immersed in water.

Further work may be done in the study of bends. The class may be set to compare a cross-section at a bend with one on a straight course. Then they can study the deposits on the bed at this point. Most of the material will be found on the inner side, and a gradual diminution will be noticed as the centre is approached; on the outer side the material will be coarse-that is, it is material which is moved in times of flood. The movements of the water round the bend 
are complicated, and it is well to select a time when the river is low, in order to see more clearly the movements of bodies on the surface. Floating twigs will prove serviceable here, and a line of sawdust released from behind a lath will give interesting results. The children must grasp clearly that the swiftest part of the current is nearer the outer than the inner side around the curve, and that the water on the inner side moves much more slowly than that on the outer side. They may now be asked to account for the difference in shape between the two banks, and they are in a position to understand that the river is at work enlarging the bend. The comparative study of bends is more difficult, and for this purpose it is necessary to plan out different bends. A fairly accurate Map may be produced by means of a tape and three pegs. Two of the pegs are fixed, one above and one below the bend. The third is moved, so as to take up several positions along the curve. In each case the pegs form a triangle, and the base is a constant quantity; and, if the length of the other two sides are measured, we have the data required for the construction of a Map of one bank. In a similar way the other side may be mapped. To trace out the path of maximum flow will now be easy. The measuring tape should he held across the stream a few inches above the water. The sawdust line may be set going, and the point at which the sawdust first passes the tape may be taken as a point on the line of fastest flow. Repeating this with the tape in a different but known position, we get another point on this line. If, instead of working on one bend, we subdivide the class into four or more sections, and each group examines a different bend in the same way, we 
can compare results. After this the children will be fairly convinced that, given a suitable obstruction to its course, a river will construct a curve, thereby changing its course.

Before concluding, we may suggest a few further exercises. In some localities areas free of vegetation and with a good slope may be found. The effect of running water will be easily observed in such places. Again, if a waterfall, however small, is found within easy reach of the school, it will prove an interesting study. The teacher and class will soon be in a position to account for the fall. Lastly, the arrangement of deposits in stream courses may be studied. To insure success in these lessons the teacher must make sure that each boy has something to do, and that he clearly understands what that something is. 


\section{IX}

BEGINNINGS OF REGIONAL GEOGRAPHY

\section{Point of View in the Earlier Treatment of} the British Isles.-The last three chapters have covered the work suggested for Standards I. and II. on several sides; in the present chapter it is intended to deal with the way of teaching the Geography of particular countries, beginning with our own. It is assumed that the detailed study is postponed to a later stage, as suggested in Chapter III.* After the home district has been studied, no attempt is made to study the adjoining district; but the British Isles are treated as a large whole, which has to be divided into natural divisions. All parts of it alike are unknown to the bulk of the class, though single members may have interests in almost any part, which will help to make it living to the rest.

This is probably the point at which the teacher who is determined to teach things and not names has to struggle most with convention. It is best fairly to face the questions-What are the things in the British Isles which would strike a well-instructed traveller as important if he actually went round the country and never looked at a Map? and which of these things are suited to the comprehension of children of this age? The salient facts would undoubtedly appear to our 
traveller to be the extraordinary development of manufactures dependent on coal, of means of communication by rail and sea, and of trade with foreign countries, and the power of the British Navy. The political institutions of our country would also attract his attention, but in a school course the History lesson would take the larger share in explaining these. The traveller would find that large portions of the country were rural, but that these parts were of relative insignificance compared with their counterparts in countries outside Europe and in many European countries. He would notice that few of the largest towns owed their growth to facilities for exporting the produce of agricultural regions, like most of the great towns of America or Australia; but that the towns of over 200,000 inhabitants were mainly either manufacturing towns, like Manchester or Birmingham; ports for exporting manufactures and minerals, like Hull or Cardiff; or ports for import, like London. He would single out a few great staple industries as specially worthy of note, such as coal, cotton, wool, and iron. He would find towns of the second rank so numerous, especially in the industrial districts, such as Lancashire, Yorkshire, South Wales, and the Black Country, that their individuality is lost, and the real industrial unit will not be the town, but the district. In teaching, the only substantial difference in estimating the importance of things consists in the fact that the children do not know foreign countries, and that the rural parts have to be given a greater place than they would occupy in the mind of the enlightened foreigner, while we have to reserve till foreign countries are taught the fact that this enormous development of manufactures 


\section{I32 THE TEACHING OF GEOGRAPHY}

as opposed to agriculture is abnormal, peculiar to Great Britain and a few other countries of Western Europe, and would not exist but for the supply of agricultural products from the newer parts of the World which specialize in them.

\section{Accounts of the Staple Industries and their} History.-The essence of arrangement in teaching the Geography of a region is to present a few clear mental pictures, with plenty of subservient detail. Isolated facts do not help to build up a body of knowledge. As the chief importance of Britain lies in its industries, the natural course is to make clear pictures of the great staple industries. Agriculture, despite its relative inferiority, is actually the largest industry. Coal, wool, cotton, and metals would be chosen by all as worthy of an important place. Then come the means of conveying these goods, by land and sea, to their destination, and the fleet to protect the whole. We have further to consider that we are now beginning the long process of building up the ideas of Economic Geography. Our task is not merely to give facts, figures, and places, but to exhibit a sequence of connections. Agriculture proper flourishes on the plains; sheep pasture on the hills; coal is only found in certain areas, which become manufacturing centres; ports have to be conveniently situated for a populous hinterland and for access to the seas that lead to other countries. Hence a division of our subject-matter according to industries means very largely a division according to districts. But the teaching of this part of the Geography economically means more than this: the very first rudiments of ideas have to be created. We know only too well from the mechanical, old-fashioned Geography that it is possible 
for children to learn, even for teachers to teach, the existence and localization of industries without any curiosity arising as to the demand that exists for these goods, the mode of conveying them, the changes that take place in the demand or in the transit, which either increase or decrease or change the locality of an industry, or any other of the countless questions which an unsophisticated child hearing of these things in a natural way would wish to ask. And some sort of a general answer to these questions is always to be found in the history of the growth of an industry, and comparatively recent history, too. The grandfathers of some of us lived through most of the changes which have made industrial England; and this generation is least of all justified in teaching geographical facts as if they possessed the stability of the Solar System. The following sections aim at showing how an elementary sketch of the British Isles can be based on a description of the chief industries, each associated with a typical region, and so taught as to illustrate the ideas of Economic Geography.

3. Agriculture: Need of Circumstantial Detail. -The account of agriculture will necessarily differ according as the school is in town or country, on a plain or in a mountainous district, in the South or in the North. In all cases teachers will recognize, first, the need of making the account a real living picture of modes of life unfamiliar to the children; secondly, the existence of several distinct varieties of agricultural districts. As regards the first, in days when the majority of teachers come from towns, it is possible that many could not give a really coherent account of the way country-folk spend their lives. The actual 
details are not important for their own sake; but it will be rather difficult to give an idea of the country to town children unless one can describe a plough, a harrow, a sower, or a reaping-machine, unless one has some idea of the seasons at which various crops are sown and appear above ground, unless one knows enough of the existence of the rotation of crops to include clover, turnips, and beans in one's idea of the country as well as wheat and oats, and can answer intelligibly inquiries from the class as to what the farmer does during the winter months. Unless there is detail there can be no interest. If a child's idea of the life of a sheep is that it eats grass in the same field, without any need of man's approach, from its birth till the day someone comes to take it to the butcher-no unfair picture, we fancy, of many a town child's ideasno idea of human effort, no sympathy with sheep or shepherd, and no interest enter. The children with whom we are dealing are not yet nine. We have to gather up the lessons of the infant school, which are much truer than the conventional Geography lessons.

Types of Rural England.-Secondly, conventional "country"-which represents neither the wheat-growing districts in the Eastern counties, nor the sheepfarms of the Cheviots, nor the deer-forests of the Highlands-leaves out too much. The general outlines may be true for many parts of the South or Midlands; but the town child will be more likely to get true ideas from a teacher who realizes the distinctive traits of various districts, and the country child should not think the whole of rural England to be a reproduction of his own district. The more specialized regions will make the clearest impression. Roughly speaking, we 
might take two types of hilly countries - the Scotch Highlands, with their deer-forests, and the Pennine or South Scotch or Welsh Uplands, with their sheep; and two main types of plain-the more agricultural districts, and those where dairy farming supplies a new interest. Nor should we forget the hop-gardens and perhaps other specialized forms of agriculture. If a typical region is taken for each and pointed out on the Map, and if a few names are taught in connection with each, the danger of letting these regions exist in an unlocalized "somewhere" will be avoided, and a close connection between mode of life and physical conditions will be established.

While we wish to avoid emphasizing the details of any suggested curriculum, it is impossible to give a clear idea of our meaning without explaining that the last paragraph contemplated a sequence of about eight lessons. It is the first introduction of the children to Regional Geography, and it is very important, for the sake of sound progress afterwards, to go slowly at first, to get them used to regarding places on the Map as standing for real things, and likewise to thinking of real things in terms of the Map. Thorough vividness of imagery and a clear system of symbolic thought are both necessary to Geography.

\section{Lessons on Coal-Fields and Leading Manu-} factures.-The succeeding lessons on the other great industries will follow the same general lines. In the past some good lessons on coal-mines, factories, etc., have been given; but they have often been described as Object-lessons, have been arranged in no sort of sequence, and controlled by no unifying idea, and have therefore lost much of their value. If they are intro- 


\section{I36 THE TEACHING OF GEOGRAPHY}

duced in their natural place in the Geography course, the descriptive element will lose none of its interest, and the sequence will unconsciously help to establish a point of view. As we are dealing with all the natural resources of the country first, we shall, after the use of land for agriculture, proceed to the resources of the rocks themselves. Coal is the most important of these resources in this country, though a lesson on quarrying might be given-e.g., on the granite of the Grampians or the slate of North Wales, and bricks would not be forgotten. The main fault of the old "Object-lessons" -as, for instance, that on coal-was that they were too pedantic, and followed a stereotyped plan. If there had not been a tradition of a quarter of a century behind these lessons, there would have been an obvious absurdity in the way in which they were given. The children began by naming "qualities" which they knew before they came into the room, under the pretext that it was "training the observation," which apparently enabled them to see that coal was brittle and hard. Then they listened to a description of a coal-mine; after this they were confused by an account of the Carboniferous period, which gave them more wrong ideas than right; and, finally, they descended to the bathos of declaring the "use" of coal to be for burning. The account should be frankly descriptive. To avoid overburdening the class with many names in one lesson, the names of the various coal-fields should be taken with their separate industries-that is, Lancashire with cotton, Yorkshire with wool, the Black Country or South Wales with iron. Perhaps the initial lessons on coal might be taken with the original coal-field-the Newcastle field, to which " it is no good carrying coals." 
The development might be traced from its local use for domestic fires, through the time when "sea-coals" were sent to supply the hearths of London, to the time when its presence gave rise to a great industrial district in Northumberland and Durham.

A natural transition is to iron and steel, with their numerous uses. The teacher should describe the various processes, from the extraction of the ore to the production of the ploughshare or the knife, the cannon or the steam-engine. Birmingham, Sheffield, and Newcastle are the most important towns connected with this industry, and all or any of them can be treated at this point. The woollen industry, associated with Leeds and Bradford, and the cotton industry, associated with Manchester, follow. The former is naturally treated first, as, historically, it originated in the use of a raw material which was produced in this country. Often older conditions, being simpler, help to explain modern conditions to children ; thus, an account of hand-weaving and of the water-mill leads them to understand more easily the present development of the industry in which it has been specialized on a coal-field. Cotton represents a further stage in the complexity of economic organization. Much of the raw material of the iron industry is still produced in this country; wool was formerly so produced; but cotton never was nor can be grown in Great Britain. If the teacher takes this point of view, the idea will gradually form in the child's mind that it is our supply of coal which has led to our modern industrial position. It first extended the existing manufactures of our own products; it then drew raw materials from distant lands which had no coal. Thus it has come to pass that, in a different climate 
and amid different scenery, the negro or Egyptian produces a tropical crop, which is carried in a ship for thousands of miles for the Englishman to work into garments. This is the first suggestion of the economic unity of the Globe.

5. Ports, Trade.-The import of raw material for manufacture leads directly to the notion of trade. We may well begin with Liverpool, the great cotton port. To many minds a great port exercises a fascination which is not felt in connection with mines or factories, however large. The economist knows that the latter are using Nature, but they look as if they are destroying it. But shipping does not destroy Nature; the sea is still the sea, even when it comes up a tidal estuary to the side of some landing-stage. The flags of many nations and the various cargoes suggest both the variety of lands in the World and their unity, and both these ideas are emphasized by the contrast which is afforded when some cargo, let us say of cattle from Ireland, is landed close beside some unfamiliar product of the Tropics. If a teacher can import some of this sense of fascination, it will be a great gain.

Lessons on London.-There are many points of view from which London may be treated, but in all probability it is best to consider it primarily as the great port for imports. This treatment is easily worked out historically. It is now known that its exact site was chosen as being the lowest point at which the river could be bridged, and that its importance originates from the times when Britain was a comparatively uncivilized island adjoining a civilized continent. A town was therefore needful for the foreign traders. London, 
by comparison with any point accessible by sea from the south or south-east, was in a central position for the half of the country which was plain, and this portion was all that had any value in early agricultural days. It grew with the increasing prosperity of the country all through the Middle Ages. From a port we pass on to consider London as a distributing centre, from which all roads radiate. Then, from regarding it as a point from which all roads radiate, we can pass to the converse of the same statement-that it is the point to which all roads radiate, the most accessible place, which is therefore chosen as the meeting-place and seat of government. Its position was so well established by the end of the Eighteenth Century, that even the rise of the manufacturing districts of the North did not affect its supremacy. It was the centre of the improved road-system of the Eighteenth Century, and of the railway system of the Nineteenth.

Three lessons can easily be given to London even at this early stage. They might be described as dealing with London as a port, London as a distributing centre, and London as the Capital; corresponding to the Docks, the City, and Westminster. The stand" point in the first lesson is foreign trade. Let the children think of their food, their clothing, and the articles of household management; let the teacher bring out how many of these things come from abroad, from the lands which have vaguely been described to them in the early lessons on foreign ports; and let him bring this knowledge to a head in the fact that, on account of its tidal estuary, most of these necessities are landed in London. Let him describe the Docks and this traffic. 
The second lesson would go on to show that these goods are wanted all over the country, and must be carried to their destination. Here the railway system of the country is first touched on. Such facts as that the fish-supply of most places, though it has been landed at Grimsby or Yarmouth, has passed through Billingsgate on its way to its destination illustrate the point which is here being taught. The great railway termini are more truly part of the geographical essence of London than the Tower or St. Paul's. We cannot explain the financial side of the City to children of this age; but we must be clear in our own minds that this is only the complex outcome of the more simple considerations which we can explain. Some description of the external bustle of the City is needed to give a pictorial setting.

The third lesson considers London as the Capital. Here there is more scope for the "guide-book" treatment, which loves buildings. Westminster Abbey, and in a less degree other "sights," are a record of the political position of London in the past ; we wish also to give the children some idea of what "government" really is in the concrete to-day. The proceedings of Parliament, the Law Courts, and the Government Offices have to be brought down to a form intelligible to children, and the externals of these proceedings described.

A few other ports should possibly be dealt with. Then the need for a Navy to protect this trade becomes obvious. Portsmouth, Plymouth, or Chatham can be taken as a basis.

\section{Other Matter for Earlier Treatment of} British Isles.-Such, in rough outline, are what 
appear to be the essentials from the point of view which we have taken. Teachers would, of course, add other topics; certain types of regions, such as Ireland, the Fens, the Lake District, have not been mentioned; some of the largest towns, such as Glasgow, Belfast, Bristol, and Edinburgh, have not fallen into place in this draft; several of the great Railways will naturally be taken. The idea has distinctly been not to burden the memory with names and minor facts. We should be satisfied at this stage with a knowledge of the names of twenty towns. The names of the counties might well be postponed. But those things which are taught should be taught in detail, and at the end the children should realize what are the great activities of the country, its divisions into natural regions, and the region in which each of these activities is carried on. Ideas should already be growing concerning the growth of manufactures, the need of foreign commerce, and the dependence of industries on physical conditions. When this is accomplished, further progress in these ideas is more likely to be obtained by working them out in connection with a continent than by a "detailed" treatment of the British Isles, which will inevitably mean the learning of many names.

\section{Aspects from which to treat North America} at Early Stage.-North America appears in every way the most suitable continent to be taken first. It needs, however, a selective treatment. It is to be illustrative of many ideas which the teacher is trying to develop in the children's minds. From the physiographic standpoint, it illustrates the principles which were discussed in the last chapter on a far more colossal scale than anything which the children can see in these 


\section{I42 THE TEACHING OF GEOGRAPHY}

islands. There is also a double economic standpoint. (I) The reader will recollect that, in the chapter on the Economic basis of Geography, the passage of mankind through the hunting, pastoral, and agricultural stages was taken as the starting-point of many useful conceptions. The American Indian is the most striking example which has been preserved up to a recent age of a hunting race in full possession of a continent, and gives a picture of the hunting life at its highest-not, as elsewhere, pushed by higher types of civilization into the heat of the Tropics or the cold of the Poles, which no other race cared to occupy. (2) Lastly, we see in this continent the operation of physical conditions on the modern Englishman, determining his mode of life. Our race has been so long established in these islands that the geographical element is in danger of being hidden by the historical. In America during the last century and a half the reverse is the case. It is the nearest approach to a laboratory experiment in Economic Geography. Take a modern Englishman, eliminate as far as possible all external influences, retain the same ideals, religion, and literary and political traditions, but move him to a new continent with warm parts and cold, seaboard and continental climates, plain, hill, and tableland, agricultural and mineral regions-and study the result in the industries, commerce, and towns which he produces; you then have as nearly as possible the purely geographical result. It is true that with a different race at a different plane of civilization the result would have been different; it is also true that economic changes in time produce changes in customs and thought; but we wish, as far as we can, to study one element in the complex at a time. 


\section{Physiographical Principles illustrated by}

North America.-It may be suspected that a properlyclassified series of physiographical examples would fail to interest the children. It is better if the teacher draws up his catalogue at the beginning of the course and distributes the items over the course. The teacher will, however, no doubt prefer that in these pages the facts should be collected. Examples are needed of the work of rivers in denudation and deposition, of wellgraded and ill-graded rivers, of the work of water underground, and, possibly, of the action of the sea on the coasts.

In America we have all extremes of climate, from rainless areas to those of great rainfall, and even in the rainless regions there are many rivers which owe their origin to mountains lying outside the rainless tracts. We also have rivers flowing for miles through almost level country, others flowing down a marked but gradual decline, and others, again, flowing rapidly down from lofty ranges or plateaux. The Mississippi system affords examples of all these kinds - the main stream of the first, the chief tributaries of the second, the headwaters of the Yellowstone of the third. But it is in the dry regions that we find phenomena differing not only in degree, but in kind, from anything which is found in the British Isles. In a rainy country every drop of water which falls does its share in the work of denudation; every rivulet carries some waste material to a brook, every brook carries more to a river, and every river the combined results to the main stream. All the streams which flow through a rainless country rise outside it; no contributions either of water or soil are received on their way through it ; and, consequently, 


\section{I44 THE TEACHING OF GEOGRAPHY}

denudation is confined to the channels of those streams which are large enough to accomplish the journey through the rainless tract. The streams continue to wear their courses lower and lower, while a few yards from their banks practically no soil is removed. Instead of the hollowed valleys by which, in a rainy country, the rivers flow from the mountains to the plains, we have abrupt cañons, often thousands of feet deep ; instead of gently-rolling hills we have dissected plateaux, in which the original level is preserved up to the very banks of the stream, which flows several hundred feet below, unseen till we approach near it.

The Mississippi Basin illustrates the principles of the carrying-power of water, which were mentioned in the last chapter. The gradient of the main stream is very slight, while its tributaries, though coming across "plains" which to the eye are level, have really fallen some 4,000 feet since they left the Rockies. Hence they bring far more matter into the main stream than it can carry ; its channel is being filled, and, to prevent floods, embankments are constructed, which from time to time have to be raised, till the lower part of its course is now artificially elevated above the level of the surrounding country.

Space forbids us to do more than mention other physiographical features. However, the Americans publish far more textbooks of physiography than we do, and the instances are usually chosen from their own country, so that the reader will find no difficulty in obtaining plenty of instances together with a full account of the principles. We therefore only suggest features which are worth illustrating. In connection with the flow of rivers, the interesting phenomenon of "loops" is well illustrated 
by the main stream of the Mississippi. As regards the "grading " of streams, the absence is shown by waterfalls and rapids. Of these the rapids of the Mackenzie and other northern streams may be taken along with the Indians and their canoes, and of course Niagara will be taken to illustrate falls. From the physiographical point of view, the most interesting fact about Niagara is the gradual eating back of its course, due to the presence of a harder rock above a softer, whereby the latter is washed away from under the former until it gives way. The Atlantic coast streams likewise all pass from a higher plateau to a lower coastal plain by falls, and many of the towns are built on this "fall-line."

The underground work of water is represented by the limestone caves, of which the Mammoth Cave of Kentucky is the most magnificent example in the world, and by the geysers and hot springs in the Yellowstone Park (Herbertson, "Descriptive Geography of North America," pp. I74-I79). The coasts of America exhibit strikingly the difference between raised and sunken coast - lines - for instance, the broad tidal estuaries from Chesapeake Bay to the mouth of the St. Lawrence, together with the existence of a submerged coastal plain stretching far out to sea, are clear evidences of sinking; while the level coastal plain of the Carolinas, where railways can run for several hundred miles inland without cutting or embankment, is an evidence of elevation. This last topic is not, however, so suitable to children as the others, since we do not wish to introduce new phenomena so much as to convey a notion of the enormous effects which may be produced by the operation on a large scale of 


\section{I46 THE TEACHING OF GEOGRAPHY}

forces which they see working on a small scale near their own homes.

9. Treatment of the Red Indian.-Interest can probably best be aroused in America by arranging our matter in the historical order. The voyage of Columbus would then be the prelude, followed by the European settlement. Then, with his intercourse with the Indian, the latter can gradually be introduced. If we were asked for an ideal teacher for this part of the subject, we should select one who had thoroughly enjoyed Fenimore Cooper's stories when he was a boy, who still had a lurking admiration for the ideal Redskin, though he had become alive to the failure of the actual North American Indian to reach it, and who saw how all these characteristics arose out of the needs of the hunting life. This life tends to individual skill rather than to joint action. The Indian is a member of a tribe for purpose of defence, but his life does not, like that of the pastoral races, tend to unite a number of men under one great owner of flocks and herds; his skill in woodcraft is astonishingly developed, and this skill is applied to war as well as to the chase. Hunting, like pasturage, necessitates a nomad life; his teepee and his migrations must therefore be described. Subsistence is hard, and he has to change his diet, hence his fishing and canoes. Only a few men can live in a large territory, hence his fighting. His lack of a house makes his property small, and there is no scope for art either in ornamenting house or household goods, hence his ideas of beauty can only be expressed in personal adornment. Longfellow's "Hiawatha" is of great value in giving a sympathetic attitude towards the struggle of the Red Man for existence and 
towards the discoveries on which he principally depends.

Io. Advance of the White Man.-The advance of the White Man into the interior furnishes another interest. Again, the teacher must be in sympathy with the spirit of the life which he is describing-the spirit of adventure. The America of which we are now thinking is not Coastal America; it is neither the New England States, where the Puritans strove to reproduce the life of the Old Country, nor the Slave States, where the Cavaliers maintained the aristocratic conditions of English country life on the economic basis of black labour; but it is rather the New World, which, beginning with the backwoodsman and the fur-trader, ends with the farmer, the rancher, and the miner of the Mississippi Basin, the Pacific Coast, and the Canadian Pacific Railway. The atmosphere of the earlier days, when the spirit of restlessness, novelty, and solitude drove men across the mountain barrier of the Appalachians into the vast unknown plains behind, which led them to escape the onflowing tide of civilization by penetrating ever farther and farther into the zone of danger and hardship, and which won a continent from the French and the Indian in a mood of light-hearted determination and exuberant recklessness which we hardly know whether to call effrontery or heroism, can be found in Churchill's novel, "The Crossing." The story of the fur-trade, the life of the lumberer, the goldrush of 1849 , the ranching of the Far West, and the occupation of the Mississippi Basin by farmers of maize and wheat, the construction of the great trans-continental lines of railway, and the tide of immigration now pouring into Canada, must all be told. In other 
words, the purpose here is to depict an English-speaking land unlike our own-a country of vast areas and varied climates, a country of raw productions, and not primarily of manufactures or of intensive agriculture.

Contrast of Earlier and Later Treatment. America can naturally be treated from another point of view, as the rising nation of the future, self-contained, with its growing manufactures and commerce, its great cities, and increasing political importance: this point of view is but reserved till a later stage, when it can be taken in contrast to Europe, and when the children's conceptions have been so developed that they regard the relative trade of countries with more interest and with more sense of reality than they could in Standard III. Here we are trying to show man face to face with Nature-primitive man and civilized man -and to point the contrast. 
THE PRINCIPLES OF CLIMATE

THIs chapter contains a short summary of the chief climatic principles on which the climate of all countries mainly depends. The summary is intended to guide teachers to whom physiography is new as to the principles which it would be useful to study more fully in a good textbook, as space is not here sufficient to give a detailed exposition. These facts are put together in a separate chapter, so that they can be omitted by readers who are familiar with them.

I. Winds. - The Trade-Winds should be the first studied. These are winds blowing in towards the Equator from the Tropics of Cancer and Capricorn respectively. To simplify the study, it is well to proceed by four steps:

(I) Take the simplest case, the situation on March 2I and September 23 (the Equinoxes), when the sun at midday is exactly overhead at the Equator, which is, therefore, then the hottest part of the Earth. The hot air at the Equator therefore ascends, and cooler air from either side comes in to take its place. Consequently a north wind comes from regions north of the Equator, and a south wind from regions south of it, both blowing towards the Equator. This is what would happen were the Earth at rest. 
(2) But the Earth is not at rest, but rotating from west to east on its axis. The air over any point is rotating at exactly the same rate as that point. But the Equator being the farthest part from the axis, any point at the Equator has to travel faster than any point elsewhere to get round in twenty-four hours, having a longer journey to go. Hence the air over points away from the Equator is travelling round slower than it would be over the Equator. But the air, as it moves in towards the Equator, as described in section (I), only maintains its original rate of rotation from west to east, and therefore moves round more slowly than the ground underneath it as it advances nearer the Equator. Just as a cyclist travelling with the wind, but faster than it, appears to have the wind against him, so the man at the Equator, being carried round from west to east through a wind which is also being carried round in the same direction, but less rapidly, finds the wind against him. And as he chooses to disregard his own movement, he describes this wind which is against him on his journey from the west through space as an east wind. So the actual winds are north-east (not north) to the north of the Equator, and south-east (not south) to the south of it.

(3) Monsoons.-Hitherto we have dealt with the case when the sun is directly over the Equator. But in the Northern Summer (the months round June), it moves to the north of the Equator, and in the Southern Summer (the months round December) to the south. Hence the belt of greatest heat, which we may call the "heat-equator" as opposed to the true Equator, also moves north and south. It is towards this "heatequator," not the true Equator, that the Trade-Winds 
blow. Thus in the Northern Summer the southern TradeWind will be blowing towards the "heat-equator," then situated to the north of the true Equator. In so doing it will cross the true Equator as a south-east wind. But directly it has crossed, it comes to a part where the earth below is moving more slowly, not faster than itself,* and will be changed by the converse process to that described in the last section, to a south-west wind. These reversed Trade-Winds are called "Monsoons," and are the chief factor in the climate of India and neighbouring countries.

(4) Finally, land-masses are heated far more rapidly than sea. Hence, in the case of Asia, the hottest part in the middle of summer is more to the north than would otherwise be expected, because Asia is the biggest land-mass in the world, and lies north of the Equator. Hence Asia has the peculiar feature of drawing in the Trade-Winds from all quarters to its centre in summer.

2. Belts of Seasonal Winds. - The remaining principles concerning the direction of winds are comparatively simple. The World may be divided into a series of belts, in some of which the pressure of the air is heavier than in others, and the barometer reaches a greater average height. The chief belts of "high barometric pressure" are in the Polar Regions and along the Tropics of Cancer and Capricorn, though these latter belts move somewhat north and south with the movement of the Trade-Wind area. Between the belts of "high pressure" are the belts of "low pressure"-

* It has, of course, been acquiring velocity as it approaches the Equator, its rate at any point being intermediate between its original rate and that of the Earth underneath it at that point. 


\section{I52 THE TEACHING OF GEOGRAPHY}

i.e., round the Equator and in the North and South Temperate Regions. The causes of the existence of these belts are complex, and it is sufficient for our purpose to regard them as ultimate facts. The effect of these varying pressures on winds is to make them

At Equinox.

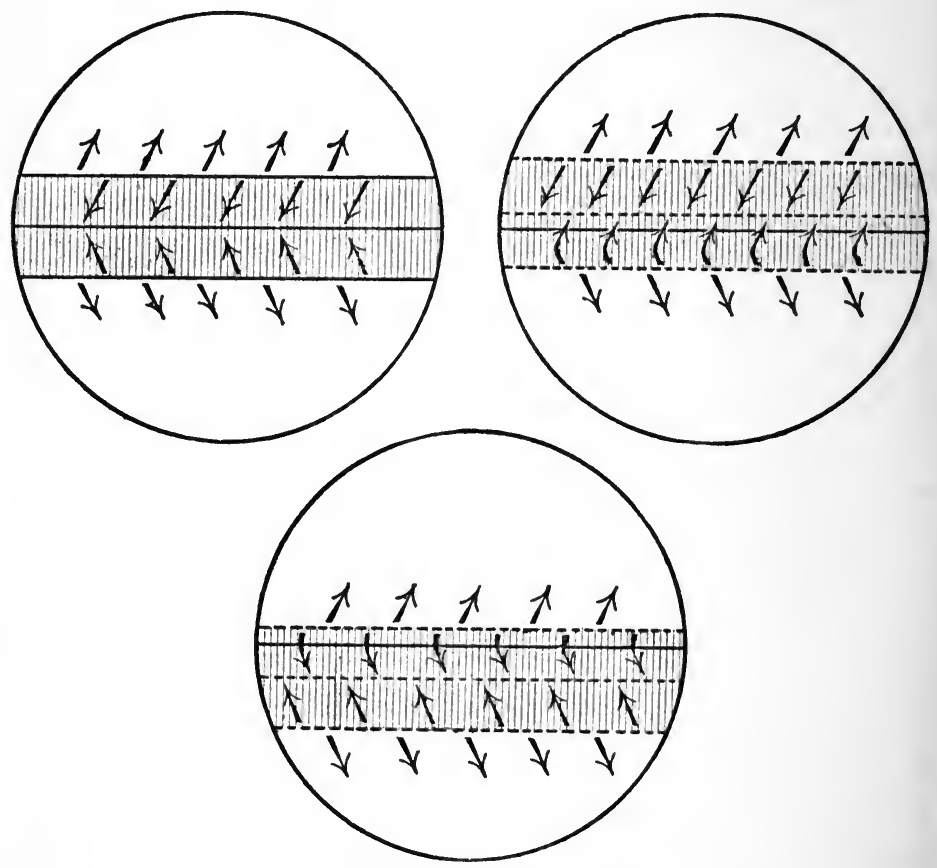

IN NORTHERN SUMMER.

IN SOUTHern Summer.

move out from belts of high pressure and in toreards belts of low pressure, in order to restore the equilibrium. The results are summarized in the above diagrams, of which the first gives the easiest state of things, that existing at the Equinox, and the other two the changes 
of the Trade-Winds in the Northern and Southern Summer respectively.

Thus, leaving out the Arctic Regions, we have a belt on the Tropics (moving north or south according to the seasons) to which no winds blow, known as the "Equinoctial Calms," and a very simple wind-system consisting (I) of the Equatorial belt between the Tropics, the belt of the Trade-Winds; (2) a North Temperate belt, affected by the inflow from the Tropic of Cancer, which would arrive as a south wind were the Earth at rest,

N.

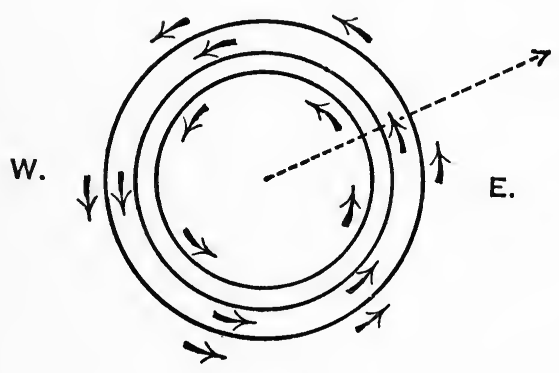

S.

Progress of a Cyclonic Disturbance.

but actually arrives as a south-westerly movement owing to the principle of deflection explained in the last section; (3) a South Temperate belt, in which, for similar reasons, a north-west wind prevails.

Beginners are always puzzled by the fact that in this country such a uniform south-west wind does not prevail. This is due to two causes: (I) The bulk of the movement takes place in the form of "cyclonic disturbances," in which the whole disturbance moves forward, at the same time rotating round a centre of 
low pressure. (2) As continents heat, much quicker than oceans, and lose their heat much sooner, the British Isles, lying on the margin between a great landmass and a great ocean, are subject to the operation of many conflicting causes. The whole topic of the meteorological conditions of the British Isles may be found a fitting subject of treatment in the physiographic side in the upper standards, where it may be so studied as to explain the Daily Weather Forecasts. It is too large to deal with in this chapter. For a clear but simple account we refer the reader to Mackinder's "Britain and the British Seas." *

3. Ocean Currents.-Ocean currents are quite easily understood when the wind-system is mastered, as they move in exactly the same directions. In both the Atlantic and Pacific Oceans a distinct rotary system exists both north and south of the Equator. The northern system is explained by the two following diagrams :
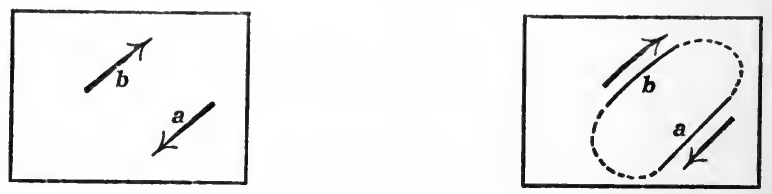

$a$ represents the current corresponding to the TradeWinds, flowing from Spain and Morocco to the coast of Guiana; and $b$ that corresponding to the south-west winds of the Temperate $Z$ one flowing from the Gulf of Mexico to the British Isles (the "Gulf Stream" or "South-West Drift"). $\dagger$ In the South Atlantic and 
South Pacific Oceans the movement is of course reversed. The Indian Ocean, which lies principally in the Monsoon area, has the curious phenomenon of a current which rotates in opposite directions in winter and summer, according to the change in the Monsoon. After this short account, a study of a Current-Map will give a clearer idea than a verbal account can possibly convey.

The effect of currents, as of winds, is to raise or lower temperature according as they come from warmer into colder latitudes, or vice versa. Our own country is the most striking instance, especially in winter, when we enjoy a climate $40^{\circ} \mathrm{F}$. higher than Labrador, in the same latitude on the opposite side of the Atlantic, or Kamschatka, on the opposite coast of Eurasia. The same result is found in the Pacific Ocean, but this ocean is so much larger than the Atlantic that the water has had time to cool. Nevertheless, Vancouver Isle has a temperature of $20^{\circ} \mathrm{F}$. higher than Newfoundland. The warming effect of currents is due to the winds which accompany them, whose heat they serve to maintain. These winds are not, like the currents, stopped by the lands whose shores they wash, but blow over them and warm them.

Some readers may possibly be puzzled by reference in some books to the "obsolete theory of the Gulf Stream." The fact is that the fight over the Gulf Stream is largely a fight over terminology. It has become customary to distinguish between the Gulf Stream proper and the North Atlantic Drift. The circulation described above enters the Caribbean Sea, passes between Cuba and Yucatan into the Gulf of Mexico, and then, thoroughly heated, flows out through the Straits of Florida as a stream of hot water 50 miles 


\section{I56 THE TEACHING OF GEOGRAPHY}

wide and 350 fathoms deep, estimated to convey $90,000,000,000$ gallons of heated water per hour past the Bahamas. It is joined by a volume of water, perhaps even greater in amount, which has short-circuited to the north of the West Indies. The actual definite flow of clearly distinguishable warm water through water of a much lower temperature cannot be detected right across the Atlantic; to this alone the title of "Gulf Stream" is now confined. The heat has, however, merely spread, and, but for the heat which accompanies the general drift from south-west to north-east, of which the Gulf Stream forms a part, the British Isles would be as uninhabitable as Kamschatka or Labrador! Candidates for examinations would be well-advised to avoid mention of the words "Gulf Stream "; but call it "South-West Drift," or "North Atlantic Drift," or what you will, the fact to which we owe our existence must surely be taught.

Before leaving the question of currents, it is necessary to mention the cold currents from the Polar Regions which enter the North Atlantic and Pacific Oceans. The former comes both through Baffin Bay and along the east coast of Greenland, and affects the east coast of America as far south as Cape Hatteras. Its cold waters render possible the cod fisheries of New England, and by contact with the warmer water cause the fogs off Newfoundland. The similar Pacific current washes the northern half of the Japanese coast, whereas the southern half is affected by the "Kuro Shiwo," the Pacific counterpart of the "South-West Drift"; hence arise fogs off Japan, as off Newfoundland.

4. Causes affecting Temperature.-This preliminary account of winds and currents is necessary 
for the explanation of the two great factors in Climate, Heat and Rainfall. The account of the temperature of any country resolves itself into two parts-(I) its actual mean temperature, and (2) the variation between summer and winter temperature. Like all climatic facts, these must be studied along with Maps made to illustrate the specific point. Actual temperature is mainly, as everyone knows, a function of distance from the Equator and elevation. The effect of the former may be seen on any Map of the World made to exhibit "mean annual temperatures." The latter may be summarized in the formula, "a drop of $I^{\circ} \mathrm{F}$. for every 300 feet of altitude." The only other factor of importance is the rise of temperature on the west sides of continents* in temperate latitudes due to the southwest winds and currents which have been explained in the last section. The curious funnel shape of the North Atlantic, which runs from south-west to northeast in exactly the same direction as these winds and currents, spreads the influence far to the north, and renders Norway the most northerly country which is capable of habitation by civilized man.

Variations of Temperature between winter and summer are also illustrated in separate Maps. $f$ The

* Continent for climatic purposes includes single land-masses. Europe and Asia form one climatic continent, which it has become the custom to designate for this purpose as Eurasia.

$\dagger$ For any useful purpose connected with the subject with which we are now dealing, it is not the variation between the highest point which the thermometer reaches on the hottest day and the lowest point to which it falls on the coldest day which need be considered, but the difference between the average of the hottest and coldest months, which in northern countries are respectively July and January, and in southern countries January and July. 


\section{I58 THE TEACHING OF GEOGRAPHY}

principles are quite simple. Equator, the less the variation.

(I) The nearer to the The cause is obvious. At the Equator Day and Night are always equal. At the Pole there is one day of six months and one night of six months. The nearer we are to the Equator, the less variation there is in the length of Day and Night. In our own country the shortest day is eight hours ( 8 a.m. to 4 p.m.), and the longest sixteen hours (4 a.m. to 8 p.m.). (2) The nearer to the sea, the less variation, especially if the prevailing winds come from the sea. The reason is that continents are heated more quickly and lose their heat more quickly than oceans. A striking instance is the fact that the greatest variation is not actually at the Pole, but at Yakutsk, in Siberia, within the great land-mass of the Asiatic continent, where the difference is $120^{\circ} \mathrm{F}$. (average of July $60^{\circ} \mathrm{F}$., of January $-60^{\circ} \mathrm{F}$.).

The reader will again find that for purpose of study, though not of teaching, exact figures are necessary to make the principles perfectly clear, otherwise an effect may be exaggerated or underrated. Thus a study of the Seasonal Variation Map of America will show that the least difference is along the west coast from Puget Sound southwards (less than $10^{\circ}$ ); the similar part of the east coast has a difference of $30^{\circ}$; while the greatest extremes are found in the interior of Northern Mexico ( $40^{\circ} \mathrm{F}$.).

5. Rainfall.-The other factor in the Climate of a country is rainfall, and this depends even more on the direction of the prevailing winds. Rainfall is, in fact, a joint product of three interacting causes-(a) distance from the sea; $(b)$ position of mountains; $(c)$ direction of winds. The failure of any one of these factors to favour rainfall is fatal. 
(I) Desert Areas.-First we may take windless countries. A belt of such countries extends along the Tropics of Cancer and Capricorn, except that during the height of summer the eastern coasts of continents receive the Trade-Wind. Except on the east coasts, if we look along the Tropic of Cancer between $20^{\circ}$ and $30^{\circ}$ north, we find a series of deserts-the Thar Desert in India, the Deserts of Baluchistan and Arabia, the Sahara, the rainless interior of Mexico and Lower California. It is specially noticeable that, in the case of the Sahara and Lower California, rainless desert extends right up to the coast. The Tropic of Capricorn traverses less land. Where it does pass over a continent we have, however, a similar succession of deserts except on the eastern side, such as Central and West Australia, the Kalahari in Africa, Southern Peru and Northern Chili in South America.

(2) Equatorial Belt.-Elsewhere some winds always prevail-Trade-Winds or Monsoons in the Tropics, northor south-westerly winds in the Temperate latitudes. The Equator is surrounded by a belt of extraordinary rainfall, giving rise to the dense tropical forests of the Malay Isles, the Congo Basin, and the Amazon Valley. Here are the two rivers which pour more water into the sea than any others in the world-the Amazon and the Congo.

(3) Temperate Latitudes.-We now come to the Temperate Regions, with their prevalent west winds. It is obvious that, other conditions being equal, the westerly sides of continents in these regions have a far better chance of obtaining a good rainfall than the eastern. The limit of the westerly region is marked by any mountain barrier sufficient to bar the further access of the wind. 
Thus, the nearer the mountain barrier is to the west coast, the less favourably is the bulk of the continent situated for rainfall. In North America, consequently, the rainy margin is confined to the westerly half of California, Oregon, Washington, and British Columbia, the rain-bearing winds being unable to cross the Sierra Nevada and the Cascades.

Variation in Amount of Rainfall Needed.-It must be remembered, in reading a Rainfall Map, that the farther we go northwards the less rainfall is needed, as evaporation is less. Thus, even in the heart of Siberia and Canada enough rainfall occurs to support vegetation, and a belt of forest runs right across each country. In the latitude of the Mediterranean, however, the rainfall that occurs in regions cut off by mountains from rain-bearing winds is insufficient. The interior of Spain, and still more of Asia Minor, could well have more; in Turkestan the grass only flourishes for a month after the melting of the snows; and farther to the east, and enclosed by mountain ranges on all sides, lies the great Desert of Gobi.

\section{Summary and Illustrations from Asia.-} The results of the preceding sections may be briefly summarized, in order to show that the cardinal principles are really few in number. Climates differ according to temperature and rainfall; both these factors depend to some extent on the direction of the winds. The World only contains three types of wind areas - the Equatorial belt of Trade-Winds and Monsoons, the two windless belts, and the two belts of Temperate west winds. Hence there are three main types of climate-(I) hot, windy, and rainy ; (2) hot, windless, and dry; (3) temperate, with many subdivisions, the 
most important difference being between west frontiers of continents and the rest of continents. A further classification has been given in Chapter IV.

Towards the end of that chapter will be found a division of Asia into natural areas (pp. 57-58). It is possible now to show how far these principles of climate can be illustrated by these areas. As regards winds, the Monsoons are the main element in the climate of the third region, on which its productivity and importance depend. The hot and dry countries of South-Western Asia-e.g., Arabia-illustrate the windless belt. No part of Asia is affected by the south-west Temperate winds; but this lack is immaterial, as we can illustrate these from our own country. The interior countries which no rainy wind reaches are illustrated by Turkestan.

A digression on currents may be naturally introduced when we reach Japan, with its hot and cold ocean currents. This helps to revise the winds.

The dependence of Temperature on distance from the Equator is marked in a continent which presents such varieties as Siberia and India; while the second determining cause-height above sea-level-will be taught in connection with the highest range of mountains in the World, the Himalayas, and the highest plateau, Tibet.

The difference in extremes between interiors and coast-lines, again, can be taught along with Central Asia, and can be revised when we take Currents.

Rainfall may be taught, as already stated, with the dry inland Steppes, the windless Arabia, and the Monsoons.

At the end, revision lessons, specially directed to 
gathering up the climatic facts given under the various countries, should be given.

The next chapter contains fuller suggestions, arranged in teaching order, the preceding sections having been arranged in logical order, so as to show the teacher what ground there is to cover.

* * * * * *

7. Importance of the Seasons.-The rest of this chapter will deal with the complicated problem of the seasons. Curiously enough, while the winds and currents have been almost totally neglected in elementary schools, this most difficult topic has been commonly taught in a superficial manner at quite an early stage, though it is doubtful if one teacher in a hundred properly understands it.

First, as to the reason of its importance. All climatic principles are affected by the changes of the seasons. The sequence of these effects may be set out in tabular form, illustrating the state of things on June 2 I (as opposed to that existing on December 22) in the Northern Hemisphere.

Sun at midday overhead at Tropic of Cancer instead of over Tropic of Capricorn. $\left\{\begin{array}{l}\text { Days longer than nights in } \\ \text { Northern instead of in }\end{array}\right.$ Southern Hemisphere. $\left.\begin{array}{l}\text { "Heat Equator" lies to north } \\ \text { of Real Equator instead of } \\ \text { to south. }\end{array}\right\}\left\{\begin{array}{l}\text { Centres of Northern Conti- } \\ \text { nents are very hot instead } \\ \text { of very cold. }\end{array}\right.$

Trade-Winds are drawn north of Equator as Monsoons

fare drawn into the Continents instead of the winds flowing out from them.

Hence rainy season in the Monsoon countries instead of dry season. 
Secondly, the essence of the matter lies in the first stage, the explanation of the cause of-(I) the variation of the circle over which the sun is directly overhead at midday, (2) the variation of the length of day and night. If the facts are known on this topic, even without the causes, the other steps are comparatively easy.

Thirdly, the difficulty to an adult is not in understanding the diagrams showing the inclination of the Earth's axis to the plane of its orbit, and the persistence of the axis in pointing in the same direction throughout its whole annual course; neither is it in seeing that the sun is sometimes overhead at the Tropic of Cancer and sometimes at that of Capricorn, on the diagram. The difficulty is in translating the diagram in which one looks at the Earth from outside into terms of actual sight where one looks at outside objects from the Earth.

8. Apparent Position of the Sun at the Yarious Seasons in Different Latitudes.-As nearly every Geography book contains a diagram illustrating the cause of the seasons, it is assumed that the reader fully understands it. $\mathrm{He}$ is now asked to take his candle for the Sun, and orange with a knittingneedle through it for the Earth, or whatever apparatus he commonly uses to symbolize those objects, and by getting them into the required positions for the stated times of year and rotating the Earth, to convince himself of the truth and cause of the following statements :

(I) At the Equator.-(a) At the Equinoxes (March, September). Sun directly overhead at midday. Due east at rising, due west at setting. Apparent move- 
ment for day, through a great circle in the sky. (N.B.- -Rises 6 a.m., sets 6 p.m.)

(b) Between March and September. Midday, at point to north of zenith.* Rises north of east, sets north of west. Course, a line parallel to his course at Equinox, beginning by rising at right angles. (This is peculiarity of Equator, that Sun always is ascending or descending at right angles to horizon, never performing a sweep round the sky as everywhere else. Also sun always rises 6 a.m., sets 6 . p.m.)

(c) Between September and March. As in last, reading "south" everywhere for "north."

(2) At Pole.-(a) Equinox. Moving right round the horizon as he rises.

(b) Summer months. Same movement, neither higher nor lower, according to time of day, but clear of horizon. Ascending gradually for three months, but not higher at greatest elevation than with us in winter. Then descends for three months.

(c) Winter months, invisible.

(3) North Temperate Zone-e.g., Great Britain.(a) Equinox. Midday, south, moderate, elevation. Rises due east, sets due west. If we could see the whole course underground, the night course would be exact complement of day's course. (Rises 6 a.m., sets 6 p.m.)

(b) Summer. Midday, south, considerable elevation. Rises north of east, sets north of west. Course parallel to that at Equinox; but if we imagine underground course, we find that the greater part of the circle pursued is above ground.

(c) Winter. Midday, south, low elevation. Rises * Imaginary point due overhead. 
south of east, sets south of west. Course parallel to that at Equinox; major part below ground.

(The figure represents the sky as seen in Britain, $\mathrm{N}$ the Pole, the shaded part the ground; $a, b, c$, in the

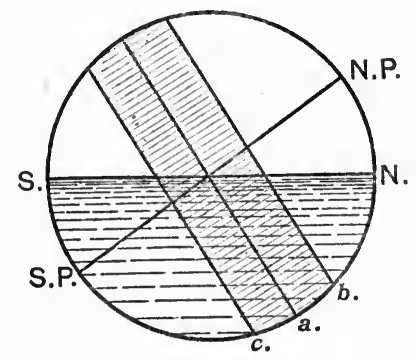

solid represent circles, showing course of Sun at Equinox, in summer and in winter.)

The reader can easily work out for himself the South Temperate Zones and the Tropics. 


\section{$\mathrm{XI}$}

ASIA AND THE TEACHING OF CLIMATE

I. General Points of Yiew. - The last chapter dealt with the subject-matter which needs to be taught under the heading of Climate. It is intended in this chapter to show how this subject-matter may be taught in connection with the Continent of Asia, which, as has already been pointed out, illustrates more climatic laws than any other continent.

It must, however, be remembered that, in teaching Geography, we are teaching not merely Climate, but the effects of Climate upon human life. We must not be so engrossed in the physical facts as to forget their bearing. It is necessary, therefore, to remind our readers that, on the human side of Geography, the first stage in the development of Man from the savage condition-the hunting stage-has already been exhibited in its highest development to Standard III. in connection with the North American Indian. The next stage in progress, the Pastoral life, may now be described to Standard IV. in connection with two of the climatic regions of Asia, the Steppe and the Desert-margins, while the Monsoon Area gives the most complete picture that can be presented of Agricultural life, comparatively unaffected up to the present by the manufacturing system of Western Europe, though in a few decades this may no longer be true. 
In order to illustrate how the physical and economic issues may be incorporated and kept in close connection, a syllabus is given, showing the distribution of the principles of Climate over the teaching of the various regions of Asia and the preliminary observational work which may be done in the preceding class (Standard III.). After this syllabus will follow a discussion of four canons which have been followed in framing it, namely :

(I) The use of Descriptive Geography as the basis for teaching all facts and principles which cannot be taught by direct observation.

(2) The preparation of the way for large and difficult topics by slow degrees through the previous work.

(3) The regional treatment of large areas-i.e., the system of treating the various divisions of a continent rather than features, such as the "mountains of Asia," " the rivers of Asia," etc., as the units of lessons.

(4) The systematization of the subject-matter, which has been taught under the various regions, by means of revision lessons on more general topics, illustrated by instances taken from the matter taught under the various regions.

\section{Preliminary Syllabus for Standard III.*-} Earth as planet moving with the other planets round the Sun, with the Moon moving round the Earth.

Evaporation, condensation, winds, clouds, etc.

Observations on the altitude of the Sun at noon, and its rising and setting, extending throughout the year.

Syllabus for Standard IY.-Preliminary study of the Map of Asia, showing the high central tablelands, 
the mountain-ranges radiating from the Pamir Plateau, and the physical division of the rest into (I) the northern plains; (2) the south-western plateaux; (3) the south-eastern plains and peninsulas.

I. The northern plains. (a) The Tundras. Revision of descriptions of Pole given in Standard I. Motion of Sun at the Pole.

(b) Siberia. Forest and wheat-growing portions. Physiographically this will be taught so as to bring out the extremes of a typical continental climate-e.g., the "pole of cold." Summarization of wheat (class having done America).

(c) The Steppe. Description full, so as to describe typical pastoral life. Comparison with hunting life. Physiographically, this region brings out absence of rains in the interior of continents.

II. The Malay Archipelago (the other extreme). Tropical forests and their animals. Movements of the Sun at the Equator.

III. The Hot and Dry South-West (including Egypt and North Africa). Preliminary physical survey of the divisions-viz.: (a) Iran Plateau, (b) Plateau of Arabia, (c) Plateau of Asia Minor, (d) Euphrates Valley, (e) Coast-line of Syria. The teacher should attempt to bring out all the characteristics which can be obtained from the children by questioning them on their knowledge of the Bible.

Life of the Arabs. Comparison with the life of the patriarchs, Job, etc. Some account of the Mohammedan religion and its rise.

Modern Palestine. Description of sites. Comparison with Ancient Palestine: effects of Mohammedanism and the bad rule of the Turks. Account of the nations 
who have lived there since New Testament times, including a reminder of the Crusades.

Deserts (Sahara, etc.). Question raised why there are so many deserts; the high-pressure belt along the Tropic of Cancer; outflowing winds to north and south; extraordinary heat of summer in the middle of the continent; movement of the Sun from the Tropic of Cancer to the Tropic of Capricorn.

Euphrates Valley. Need of irrigation in hot, dry regions. Origin of agriculture. Ancient Nineveh and Babylon, connected with the Bible. The story of the excavations. Egypt, the Nile. Ancient Egypt, as in the Bible. The British in Egypt. North Africa.

The Turk, his conquests and destruction of the old civilization. His recent attempts at reform. Persia, the Oriental burlesque of government.*

IV. The Monsoon Countries.

A. India: Preliminary survey.

Cause of the dry and rainy Seasons. The TradeWinds. The Monsoons. The bursting of the Monsoon.

Natural products and divisions. Revision of the account of the Jungle (Standard I.). Contrast of Thar Desert and of Deccan Plateau with the Plains, and the climatic reason for the differences.

Native life and productions.

Europeans in India; productions for export, etc.

This section might be followed by a lesson gathering up into a focus the children's knowledge of winds, and introducing the south-west wind of our own areai.e., distinguishing the Trade-Wind area, windless area, and westerly Temperate wind area.

* This may need alteration if the Revolution of 1909 effects a permanent improvement. 
B. China : Mainly description of the life of the people, the aim being to exhibit an entirely agricultural population as dense as that of our own country. The dependence of this population on the Monsoon and the importance of rivers in a tropical climate must not be forgotten. Tea.

C. Japan: Mainly description and some account of the recent advance.

Lesson on the Currents of the North Pacific and North Atlantic.

Lesson on Earthquakes and Volcanoes.

V. Interior Plateaux. Effects of elevation on temperature. Buddhism.

VI. Revision lessons on a climatic basis, co-ordinating the facts which have been given separately under the various regions. Also lessons arranged on some other basis-e.g., the various European races in Asia.

The above syllabus is only one of many which could be drawn up, and it is not implied that it is in any sense the right or the only order of taking Asia. It is, however, intended to be an application of principles which are of general validity, not only for Asia, but for all continents or large areas. It has been given because the significance of general principles can only be seen from an attempt to work them out in detail.

It is now intended to elucidate this syllabus more fully in connection with a separate treatment of the four canons laid down at the end of the first section of this chapter.

\section{Descriptive Geography as the Basis of} Climatic and Economic Teaching.-The first of these canons declared that all geographical facts and principles which cannot be taught by direct observation 
should be taught as part of a course based on Descriptive Geography. It is not meant that no special lessons on topics of Climatic or Economic Geography should be given, but that, in order to preserve the sense of reality, they should be worked into a course of which the framework is descriptive rather than be made the subject-matter of a special term's work in Climatic or any other special form of Geography.* By this means, not only is a concrete character given to matters which would otherwise be of an abstract nature, and quite without interest to children, but time is given for each principle to be assimilated while Regional Geography is being done before the next principle is attacked. This latter point may be exemplified by the gradual way in which the Seasons have been introduced in connection with the various countries. $t$ The interest which may be acquired for abstract climatic laws by their association with the striking concrete phenomena of particular regions may be illustrated by the Monsoon. The account of that wind given in the last chapter $\ddagger$ was undoubtedly abstract, and doubtless exceedingly dull to most readers; but let any teacher read the account in Herbertson's Descriptive Geography of Asia of the "Coming of the Monsoon" in Ceylon, and narrate the substance to the class, and he may hope with some success to invoke curiosity as to the reasons for so wonderful an occurrence. The grandeur of the bursting of the storm will soon remove any impression that Climatic Geography is studied, as Plato wished

* It must be remembered that this canon does not apply to matters which can be taught by the still better means of direct observation.

†. Worked out fully on pp. I79, I8o.

+ P. I50. 
Astronomy to be studied, not to trace the movements of the concrete heavenly bodies, but to understand the mathematical laws in conformity with which an ideal system might be conceived as working.

\section{Gradual Introduction of Difficult Topics.-} The second canon was to the effect that the way must be carefully prepared beforehand for large and difficult topics by slow degrees through the previous work. This applies particularly to the Seasons and the winds. At first sight they may appear too difficult to attempt with children; but adults tend to overrate the difficulty of certain topics for children because they have tried to master them in a short time from books in a purely abstract form, whereas it has to be remembered that much of a teacher's school-life is spent in teaching still more difficult matters to children quite successfully because he goes slowly. For instance, the principles of English Spelling and of the four "simple" rules of Arithmetic would be more difficult than anything contained in this course, if we attempted to cover whole topics in single lessons, as has usually been done in the case of Geography.

\section{Matters to be taught by Observation and} by Descriptions of Foreign Regions Respectively.-The application of these two canons, especially in the matter of the Seasons and the Winds, will be considered at length before we pass on to the other two canons.

It is to be noticed that, in accordance with the first canon, whatever can be taught by direct observation should be so taught, and this is, of course, taught apart from the description of any foreign country. Whatever cannot be taught by direct observation is to be taught 
along with the descriptions of suitable foreign regions. By the second canon careful arrangement in stages is required. Some ingenuity is therefore needed to arrange that the regional syllabus facilitates the progressive development of the climatic teaching instead of hindering it. It is, of course, never desirable to be tied down in teaching to a purely logical order; and it must not be expected that the topics can be presented to children in exactly the same sequence as that adopted in the preceding chapter. But the syllabus is intended to show that it is possible to arrange a course on a regional basis, and at the same time to follow the sequence in the teaching of climate which is most suited to children.

The matters which can be taught by direct observation are set down for Standard III., and lead up to the matters which can only be taught by accounts of other countries, which are set down for Standard IV. in connection with Asia. It is assumed that, at the stage when Observational Geography is being taken, part of the time allotted to "Nature-Study" or "Elementary Science" will be available, as this work has usually been included under those terms in the past.

\section{Teaching of the Seasons.}

\section{Apparent and Real Moyements of the Sun.} - Textbooks of elementary science usually begin the explanation of the Seasons by explaining the real movements of the Earth in relation to the Sun. In the days of our great-grandmothers, when the "Use of the Globes" was a recognized subject of instruction in all properly-conducted "academies for the instruction of youth," an elaborate apparatus was invented to illus- 


\section{I74 THE TEACHING OF GEOGRAPHY}

trate these movements. More than a century ago, however, Rousseau pointed out the futility of all such attempts, and insisted that we ought to begin, not with the real movements of the solar system, but with the apparent movements of the Sun, which could be observed in our own country.

The advantage of this method is obvious. Without observational work the whole subject is unreal. If children have never noticed the position of the Sun at home at any time of day and year, its position at some place abroad can mean nothing to them. Yet the difference may be the reason why this foreign place is a burning desert or a frozen ice-field, just as the position of the Sun in Great Britain determines our own summer and winter. Where comparison is everything, the starting-point with which everything else is compared must be made absolutely secure.

If it be admitted that the subject must be begun observationally, it follows that it must be kept in hand for a whole year, as the cycle of the Sun's apparent movements is completed in that period. The syllabus contemplates observations during the year occupied by Standard III. These should be kept to the fore enough to secure that in the later work, when the children have to trust entirely to their imagination, any reference to them should be sure of a response. From time to time they should be gathered together in a few formal lessons, the matter of which, having been learned slowly by observation, will easily be understood.

\section{Observations of the Apparent Movements} of the Sun in this Country.-Were it possible, the points to be observed would include the position of the Sun at rising, at noon, and at setting, and the times of 
rising and setting at intervals of, say, a week all through the year. The position at noon can fortunately be always observed on a fine day, as it is the usual dismissal time. The setting occurs about the time of closing afternoon school in December. The children can easily be led to remember roughly the time of "lighting up" the evening before, and the rest of the information can be supplied. Enough has been noticed by the children for themselves to keep up their interest and make the work as a whole observational.

The points which need emphasis must be discussed in more detail.

(a) Children do not usually notice for themselves that the Sun is much higher in the sky at noon in summer than in winter. One way of measuring the height of the Sun is by measuring the length of the shadows. The higher the Sun, the shorter of course is the shadow. When this point has been made clear, some object in the playground can be chosen, or a stick set up permanently for the purpose, and its shadow at noon measured at weekly intervals.* It will be found that the shadow lengthens from September 23, when the observations should be begun, to December 22, and then shortens till it reaches its minimum on Midsummer Day, when the Sun reaches his greatest elevation.

(b) The statement that the Sun rises in the east and sets in the west is probably believed by most children to be literally true. It is only the exact truth on two days in the year (September 23 and March 2I). In the winter months it rises south of east and sets south of

* It is hardly necessary to say that the same time of day (noon) must be kept all through the year, as the Sun is then at his highest point. 


\section{I76 THE TEACHING OF GEOGRAPHY}

west; in the summer months it rises north of east and sets north of west.* One of these statements, that it sets south of west in the winter months, can easily be observed at the end of afternoon school in December. But the principle, which is more comprehensive, is that at any given time of day the direction of the Sun is always the same, but his height varies according to the time of year. This can easily be impressed by observing the Sun from a window or other fixed spot passing at the same time daily over certain buildings or hills. Interest will be easily kept up by inducing the children to look out for the first day on which he passes behind some chimney-pot or distant tree, or, when the days are lengthening, the first day on which he clears it without passing behind.

Along with the observation of these points goes the systematizing of them. This can best be done by representing the sky by a glass globe containing the Earth inside. The globe must be fixed to rotate round an axis fixed at the proper angle for Great Britain, $\uparrow$ and the lower half must be covered over by some opaque case, so that only the upper half is ever visible at one time. Nothing new should be taught in this standard from the globe, but everything should be marked on the globe as it has been observed in Nature. This is the work of the lessons which gather up and systematize the observations. This would be distributed over the year somewhat as follows :

* A true statement would be that it is always east at 6 a.m. and west at 6 p.m. ; but in the winter it is, of course, below the horizon at that time.

$\dagger$ I.e., the axis must point straight to the Pole Star when it is turned due north and south. 
Between Opening of School Year and Equinox, teaching the principle of the length of shadows, and showing thereby that the Sun is at his highest at noon ; revision of the points of the compass and the Pole Star. Explanation of the glass globe.

At the Equinox (September 21).-Observation of the length of shadow at noon begun to be recorded on a chart. The time of sunrise and sunset similarly recorded.* The Sun marked on the glass globe, and the general nature of his daily course on the globe, and in reality compared and firmly fixed. A line representing his daily course marked on globe.

From Equinox to Shortest Day.-The two sets of observations kept up weekly, together with the observation of the Sun passing behind or above buildings or other objects. The matter of the last section kept up, but no new generalization made.

About Shortest Day.-Position of Sun again marked on globe.

Lessons bringing out the three points - (i.) that the altitude of the Sun is less; (ii.) that the day is shorter; (iii.) that he rises south of east and sets south of west. A line representing his daily course marked on globe, and the setting point south of west emphasized.

Spring Term to Spring Equinox.-Observations continued, and points which have been already taught and not lost sight of.

Spring Equinox (March 2I).-Lesson showing that the Sun has now got to the same position as on September 2I. The half-year cycle revised as regards

* The time of sunrise would have to be taken on trust by the children during a part of the year. 
the three points-(i.) altitude at noon; * (ii.) length of day; (iii.) rising and setting point. Definite attention is now called to the fact that the Sun at this time rises due east and sets due west in reality and on the globe.

Summer Term to Longest Day. - Observations as before.

Longest Day.-Position of Sun marked on globe, and his daily course marked by line. The next quarter anticipated, and revision of the three points for the year.

Three lines are now in existence on the globe, representing the Sun's daily course at the Equinox on the shortest day and on the longest day. They may be called respectively the "Sky-Equator" and the "SkyTropics." The children also know the "Sky-Pole," represented visibly by the Pole Star.

7. Accounts of the Apparent Movements of the Sun in Other Parts of the World. - In Standard III. the lines marked on the globe are the result of observation. The children now know the apparent movements of the Sun in Great Britain as well as their ABC or multiplication table. The difference of method in Standard IV. consists in the fact that the children are now expected to imagine the apparent movements of the Sun in other countries. The globe is now used not to record observations, but to help imagination. The key to the new work lies in the fact that, if one were to go to the North Pole, the "Sky-Pole," represented by the Pole Star, would be

* The children should be definitely made to notice that in this country the Sun is never due overhead. They sometimes use the word "overhead" so loosely that they fail to understand its meaning. 
directly overhead, and if one were to go to the Equator, the "Sky-Equator" would pass directly overhead; but these two cases must be introduced separately, and after a substantial interval. The globe must admit of a change in the elevation of the axis, so that in the former case it may be vertical to the horizon,* and in the latter case horizontal with it.

(a) At the Poles.-The account of the Sun's movements at the Pole would be taken along with the Tundra. + The change of the position of the globe with respect to the horizon has left unaffected the position of the Sun in "Sky-Equator" on September 23 and March 2I, and in the "Sky-Tropics" on June 2I and December 23. The rotation of the globe brings out the facts that the daily rotation is merely round the sky parallel to the horizon, that for six months therefore the Sun never sets and for the other six months never rises, and that his elevation even on June $2 \mathrm{I}$ is very small. These facts are worked in with the description of their results upon the climate of these regions.

(b) At the Equator.-After the one extreme of the Poles, the other - that is, the Equator - may well be taken. For this purpose the Malay Archipelago has been arranged to come earlier in the course than would be otherwise the case. $t$ The axis of the globe is again adjusted, and the points brought out that twice a year the Sun is overhead at noon and always at a high elevation, and that the days and nights

* The horizon, of course, is the edge of the dark covering of the lower half of the Globe.

+ Syllabus, section I $(a)$.

$\ddagger$ The teacher should begin the new region by emphasizing the contrast, and thus getting the children interested in the cause of the difference. 
are always of equal length. These facts are easily seen by rotating the globe. The effects of the difference in the Sun's elevation are impressed by the account of the tropical forests.

(c) At the Tropic of Cancer.-Only one other position needs to be taken-that is, the Tropic of Cancer. This is, perhaps, the most essential to the comprehension of the extremes of climate possible in large continents. The axis being once more adjusted, so that the "Sky-Tropic" passes directly overhead, the Sun is seen to be overhead at noon on June $2 \mathrm{r}$, and at his lowest elevation on December 22, which are, as with us, the longest and shortest days.* As with us, the difference of heat in summer and winter is due to these two causes-the variation of the Sun's altitude at noon and of the length of day. The extraordinary intensity of the summer heat is increased by other causes, namely, the absence of sea-breezes and the quick heating power of large land-masses.

The topic is thus practically completed before we reach the Monsoons. This is necessary-first, because the children must be fully familiar with the yearly northward and southward movement of the Sun before they can understand the cause of the Monsoons; secondly, because we only ought to have one new principle of Physical Geography in hand at one time.

The advantage of this method consists in its comparative ease. This ease is disguised in a written account, because there is no globe at hand with which to expound the matter. The simplest movement of the globe can only be expressed in an involved sentence. It is to be noted throughout the course described in * The difference is naturally much less marked. 
ASIA AND THE TEACHING OF CLIMATE I8I

this section that we have only shown pictorially what happens, and not tried to explain why it happens. The children have spent a year in becoming familiar with the way in which the globe represents observed movements before it is used next year to represent new movements. The movement of the painted Sun round and round the globe will, therefore, at once suggest what it is meant to represent, though the class will doubtless be amused at such ridiculous conduct on the part of the Sun at the Pole as to move round and round the horizon without setting.

\section{Teaching of the Winds.}

\section{Teaching of the Regular Winds.-In teaching} the Winds, as in teaching the Seasons, the first work is Observational, and has been arranged for Standard III. ; the next work is Descriptive, and has been allotted to Standard IV.

The teaching of Evaporation, Condensation, Winds, Clouds, etc., in Standard III. will not be discussed, as teachers already teach these matters as Elementary Science, and they hardly fall under the scope of this book, but are rather an instance of the Correlation of Studies.

In the work allotted to Standard IV. the study of the regular winds as affecting Climate has been spread over the descriptions of the various countries of Asia in the same way as the study of the Seasons, and is begun when that topic has been completed.

We begin with the windless region or region of outflowing winds as the simplest. It will be noticed that the teaching of the existence of this windless region at the Tropic of Cancer follows immediately 
after the teaching of the Sun's movements over that Tropic, and the two sets of circumstances together are used to explain the existence of the numerous deserts of Asia and Northern Africa. This treatment gives the Tropic a greater reality than it ordinarily possesses. So far from being an "imaginary line," it is a howling wilderness, and a manufactory of winds, and for intense heat in summer vanquishes even the Equator itself. (See Syllabus, Section III., under Deserts.)*

The teaching of the Trade-Winds and Monsoons comes next in order. They are the most noticeable instance of extreme fertility being produced by a regular wind, and therefore stand out in fine contrast to the extreme of infertility pictured in the last-mentioned region, and arising from a similar cause. These contrasts, as has already been noticed, have much effect in impressing on children the real importance of the causes lying behind Climate.

The Monsoons are naturally taught with India ; $\uparrow$ but China, Japan, and the other Monsoon countries follow immediately. The teacher will find the facts given above in the last chapter. $\ddagger$ They are mainly (I) the cause of the inflow of wind to the Equator; (2) the cause of the deflexion of the winds to north-east and south-east; (3) the annual movement of the "HeatEquator"; (4) the cause of the deflexion of the Monsoon to the south-west; and (5) the effect of the heating of the interior in drawing the North-East Trade-Wind and South-West Monsoon in towards the centre of Asia.

The teacher has considerable latitude in choosing how much he thinks it expedient to teach. Quite a * See p. 169 ; also p. I8o. 
reasonable amount can be given by suppressing (2) and (4) altogether. The sequence then consists of the first section; ${ }^{*}$ when this is understood, the children are already familiar enough with the Sun's northward march, and the intense heat of the Central Asiatic summer to render (3) and (5) easy corollaries. A second course is to state the deflexions, but declare them due to a reason "you would find it too hard to understand." A third is to teach them. In this case the teaching should be spread over parts of several lessons-i.e., each of the sections on pp. I49-I5I might take part of a lesson. On the whole we prefer the first plan, with the reservation that we might introduce the deflexions in the systematizing lessons in Section VI. $†$ of the syllabus, when a failure to be understood would not have such serious consequences as in the earlier stages. We would prefer to make sure of teaching the fact of the deflexions and the whole matter of the diagrams on $\mathrm{p} . \mathrm{I}_{52}$ at this stage, as they are the basis of the Climate of North and South America, Europe, and Australia.

9. Other Climatic Principles.-Apart from the Seasons and the Winds, no special provision is required for leading up to the other climatic principles introduced. These two topics in themselves do all in that direction which is necessary. The matters introduced in connection with particular regions or in lessons taking up points suggested by different regions and elaborating them are continental extremes (Siberia), continental drought (Steppes), currents (Japan), volcanoes (Japan or Malay Isles), effect of altitude on temperature (Tibet). When once a principle has been

* For facts, see p. I49. $\dagger$ See p. I7o. 
explained, it can be utilized in each new country where it is at work. It is in regard to this continuity, as opposed to the self-contained lessons of the past, that the greatest progress in geographical teaching may be looked for.

\section{Regional Teaching.}

Io. Regional Treatment of Ásia.-The preceding paragraphs have illustrated the first two canons. We now come to the third-the Regional treatment of continents. This means the absolute abolition, except as revision lessons, of lessons on "the Rivers of Asia," "the Mountains of Asia," etc., * and the substitution of the system of proceeding to the division of a big area as soon as possible. The only preliminary lessons should be those which are necessary to divide up the large area and show the basis of division. A good Physical Map of Asia shows this basis almost at a glance. A certain number of names have to be taught at once in order to refer to them, but one lesson would probably do all that is needed in this respect.

This division and subdivision goes on till we reach an area sufficiently homogeneous to be covered by a simple description. In a continent where we are concerned only with the greater and more typical features these areas may be very large; the Steppe region, for instance, is at least ten times the size of the British Isles, and may yet be treated as a single type, whereas at home a single coal-field would deserve separate treatment.

The kind of facts on which stress should be laid is of great importance. The natural order of presenting the

* Lessons of this type are quite in place as revision lessons. See below, p. 187 . 
ASIA AND THE TEACHING OF CLIMATE I 85

facts will be-first, the physical facts which determine Climate or Civilization; secondly, Climate with the facts which illustrate it ; thirdly, productions, including the natural growths; either here or in the next section, the growths which will flourish if introduced by Man, and the mineral products which Man can turn to account; fourthly, the Civilization as influenced by the preceding considerations ; lastly, any political facts of importance.

Regional Teaching illustrated by-(a) Siberia.Space absolutely forbids any attempt to discuss the teaching of every region in detail. A few examples must suffice. Siberia may be taken as the first. Under the first of the headings mentioned above come the level nature of the western half of the country and the line of heights in the eastern half, as determining the extent of profitable European occupation; the situation, exposed to the cold North and cut off from the South by tablelands; the northerly direction of its three great rivers, which makes them useless as commercial outlets and even harmful by reason of their floods. Under the second heading come the principle of the extremes of continental climate illustrated by the "Pole of Cold," the miseries of the exiles, sledging, and any vivifying descriptive matter. The third brings in forests and agriculture, and traces the conditions under which the forests exist in Nature, and under which wheat will grow under the care of Man. The subject of Wheat is followed up by considering to what extent wheat growing is likely to spread, and by a comparison of the amount grown in Siberia with that grown in other countries already taken. The minerals are next considered, and the system of exile is used to give the treatment vivid- 
ness. The fourth topic-Civilization-may be omitted, because the natives are unworthy of notice. The TransSiberian railway and the constant desire of Russia to expand are facts belonging to the last class-that is, are facts of political importance. Under each topic descriptive matter should be abundant and names few.

(b) By IndiA.- India presents an instance of a more complex country. The preliminary physical facts are the Himalayas, the cloud-catchers of India; the isolation of India by sea and mountains, producing its selfcontained civilization; its division into plateau and plain ; and its two great river-basins, the abode of its great populations. The climatic interest centres round its wet and dry seasons and its heat, the distribution of rainfall bringing the matter to a head for the next section. The section on productions brings in the jungle, the forested and unforested portions, and the enormous productivity of the river-basins. The central idea of the human life lies in the existence and characteristics of the pure agricultural type, which is especially seen in districts where rice is the staple food. The rice-fields themselves have to be described, the necessary irrigation, the several harvests, and the work involved. Numerous village communities with few wants are the social outcome. From the social condition of the inhabitants arises their peaceful character, leading to the frequent conquests and establishment of great despotic Empires. We cannot hope to explain all the facts of the civilization by geographical causes; but the topics already mentioned, amplified by descriptive detail, will cover much of the ground. The great varieties of race and language, the competing Hindoo and Mohammedan religions, the character of the worships as revealed 
in temples and mosques, in sacred rivers and festivals, must, however, not be omitted. Lastly, there is the political story of the British occupation, and some idea must be given of the mode in which a few thousand British officials govern the $300,000,000$ inhabitants.

India can itself be subdivided into at least three main regions-the Ganges Basin, the Indus Basin, and the Deccan. The general resemblance, for the need of Standard IV., is, however, greater than the particular differences. The separate treatment will largely turn on the typical products of those regions. In each of the regions the towns that are selected for treatment should be described in some detail, and made to illustrate definite points. For instance, in the Ganges Basin, Benares illustrates the Hindoo religion, Delhi the Mogul Empire, Calcutta the British rule and commercial activity, while the story of Lucknow and Cawnpore is needed to impress one of the two chief causes of the success of the British occupation, the determination which, along with its justice, has insured its continuance.

\section{Systematizing and Rexising Lessons.-} The fourth and last canon laid down at the beginning of the chapter was the systematization of the subjectmatter which has been taught under the various regions by means of revision lessons on more general topics, illustrated by instances from the matter which has already been taught in connection with the various regions. Effective comparison and contrast are possible only after the facts to be compared and contrasted are known. There is an advantage, too, in revising the facts in a new order, and in emphasizing some one point of view. Some of the lessons involving such 
gathering up of the climatic principles have been suggested in the syllabus. Thus, after India, we might have a lesson bringing together the wind-systems of the Earth (the Trade-Winds taught with India, the windless regions taught with the deserts, and the southwesterly winds of our own area), and systematizing them in the form of a diagram.* After the whole continent has been completed in original order, there are many topics which can be used for the double purpose of systematization and revision. Take, for instance, the Rivers. We can question on the advantages which we have found the various great rivers to afford, and compare them with those offered by the rivers of our own temperate climate. The first is irrigation. The children can instance the natural irrigation of the Nile which makes Egypt, which would otherwise be a part of the Sahara, one of the most fruitful of lands; the irrigation of Lower Bengal or of the province of Szechuan on the Yangtse, which support agricultural populations as large as that of the British Isles; and the Euphrates, which made old Assyria and Babylonia great Empires, whereas now they are almost deserted because the irrigation has been abandoned. Irrigation, then, is necessary both in hot-wet and in dry climates, but is little needed in wet temperate lands. Then there is the use of rivers for drinking-water, in striking contrast to our own country. And, finally, as arteries of trade, a use even more necessary in countries where roads and railways are few or unknown. We can revise by taking the great trading rivers, the Ganges, Yangtse, and Sikiang, and those which for various reasons are useless-the Hoangho through its floods, the Siberian 


\section{ASIA AND THE TEACHING OF CLIMATE I 89}

rivers through leading to no outlet, the inland Syr, Amu, or Tarim. Finally, we can compare their mouths and estimate their suitability for ports according as they are clear or blocked by deltas or sandbanks. The physiographical interests of rivers could be also revised with the rivers of Asia.

Other possible lessons deal with the races of Asiayellow, white, brown, and black (Southern India); the religions-Buddhism, Hindooism, Mohammedanism; the interests of European nations-English, Dutch, French, Russians, etc. ; trade-routes. All these, which are mere memory work if taken otherwise, are most valuable if taken for systematization and revision. 


\section{XII}

TEACHING OF WHITE MEN'S LANDS

\section{Review of Work of Lower Standards-} South America, Africa, and Australia.-Both climatically and economically a definite stage has now been reached. Economically North America gave a picture of the hunting stage, the Steppes and hot-dry countries of the pastoral stage, the Monsoon area of the agricultural stage. Climatically, the great principles of Winds, Temperature, and Rainfall have been taught. The work with the three simpler continents-Africa, South America, and Australia-represents a kind of pause, in which climatically the principles are applied, and economically we show the expansion of white men who have already reached a high stage of civilization over countries favourable to the agricultural and pastoral life. The teaching of Europe and the second consideration of the British Isles and North America deal mainly with the more complex stage of industrial organization. This is, of course, a rough generalization, for in South America the white man has fallen back, and the interest is rather in the climate than in the inhabitants, and in North America the development of agriculture by means of machinery is as important as that of manufactures.

The teaching of the three simpler continents need be discussed only briefly. We may, however, utilize 
South America by showing how a deductive treatment of Climate is possible. By a deductive treatment is meant the method by which the class is led to infer the climate of a country from its physical characteristics and the general principles which they have already learned in connection with other parts of the World. Physically, the chief characteristics of South America are the great climatic barrier of the Andes, which runs quite close to the west coast, the less important highlands of Guiana in the North and of Brazil in the East, and a great interior plain, which is more or less divided into two parts-the tropical plain of the Amazon and the warm-temperate plain of the La Plata system. No part of South America is, however, thoroughly central -that is, the winds from one or other ocean will penetrate in some degree to every part, provided they blow in the right direction. It is necessary to notice the point at which the Equator and the Tropic of Capricorn cross the continent. We can now deduce (I) a large area of Equatorial forest, since the great breadth of the continent is in the Equatorial region; (2) a small area of desert on the Tropic of Capricorn-small because the bulk of the continent in this latitude, as elsewhere, lies east of the mountain barrier, and all that remains on the west side is the tract between the Central Andes and the sea; (3) a small area affected by the north-rest temperate winds, again small through the proximity of the Andes to the sea. The facts will be found to correspond. The areas deserving description are the Amazon Forest, the existence of which can be anticipated in (I) ( $c f$. the Malay Isles); the "Savannah" region-that is, the region which is sufficiently in touch with the Eastern Ocean to escape being desert, 
but is only grass-land ( $c f$. the more fertile part of Hotdry Asia) ; and Southern Brazil, a country corresponding in latitude to China, and deriving its moisture from the Summer Trade-Wind.

A useful comparison can be made when we come to Australia. Here the great divide is on the east, not on the west; therefore we have a great stretch of Western influence on the Tropic, and so a very large desert. Unfortunately, Australia does not extend so far south as South America into the temperate regions, and only a corner of West Australia, Victoria, and Tasmania catch the west winds. Both continents may again be compared with Africa when we come to it. Here, owing to the great plateaux, most of the country is "interior," and there are only small belts either of east or west influence.*

Economic Treatment of Development of New Continents.-South Africa and Australia introduce the subject of Colonization, which has already been touched in the earlier treatment of North America. The early stages, involving the difficulties encountered in a country for which man had as yet done nothing, are important, as already shown, from the point of view of Economic Geography. They bring out the nature of capital, by showing the difference between a country on which labour has been spent and one on which it has not. The beginnings of different varieties of agriculture in the regions which are suited to them, and the rise of towns because they were suitable points for exporting these products, can be treated in these countries more easily than elsewhere, because the whole of this rise is

* The reader is referred to the division of Climatic Regions on pp. $5^{1}, 5^{2}$, and its application to these continents. 
TEACHING OF WHITE MEN'S LANDS I93

comprised in a period of not much more than half a century.

2. Analysis of the Position of Seaports.-The way is thus prepared for the more complex work in connection with the Western nations. Here, where towns are of such great importance, it will be found useful to emphasize the reasons determining their sites. A few examples will show how much often requires to be said about the causes which lead to the importance of certain towns, and how they can be used to test the knowledge of the physical and economic facts of a country.

(I) Hamburg.-Hamburg is, after Berlin, the largest town in Germany, having, with suburbs, about a million inhabitants. Though an old town and an important member of the Hansa League in the Middle Ages, it was then subordinate to Lubeck as a port, and to various inland trading towns, such as Magdeburg. Its predominance is modern. We have to look for the reasons, first, to the "hinterland" of which it is the outlet; secondly, to the facilities for trade beyond seas. Considering the former, we find that it leads by the Elbe (I) to Berlin, the capital and largest town in Germany; (2) to the beetroot-sugar district of Magdeburg; (3) to the Saxon coal-field, potteries, and ironworks; (4) to the Bohemian coal- and iron-field; and (5) by means of the canals, which take advantage of the close approach of the Oder to the Elbe, by way of the Oder, to the Silesian coal- and iron-field, and to Breslau. As regards the latter, Germany has a coast-line on the North Sea and the Baltic-the former is a branch of the Ocean, the road to Great Britain, France, and all the continents outside Europe; the latter leads only to 
Sweden and to part of Russia. A more open oceanapproach would be by way of Holland; but, apart from the need of going through a foreign country, the landtransport would be much longer, and would not be helped by waterways. Hence, its only competitors are Bremen and Emden. The Weser, however, on which Bremen is situated, does not lead to a hinterland comparable to that of the Elbe; and Emden taps a different region, the coal-field of the Rhine. Thus Hamburg must remain unrivalled as the port for the eastern half of Germany.

(2) New York.-New York can be studied on the same lines. It stands on the mouth of the Hudson, which flows through a narrow trough, skirted by the White Mountains to the west and by the Catskill portion of the Alleghany Upland to the east. If we follow the river I70 miles up to Schenectady, we find two streams meeting. Each of these flows through a trough, of which the one leads via Lake Champlain by an easy water-parting to Montreal; the other, the Mohawk, to a point from which Buffalo, on the Great Lakes, can easily be reached. Neither journey takes the railway as high as 500 feet, and both routes are canalized. To reach Buffalo is to reach the heart of the continent, for the Lakes give an uninterrupted route (I) to Cleveland, the great iron town; (2) to Chicago, the outlet of the maize-lands of the middle Mississippi ; (3) to Duluth, I,000 miles from Buffalo, the outlet of the wheat-lands of Dakota, Minnesota, and Manitoba. Any point in the Great Plains can be reached from the Lakes by rail. From the other point of view, New York directly faces Europe, its chief customer. The importance of these facts is only 
brought out by a comparison with other possible rivals. The outlet for the interior of the continent must be either (I) by the Mississippi and Gulf of Mexico, or (2) by the Atlantic ports. The great disadvantage of the former outlet lies in its relatively greater distance from Europe. On the Atlantic coast-line the height and complexity of the Appalachian system makes the southern half useless. New York is therefore left to compete with Baltimore, Philadelphia, Boston, and the St. Lawrence. The St. Lawrence seems at first sight to be the natural outlet, but is spoiled by the interposition of Niagara between Lakes Erie and Ontario, and by the fact that its mouth is frozen for a large part of the year. We will not enter on a detailed comparison of New York with the other three great Atlantic ports, but will leave the reader to trace from the Map how, by the Hudson route alone, we avoid crossing the mountains, and will suggest that he reads a description of the route.*

(3) Hull.- Hull may be taken as an instance in our own country. Its natural hinterland consists of the basins of the two streams which form the Humber, which contain (I) the woollen industry of the West Riding, (2) the steel of Sheffield, and (3) the lace of Nottingham. But further, as regards the continent, it is (4) far more convenient than Liverpool as the outlet for the cotton manufactures of Lancashire, and actually exports more of the manufactured article than Liverpool. The oversea countries for which it is favourably situated are: (I) Hamburg and Germany, and, as far as the North of England is concerned, Antwerp and the Rhine ports, with all of which there are abundant reasons both

* See Herbertson, "Descriptive Geography," North America, pp. 93-99. 
for a large import and export traffic; (2) the Baltic, from which it can import timber and Swedish iron. Coming to a comparison with possible rivals, we find that there is no suitable port south of Hull till we come to London, and that the numerous ports to the northMiddlesbrough, Sunderland, and the Tyne ports-only afford access to their own more limited districts. It should be borne in mind that in a country as small as Great Britain the general imports which require to be distributed all over the country are more likely to be brought to some one port like London, and thence distributed; but the specific imports, such as those needed as raw products for a localized industry, are likely to be brought to the port nearest to that industry. The exports are nearly all specific, consisting of raw products, such as coal, or of manufactured goods produced in special parts; they will, therefore, be exported from a port near to the place of production. The work of ports is, therefore, much specialized: Cardiff, for instance, is almost entirely an export centre for coal, while London is predominately a port for general imports. Certain import ports, owing to their position, have also established special connections with different parts of the World, as, for instance, Bristol with America, and Southampton with South Africa.

\section{Analysis of Position of Inland Towns.}

The instances which have hitherto been taken have all been ports. In the case of manufacturing towns, it is rather the reasons for the localization of the industry than of the particular town which have to be taught. Manchester is merely the business centre of Lancashire, which from this point of view is one large town. The reasons which have led to the specialization 
of the cotton industry in Lancashire, of the woollen manufacture in Yorkshire, etc., are to be found in almost every textbook, and will therefore not be discussed here. There is, however, a class of towns which, like ports, owe their position to special facilities for communication, but not by water. It consists of towns whose position is determined by the fact that trade is there restricted by mountain barriers to one definite route. We will select as examples Vienna and the two North Italian towns of Turin and Milan.

Of Inland Towns on Lines of Traffic-e.g. (i.) Vienna.-The mountain barriers of Central Europe which affect Vienna are: (I) The Alps, especially their eastern prolongations running up as far as the Hungarian Plain; (2) the Carpathians, beginning to the north-east of Vienna, and forming a barrier between Hungary and North-Eastern Europe; (3) the ranges flanking the plateau of Bohemia on the north-east, north-west, and south-west; and (4) the FranconianSuabian Jura, running from the north-west angle of Bohemia in a south-westerly direction. These barriers cause all the following routes to converge on Vienna: (I) The direct route $u p$ the Danube, and then from the Danube to the Rhine Valley; (2) the direct route down the Danube into Hungary, and then via Belgrade to Constantinople or to Saloniki ; (3) the route via Prague and the gap by which the Elbe breaks through the Bohemian barrier of the $\operatorname{Er} z$ Gebirge to Saxony, Berlin, and the North German Plain; (4) along the Moravian gap into Poland and Russia; (5) by the Semmering Pass into the Drave Valley, and thence by the Brenner Pass into Italy, the historic route across the Alps from Northern to Southern Europe. It is no exaggeration 
to say that Vienna has made the modern AustroHungarian Empire possible, apart from its historic importance in connection with the revived Holy Roman Empire of Rudolf of Hapsburg, and as the barrier to the advance of the Turks after their conquest of Hungary.

(ii.) Milan and Turin.-Milan and Turin depend on the Alpine Passes. The circular arrangement of the Western Alps round Turin as a centre brings it about that, from whatever point a route starts on the other side, it ends by reaching the North Italian Plain somewhere near that town. Milan is the natural outlet for the passes of the Central Alps. These towns, beginning as trade centres, have now collected the manufactures of Northern Italy, which, owing to the homogeneity of the Lombard Plain, can be carried on well in any fairly central position.

Analysis of Position of Capitals. - The last type of towns which needs to be mentioned includes those situated in the centre of a large plain. These often become capitals, as large physical unities like plains frequently become political unities or the nucleus of them: for instance, Russia is a large plain; the Paris Basin was the nucleus of France; the plain of Prussia was first a separate State, and now is the "predominant partner" in the modern German Federal Empire; and Hungary is one of the two component States of the Dual Monarchy. Sometimes the exact site is determined by no special cause, as is the case with Moscow, the old Russian capital; sometimes by some very local circumstance, such as facilities for defence in early times - thus Paris was on an island in the Seine ( $c f$. Shrewsbury on a peninsula in the Severn); sometimes by special commercial advantages, such as a 
confluence of rivers, a bend which generally implies that some traffic here joins or leaves the river, as in the case of Buda-Pesth, or, in the case of Berlin, by a favourable position with regard to two rivers.

Capitals are sometimes chosen for strategic or other reasons which do not imply that they would otherwise be important towns. Madrid was chosen from its central position, but, being the centre of a rather barren tableland, has no commercial importance. Rome was selected from its historic fame, and St. Petersburg to suit the policy of Peter the Great. The fact of their being capitals has made them important places, as it has vastly increased the size of London, Paris, and Vienna; but towns, such as these three, which depend on more substantial reasons for their importance, greatly outstrip the towns which are capitals and nothing else. Berlin was small till it became a capital, but was in a position which held great latent advantages. Constantinople has a splendid position as the gateway of two continents and two seas.

\section{Regional Division of Europe for Teaching.} - The division of Europe into units for purposes of teaching may cause teachers some difficulty. Attempts are frequently made to escape from the political divisions, and to adopt some more physical basis. Excellent as this plan sounds, we believe the attempt to translate it into concrete terms will lead to its abandonment, apart from the divison of the countries of Europe into three main climatic types. A very common plan is to take River-basins as units, as is done with the Amazon, the Congo, or the Ganges in other continents. The Rhine and the Danube are most commonly selected. The objection is that these 
basins are not real physical units-that is, there are no characteristics common to the whole of the Rhine or of the Danube Basin, marking them off from other regions. On the other hand, the Rhine Basin contains parts of three much larger natural units, the Alpine mountain-system, the hill-country of Upper Germany, and the plain of Lower Germany. The Danube flows through two distinct plains, and its upper reach, like that of the Middle Rhine, is in the hill-country of Upper Germany. On the other hand, the main physical divisions of Europe correspond fairly well to one or more political units, such as the British Isles, the Scandinavian Peninsula, Spain and Portugal, Italy, the Balkan Peninsula, and France. The divergence arises in the countries in the "trunk" of Europe, as opposed to its outskirts. The natural units here are: (I) The Alps, occupying Switzerland and several provinces of Austria; (2) Hilly Germany, including Bohemia; (3) the plain of North Germany, including the Netherlands; and (4) the plain of Hungary. The Alps must be treated as a unit for teaching purposes. For the rest, the lessons on the physical side of Germany should cover the whole of the second and third divisions; while Austria-Hungary only revises what is necessary of the Alps and the second region. There is no objection to revision lessons based on Riverbasins.

5. Lessons on the Alps. - The lessons on the Alps will vary considerably from the traditional treatment. The reader can now find accessible in the newer textbooks all the information he needs. ${ }^{*}$ The standpoint which is adopted nowadays is based on asking what * Herbertson, "Senior Geography," pp. 56-70. 
effect the Alps have had on human history, and the answer is, that above all they have been, and are, a barrier. They represent a climatic barrier between the sunny lands of the South and the cold lands of the North, and a line of demarcation between the races which these lands produce; they form likewise a physical barrier, which has had to be crossed by generals, emperors, pilgrims, scholars, and churchmen, seeking Italy for their several purposes, for ages before the modern railway came to take the tourist through a tunnel. Even now there is much hill-climbing for the train to do before it enters the tunnel, and the engineer has to choose his valleys as carefully as the makers of the older roads. In teaching mountains there are two main points to remember: the first is that passes, not peaks, are important; the second is that children, if not taught otherwise, will regard all mountain-ranges of which they read in school as made up of a single long and more or less uniform ridge. The importance of the passes is that they constitute to some degree gaps in the barrier, on which all routes converge; thus they determine the position of towns, and affect strategic questions of attack and defence. The teaching of the height of peaks was a mere concession to the Englishman's and the American's love of "records" and the "biggest thing on Earth." The schoolboy's idea of mountains was a product of the method of representing them on old Maps, whether by hatcheting or by thick lines. A modern Physical Map ought soon to dispel this idea. The real breadth of the Alps varies from 200 miles downwards. The points to be borne in mind in reading the newer geographies on the Alps are: (I) The differ- 
ence in characteristics between the eastern and western sections; (2) the longitudinal valleys of the eastern section, and the consequent difficulty of crossing it; and (3) the determination of the chief passes that need to be taught. These should be very few, but the routes leading to them from both sides should be carefully marked.

But, above all, the teaching must give a living picture. During this paragraph many readers have no doubt been mentally protesting that people nowadays who have been to the Alps do not talk about them as barriers, but as places in which to spend a pleasant holiday. This is true. The consequence is that the subject-matter of lessons on the Alps frequently resembles a guide-book. The difference between a guide-book and a lesson is that the former is written because the readers are going there, and the latter is given because the hearers are not. The guide-book records all the places worth seeing, and where to stay in order to see them; it then leaves the tourist's eyes to see and his taste to admire. The lesson has to enable the class to see with their mind's eye, but need not give the route, because thought can move without a Bradshaw. Let us, then, make up our minds not to tell the children about other people going there, but to take them there in imagination themselves.* Of course pictures will be used, and the section in a previous chapter on the use of them will apply.

6. Point of View in Teaching the Separate Countries of Europe. - Considerable thought is needed as to the point of view from which to treat the

* In order to get the spirit of the Alps the reader is recommended to read Whymper, "Scrambles amongst the Alps." 
separate European countries. The touch of individuality is required to convey a lasting impression; and this is not so apparent in European countries as in the abodes of picturesque Orientals, or in the scenes of discovery, adventure, and colonization. Purely intellectual work, such as the tracing of the importance of towns, which has been discussed above, appeals only to exceptional children, unless the countries in which the towns are situated have this "character" given to them. It is much easier to give it to some countries than to others, even in Europe. The mood in which to approach Russia is suggested by its vastness and silencethe silence of its forests and snow-covered plains, and the voiceless sufferings of its hundred million peasants. The semi-Oriental Balkans and the haughty medievalism of Spain are clear enough concepts ; in the smaller countries, the gallant fight of the Swiss for their liberty in their mountain-fastnesses, and the patient toil by which the Dutch have made their swamps the home of commerce, give us the clue to the treatment of those countries. Norway is the bracing land which lives by the sea, the land of fjord, forest, and fishing; and a description of a Norwegian fish-market must not be thought trivial. But the teacher must find his own line by which to make the great civilized and commercial nations of Germany, France, and Italy mean something to the class. To the adult, Germany is the land of research, France of refinement, Italy of art; each man has his own special love, which the child cannot understand. Merely to learn by rote the names of great buildings and of towns famous for their art galleries is useless; the safest rule is for the teacher to deal only with such matters as interest him personally. 


\section{4

In matters of taste, knowledge is useless without interest. The following suggestions are therefore very tentative. In France we believe the true life to be that of the frugal, home-loving, and homely peasant, whether among the vineyards of Burgundy, the orchards of Normandy, or the mulberries of Provence; a life that would go on uninterrupted whether every stone of the Tuileries and Notre Dame were removed, or Paris no longer were the abode of gaiety and no longer set the standard of fashion. In Italy, if we cannot give children a love of art, we can give them an idea of those features in the country which have made the Italians an artloving people-the bright sunshine, the clear air, and the blue sea. The music of Italy and of Germany represents a side of art which may appeal to many teachers and children. Something of the substantial, thorough-going character of the Germans may be brought out, the quality which has made them efficient in every work to which they have set their hands, whether commerce, war, or learning. The teacher should take a just estimate of their " militarism," the spirit of determination to overcome the difficulty of a dangerous position between France, the aggressor of the seventeenth and eighteenth centuries, and Russia, the aggressor of the nineteenth, a spirit which led to the War of Liberation as well as to the aggressions of Frederick the Great, and animates the reflective bourgeoisie in a determination that they will sacrifice a certain amount of freedom and submit to the inconveniences of officialdom rather than lose their national independence. This is essential to an understanding of the German people, which does not consist entirely of arrogant officers and bullying drill-sergeants. 


\section{Attitude of the Teacher to National Char-} acteristics. - The natural resources of the various countries will, of course, be described; they can be found in any of the ordinary sources of information. We must not forget, however, the varying degrees and manners in which the various peoples have used their resources. Such observation helps to create valuable moral ideasat least, if we avoid using them as texts for "direct moral instruction." In case of failure the fault is sometimes with the character of the people, sometimes with the lack of capital, or defective education, or bad government. Germany, Switzerland, Holland, and Scandinavia all suggest industry and thrift. The three smaller countries have utilized to the best advantage lands of very little commercial promise. In Spain, a land of great mineral wealth, and a fertile sea-fringe, the effort to overcome the difficulty of means of communication has been slight. Haughtiness and laziness seem to be the relics of her former greatness, the nemesis of easilygotten wealth and of persecutions which killed off or drove out her best thinkers and workers. In France, the peasantry seems to have recovered from the horrible conditions of the eighteenth century. Despotism has left its mark on Italy, though the Italian labourer of the North is one of the best in Europe; but in the South the ignorance and lawlessness that came from lack of respect for the government of men like Bomba still weigh down her social and economic condition. To the patient Russian, who has never yet learned the greatness of initiative, because initiative has always been crushed, sympathy is due, because now and again there appears in him an irresistible longing for an opportunity. Such estimates, or truer ones if the 
reader finds these prejudiced, provided only that they come fresh from a teacher's true convictions, show the children how these qualities appeal to a thoughtful man, and at least make them think about such matters, even if they are not in a position to weigh the correctness of his judgments. In our opinion, the best moral teaching is that which makes the learner exercise his thought on moral problems and feel their reality. The problem must be of some substantiality and some interest. It must be out of the range of bias. Further, thought on the characteristics of nations gives the sense that the individual is a part of a larger whole. It brings out the good side of pride of race, which consists in a sense of the need that the race should be something to be proud of. It seems paradoxical to say that sympathetic but impartial thought about other races is one of the greatest factors in building up true patriotism-and true patriotism means useful, effective patriotism-yet it makes children think for themselves, a thing which a list of the British possessions by itself does not effect. We believe that sentiment without thought is not far removed from prejudice, and that prejudice cannot stand the strain of sacrifice or prompt to counsels of wisdom. 


\section{XIII \\ THE TEACHING OF GREAT BRITAIN}

THE present chapter will deal with the more detailed treatment of the British Isles which is possible in a higher standard. The teaching, as in the case of other countries, will in the first instance be regional ; and this regional treatment will be followed by lessons of a more general character. That is to say, there must be separate lessons on such areas as Lancashire and Yorkshire, and afterwards a more systematic revision of topics, such as the Imports and Exports of the whole country. The first problem is therefore to secure a satisfactory division of the country into regions which can be given a separate treatment. The second is to avoid sacrificing a broader treatment to the necessity of teaching conventional information. This is a special difficulty which besets the Geography of our own islands. Thirdly, we must consider how to secure a sufficient drill in facts to make sure that they are systematized and remembered.

I. Division into Regions-(a) Geological Division.-In dividing Great Britain into regions, even for purposes of teaching, great help may be obtained from a knowledge of the geological divisions, though we cannot adopt them absolutely. A brief statement of the most essential facts regarding these geological divisions will therefore be given before we pass on 
to consider the divisions which may conveniently be adopted for teaching.

(I) Rocks are divided according to age into three groups: (a) Older, formed before the close of the Carboniferous Era;* (b) Middle, formed between the end of the Carboniferous Era and the end of the Chalk Age ; (c) Newer, formed since the end of the Chalk Age. Each period is further subdivided. Rocks of older periods often crop up among newer rocks, and "islands" of new rocks have been deposited among older rocks; but in a first survey these may be disregarded. We can then lay down the general rule that the older rocks occupy the north-western half of England and Wales, $\uparrow$ and the newer rocks the south-eastern half.

(2) Two dividing-lines are of special importance. The first is the Jurassic Escarpment, or north-western edge of the second of the three divisions into which the Middle rocks are subdivided. This escarpment divides the country into two nearly equal parts, and only one river, the Humber, pushes through it. It separates the basins of the Severn and Trent from those of the Thames and Wash. The Cotswolds, Edgehill, the Leicestershire heights, and the Wolds, are part of it. All the coalfields of England and Wales lie to the north-west of it, the best agricultural parts to the south-east. The second line, the Chalk Escarpment, is less important. It contains the Marlborough Downs, the Chilterns, and the East Anglian heights; it reaches the Wash at Hunstanton Point in Norfolk, and runs under it into Lincolnshire. The area between the two escarpments

* The period in which the coal-fields were deposited.

$\dagger$ The discussion of Scotland and Ireland is postponed to Section 5 . 
drains entirely into the Wash or Upper Thames, and includes the Fen Country.

(3) Another point worthy of notice is the order in which the hills and uplands have been uplifted. The age of the uplift and the age of the rock are not necessarily the same, as the rock may have been deposited for many million years before it was uplifted into the existing hills. Three groups of hills and uplands may be distinguished according to the age of uplift, each with its separate direction: (a) The oldest and most numerous, with a general direction from south-west to north-east, including the hills of the Lake District and of North Wales; (b) the Pennines, running from north to south; and (c) the hills of the South of England and South Wales, the newest in time of uplift, running from west to east.

(4) Coal-fields, which are, from the economic point of view, the most striking geological features, occur at intervals over the whole of the north-west half of England and Wales, except in the regions of older uplift, where they were never deposited, or in the loftier parts of newer uplifts, from which they have been washed away.*

(b) Division For Teaching.-So important to a country is the distribution of coal-fields and of mountain and plain that any division into regions must largely rest on a geological basis. A purely geological division, however, would be much too intricate for teaching purposes, as any large Geological Map will show. It is best therefore, in arriving at a satisfactory division for

* Thus the coal-fields of Lancashire and Yorkshire were once continuous, but the portion which once covered the Pennines has been removed by denudation. 
purposes of teaching, to combine geological factors, river-valleys, and economic dependence.*

The division of the country into two halves by the Jurassic Escarpment may be taken as a basis. All the coal-fields are thus treated in one half. The only compromise required with Geology is to treat the oldest of the three divisionst of Middle Rocks as Old and the two newer divisions $\ddagger$ as New.

The Older half of the country, then, presents two types-Upland districts and more level portions. Three distinct Upland districts would require separate treatment : first, the Lake District ; secondly, Wales, except Glamorganshire ; thirdly, the peninsula embracing Devon, Somerset, and Cornwall. There is less to be said about the Pennines. It must then be pointed out how the arrangement of uplands leaves only two means of access to the West Coast, first by the Cheshire Gap between the Pennines and the Welsh hills, secondly by the Bristol Gap between the Welsh and the Devonshire hills. Each of these gaps has given rise to a great port, the first to Liverpool, the second to Bristol. They are also the pivots of our two greatest railway systems. The London and North Western line runs straight for Crewe in the Cheshire Gap, and there divides into lines leading to Liverpool, to Manchester, to Carlisle for Glasgow, and to Holyhead, the packet-station for Dublin. In other words, the Cheshire Gap affords the means of access to all places on the coast of the Irish

* A seaside resort is in economic dependence on London if it is frequented mainly by Londoners, and an agricultural district if it is mainly occupied in supplying London with market-garden produce.

$\dagger$ The Triassic.

$\ddagger$ The Jurassic and Chalk. 
Sea. The Great Western Railway runs to Swindon, where it divides into two portions, the one leading to Bristol, and the other by way of the Severn Tunnel to the South Wales Coal-field and Fishguard, the packetstation for the South of Ireland.

The remainder of the Older Area may naturally be divided into (a) Lancashire, on the western side of the Pennines; (b) the counties on the eastern side; and (c) the portion of the Midland Plain lying within the area of Older Rocks-that is, to the north-west of the Jurassic Escarpment. The last division, owing to its size, may be subdivided into the Trent and Severn Basins; and the second into Yorkshire, corresponding to the Ouse Basin, and the Northern Coal-field, comprising Northumberland and Durham. The Lancashire, Yorkshire, and Durham coal-fields are the centres of interest in three of these divisions, and separate treatment may be given to the Staffordshire and South Wales fields.

The division of the Newer Area is more difficult. The Chalk Escarpment should be traced as soon as this area is begun; but it is inconvenient to take it as a basis of division, and thus to separate the account of the two halves of the Thames Basin. The geological division into Chalk, London Clay, Weald, Hampshire Basin, Fen, and Jurassic belt does not give us areas compact enough for our purpose, though the physical characteristics of the Fen Country and the Weald should be treated separately when they are reached. On the whole, teachers will probably find the simplest teaching units to be (a) the Thames Basin; $(b)$ the area in economic dependence on London outside the Thames Basin-that is, Kent and Sussex; (c) East Anglia; 
(d) the Wash Basin; and (e) Hampshire, with the counties beyond.

2. Axoidance of Rote Learning. - The second problem which we set before us was to find means by which we might avoid sacrificing the broader treatment to the teaching of too large a crowd of names and isolated facts. There is a greater danger of such a mistake in the teaching of Great Britain than in that of other countries, as we are compelled to teach many facts which are not necessary to illustrate general principles, but have a quasi-conventional value.* The number of such facts may be reduced, but many will still remain.

(a) Omission of Unnecessary Facts. - In the first place it may be well to see what may be omitted altogether. A good test may be found in our own experience of the practical use to which we have put various classes of facts. In one sense, indeed, the name of every village in the country might conceivably be useful; but the time taken in learning them would be far greater than the time which would be spent in looking them out in an atlas when we needed them. Post-office sorters must learn their trade in the sortingroom, and travellers by practical experience of Bradshaw. At school it is only necessary to give a framework into which knowledge which is acquired afterwards may be placed. The names and positions of counties undoubtedly supply such a framework, and for this reason it would be mere geographical pedantry to exclude them. When once a child knows the counties, he can localize by reference to them any places of which 
he subsequently hears, and if he also knows the directions of the main railway routes, he has a sufficient framework to meet the practical needs of life.

There remains a mass of facts which have been commonly taught, which nevertheless do not form part of our working knowledge of the British Isles, and these may, without hesitation, be omitted. Under this heading may be included (I) names of capes; (2) rivers other than those of commercial importance or those possessing large basins; (3) towns which an express train would disregard; (4) the counties of Scotland and Ireland in English schools; and (5) the names of many peaks and lakes. Probably teachers would be justified in throwing much more overboard; but as the majority would probably prefer to adopt a conservative position, it is assumed in what follows that the course includes (I) the names of the forty-three English and Welsh counties ; (2) a list of about a hundred towns; (3) the chief railways; and (4) a restricted list of physical features.

(b) Emphasis on Causal Connections. - The mere restriction of the amount of matter that is required to be memorized is not, however, sufficient to secure a broad and living presentation of the Geography of our islands: the method of treatment is of equal if not of greater importance. In regard to the more important features, what has been already said about the treatment of other countries and about the more elementary treatment of our own country will be enough to put the teacher on the right lines. The tracing of the causal connection between physical and economic facts continually preserves the appeal to the intelligence and prevents the teaching from degenerating into a mere 


\section{THE TEACHING OF GEOGRAPHY}

tax on the memory. The systematic division of the country into regions, which was proposed in the last section, also serves to prevent facts from being treated in isolation, without reference to their causes and effects. It provides the children with landmarks in the maze of facts, and discloses the existence of resemblances which diminish the effort of memory.

(c) Special Expedients. - But, even when the physical features and the main industries have been so connected as to present rational relations, and when the reasons for the importance of the larger towns have been analyzed after the manner which was suggested in the last chapter,* there is a danger that the smaller industries, the counties, and the smaller towns may be so treated as to make them mere catalogues. A continual effort on the teacher's part is required to avoid this risk, and a rich variety of expedients must constantly be brought to the fore. A few of these may be mentioned separately.

First, the thought of the pupils may be exercised in applying principles with which they are already familiar to new instances, as, for instance, in attempting to find out the reasons for the importance of a town, when those reasons can be ascertained from a study of the Map. Thus, when sufficient examples have been taken of towns which owe their importance to the command of the easiest routes through geographical obstacles, the class might be asked to find out for itself anything in the situation of Oxford and Reading which would help to make them the chief towns on the Upper Thames, in the hope that some of the pupils would notice that these two towns command the two ends of the "Goring Gap" 
through the Chalk Escarpment, or that they are situated at the junction of the chief tributaries.*

Secondly, new geographical or economic principles of an easy character may be noticed. Thus, the principle that an industry often remains in the place where it has once been established, even when the cause which originally led to its localization has disappeared, may be noticed when the teacher comes to the Potteries, which have exhausted their clay, but still maintain the pottery industry with clay brought from a distance. The same thing has happened at Luton with the straw for hat-making, which is now mainly brought from abroad. A comparison of instances is particularly useful in such cases; in fact, it is best not to enunciate the general principle as such till a second instance is reached.

Thirdly, it is occasionally well to introduce considerations which are not really germane to any of the main purposes for which we teach the British Isles, if by so doing we make the necessary facts clearer or more interesting. An instance of this kind is found in the explanation of the division of the country into counties, which would certainly not be taught unless we were teaching the counties themselves, though its inclusion is justified by the principle that "it is often easier to remember two things than one "if the relation between them catches the fancy. Children are always curious as to the reason why Yorkshire is so much larger than

* These facts in themselves are of no particular advantage either to a University or to biscuit-making; but the University arose in Oxford because it was already the most important town in that part of the country; and Reading was already important before it attracted the biscuit industry. On this principle, see below, p. 217 . 


\section{I6 THE TEACHING OF GEOGRAPHY}

the other counties, and teachers may be surprised to find to what an extent causes have been assigned to such apparently meaningless anomalies.

2a. Origin of Counties. - A slight sketch of this subject is therefore given, as it will probably be new to many readers.

It is necessary to remember that originally England was full of inaccessible forests and marshes, such as the Wealden Forest, situated in Kent and Sussex, and the London Marshes, lying on both sides of the Lower Thames; and that, even up to the end of the Middle Ages, roads were mere rights of way, over which vehicles had a legal right to travel, but that they were prevented from doing so by ruts and other obstacles to such an extent that the rivers were the main lines of traffic.

The counties may be divided into (I) old kingdoms or settlements isolated from the rest of the country by forests or marshes-e.g., Sussex and Kent by the Weald, East Anglia (afterwards divided into the North-folk and South-folk) by the Fens; (2) the divisions made by the successors of King Alfred as they recovered the country from the Danes, including all the Midland Counties; (3) those counties which we may style "afterthoughts," which were thinly inhabited or unorganized in early times, and were only gradually brought into the system -e.g., Yorkshire.

The counties in the first class have all a considerable measure of individuality, and the physical reasons which give them their separate character are usually well marked. Those of the second class, however, are almost the creation of the county town from which they take their names. The Saxon kings, in their steady and thorough reconquest of the country, erected 
a number of mound-fortresses, which served at first as centres of defence and afterwards of government, and grew into the county towns. The counties, therefore, consisted of a district easily accessible, usually by river, from these centres, and probably no accurate boundaries were drawn till later. The shape of the counties therefore cannot, as a rule, be explained; but the towns were placed at suitable distances along rivers, wherever a hill or bend in the stream made defence easy.

A curious result may be noticed-namely, that the exact position of a modern manufacturing town has often been determined by causes which are now of very small importance. A town had been in existence from very early times; then it was found in modern days that some suitable conditions rendered possible the development of a manufacturing town in the same neighbourhood, and the manufacture took up its abode in the ancient town merely because it was already in existence. Thus Leicester and Northampton have developed into large manufacturing towns, though there is nothing in the exact sites which renders them particularly suitable.

The following list shows some of the reasons which have determined the exact position of certain older towns :*

Mouth of river or highest point accessible by the small vessels of early times : Norwich, Ipswich, Exeter, Gloucester, Chester, Lancaster.

Rock by the side of a river suitable for a mound:

* The rise of any of these towns to the front rank in modern times is not, of course, to be explained by these reasons, but only their exact position. 
Nottingham, Cambridge, Warwick (all chosen during the reconquest of the country from the Danes), Old Sarum (the original Salisbury), Durham.

Fords : Oxford (where the river divides into a number of arms), Bedford, Chelmsford.

Bend in the river which could easily be fortified: Shrewsbury (the river almost formed an island, the castle being situated on the isthmus).

Junction of rivers : Reading, Salisbury.

Passage of river through hills: Lewes.

Centre of plains: York, Worcester, Hereford.

3. Systematization and Drill in Facts.-It remains to consider how we shall secure sufficient drill in facts to make sure that they shall really be systematized and remembered. It is true that in the best type of lessons the subject-matter is such that an impression is left which may alter our whole mode of thought even after the details have been forgotten. No such plea can, however, be accepted in the case of lessons which aim at teaching the counties of England for utilitarian purposes. If they are not remembered, the whole time spent over them has been wasted; and the memory of the facts should be complete, accurate, and unhesitating. Reiteration and the formation of numerous associations are the only means of securing such a result. The memory should be at once verbal, visual, and schematic -that is to say, the children should remember verbally in what county a town is situated, they should visualize its position on the Map, and they should become used to thinking of its position relative to that of many other places. The third, or schematic memory, which is probably the most enduring, requires frequent Mapmaking. Those fortunate individuals who learned the 
counties by the pleasant method of putting them together as a puzzle, instead of learning them at school, never forget them. This method of learning is unfortunately impracticable at school for obvious financial reasons.* The twofold knowledge of the shape of the counties and of the position of towns on railways localizes almost every place. The latter knowledge, as regards the smaller towns, is more than we can hope to gain except by much railway travelling. But a kind of general outline can be obtained by making the class follow out some such scheme of Map-making as the following :

Filling up of a general outline Map of England and Wales with the two escarpments, the hill-districts, and river-basins as each is reached.

Construction of Maps of some of the districts as they are taken, the children putting in the physical features, counties, and towns, which are mentioned. Railway lines, if a whole section is comprised within the district, should be entered-e.g., G.W.R. from Bristol to Penzance in Map of South-West Upland District; G.E.R. from London to Norwich in that of East Anglia; Midland from Leicester to Manchester, and from Birmingham to Sheffield, crossing the former at Derby, in that of the Trent Valley; C. and S.E. from London to Chatham and Dover in that of South-Eastern England. $†$

* If cyclostyled on thin cardboard, however, the children might cut out the counties; this, and piecing them together again, would answer the same purpose.

$\dagger$ The Chatham line has been chosen in preference to the Continental mail route through Tonbridge Junction, because it follows the line of the old road used from Roman times, which skirted the Weald and ran from Dover, crossing the Stour at 
Construction, towards the end of the course, of a fair-sized Map of the whole Midland Plain, including the three main rivers, the two escarpments, etc.; the course of the L. and N.W.R. from London to Liverpool with loop through Birmingham, that of the Midland from London to Manchester, and of the G.N.R. from London to York, to be entered. Counties to be inserted afterwards.

Revision lessons on such of the railway systems as have occupied several districts-i.e., G.W.R., L. and N.W.R., Midland.

Readers will at once notice the contrast between the work which is here described and anything else which has been suggested in this book. The reason is, that if we are constrained to teach counties and towns for useful purposes, we ought not to adopt half-measures.

Care should be taken that the Wall-Maps which are used in connection with the Geography of England and Wales should exhibit clearly the main physical features which have been already mentioned. The sheet of Bartholomew's Maps* in which the school is situated should certainly be at hand, and any other sheets which take in striking parts of the country will be found useful.

\section{Teaching of Wales in Welsh Schools.-Before} dealing with the revision lessons on more general topics, special sections will be given to the teaching of Wales, Scotland, and Ireland. In English schools, Wales is

Canterbury and the Medway at Rochester, thus giving rise to these two towns. Their choice as cathedral cities by Augustine shows that they were the chief towns in Kent in his day.

* Bartholomew's "half-inch to mile" Map of England and Wales in sections. On paper, Is. ; on cloth, 2 s. 
naturally taught along with England for physical reasons. A special discussion is needed concerning the teaching of the Geography of Wales in Welsh schools.

The teaching of the Geography of Wales is frequently made to take as long in Welsh schools as the Geography of England and Wales in English schools. Teachers are consequently at a loss in choosing material to teach, and the number of names taught is alarmingly on the increase. It is not uncommon to find children made to learn over a hundred names of towns in the six counties of North Wales alone. This, of course, implies a total misunderstanding of the purpose of Geography teaching.* In any case, apart from local and outdoor Geography of the country immediately around the school, which is capable of almost indefinite extension, a year is far too much to spend on the Geography of Wales.

The special aim which we think a teacher should set before himself in this part of his work is to give the class a historical outlook on Welsh Geography. In dealing with foreign countries, we have been forced to avoid this interesting side of Geography owing to the children's lack of knowledge of General History. In England we have only referred to it in connection with county towns. England is on the whole a level country; and the more easy a country is to travel over, the less importance attaches to certain spots in comparison with others, and the less there is to be said of its historical Geography. In Wales, always excepting Glamorgan, Geography is historical or nothing.

Taking the order of historical sequence, we find that Geography determined the division into four princi- 
palities, the lines of invasion, the resulting blocks of country which could preserve their independence, the natural lines of castle-building to isolate these blocks, the lines of traffic when the country finally settled down to peace, the sites of towns, whether as centres of valleys or as commanding passes, the coach-roads, and the railways. Thus geographical considerations have affected History to an extent undreamt of in the more uniform English plain.

Amongst the matters which might well be taught are the sheltering hill-masses of the Snowdonian Range and of the Berwyn and Cardiganshire mountains; the four means of penetration from England by the valleys of the Dee, Severn, Wye, and Usk, as well as by both coasts; the routes from the inland to the coastal basins, from the Dee to the Mawddach by Bala and Dolgelly, from the Severn to the Dyfi by Machynlleth, and from the Usk to the Towy by Brecon and Llandovery; the cross-routes, as from the Wye to the Towy by Builth and Llandovery, and from the Severn to the Wye by Llanidloes ; the old coach-road to Holyhead by way of the Dee and Conway Valleys and the Nant Ffrancon Pass; the Snowdonian passes of Aberglaslyn, Llanberis, and Nant Ffrancon, with Portmadoc, Carnarvon, and Bangor as their outlets to the sea; the successive lines and rings of castles; the modern express routes by the north and south coast lines; the lesser through routes of the G.W.R. from Ruabon to Dolgelly, of the Cambrian from Welshpool to Machynlleth, and of the L. \& N.W.R. from Craven Arms to Swansea. Such a list is representative of the way in which, both in medieval and in modern times, roads and railways have been determined by the physical features, and of the 
way in which towns have resulted from the existence of natural routes.

Towns in Wales can always be localized by rivers, not because the mountain torrents themselves are means of communication, but because their valleys afford such means. Quite small streams may therefore have comparatively large towns situated on their banks, if the valleys afford access to some place worth reaching. These remarks apply to the Glamorgan coal-field as much as to the rest of Wales. A railway runs up every valley to bring down coal to the sea. Cardiff, at the mouth of the small River Taff, has become a town more than twenty times as large as Chepstow, at the mouth of the much larger Wye, because the Wye Basin does not lead to any industrial district. It may be convenient to classify Welsh towns as-

(I) Coast towns which are the outlet of valleyse.g., Conway.

(2) Towns at the outlet of valleys into the English plains-e.g., Wrexham, Hay, Welshpool, Abergavenny.

(3) Towns which are the centres of valleys, generally at the entrance of tributaries-e.g., Brecon, Pontypridd.

(4) Towns on cross-routes from valley to valleye.g., Llanidloes, Lampeter. (It is sometimes difficult to distinguish between the last two types.)

Rhuddlan is in a peculiar position for a Welsh town; it is situated at a crossing-place of a river, the lower course of which was occupied by swamps, the Morfa Rhuddlan; its position may to some extent be compared to that of London* or Cambridge.

* The site of London was determined by the fact that it was the lowest point at which a bridge could be constructed, owing to the marshes along the Lower Thames. 
5. Teaching of Ireland and Scotland.-We now return to the general needs of English and Welsh schools. The lessons on Scotland and Ireland must be given before any topics are taken which concern the British Isles as a whole. It is not intended to discuss the special needs of Scottish or Irish schools. In the case of Scotland it would be carrying coals to Newcastle,* and we are not sufficiently familiar with the needs of Irish schools.

Ireland is so homogeneous, except for the manufacturing districts of Ulster, that no useful purpose is served in English schools in giving much time to it. It may be treated as a single region.

Scotland should be treated regionally, falling into three divisions: (I) The Highlands, subdivided by the trench of Strathmore; (2) the Central Plain; and (3) the Southern Uplands. Most time will be given to the Central Plain and the routes from it to the other two divisions. Physically, the dominant features are the Rivers Clyde, Forth, and Tay. Their valleys in the upper part are all at right angles to the south-west and north-east trend of the mountains; the lower part of their course, parallel to the trend of the surface-features -that is south-west or north-east-has in each case been drowned by the incursion of the sea, which has turned this part of their valleys into firths.t Thus there are formed a number of more or less separate sub-divisions of the middle region, and the number is

* Scotland has contributed more than her fair share towards he growth of modern scientific Geography.

$\dagger$ This distinction between the direction of rivers in different parts of their course, technically termed the Consequent and Subsequent directions, may be found discussed in Mackinder, "Britain and the British Seas," pp. I 6 sqq. 
increased by the occurrence of the Ochill and Sidlaw Hills, with the general north-east to south-west trend in the middle of the plain. The most important of these subdivisions are Glenmore, Fife, Lothian, Strathclyde, and Ayrshire. The reasons for the importance of the towns are often very striking in consequence of the divided character of the plain. Perth, which is primarily the gateway of the Highlands by the Tay Valley, also affords access up and down Strathmore to Dundee, and from the north to Fife. Stirling, at the crossing of the Forth, occupies an equally good position. Edinburgh at once occupies a central position in the district of Lothian, and commands the entrance to the Scottish plain from England by way of Berwick. The Scottish counties are often too small and of too little interest to make it desirable to teach their names in English schools. Counties with distinctive characteristics, such as Argyll and Lanarkshire, might be taught; and some of the older districts, such as Lothian, Galloway, and Fife, the last of which has become a county, might be included.

\section{Lessons on General Topics.-The principle} laid down in connection with continents, $*$ that lessons on general topics at the end of the regional treatment serve to systematize and revise the matters which have been previously taught in connection with particular regions, applies also to the British Isles. Some topics might serve to recapitulate England and Wales only; but it should be borne in mind that for some purposes, such as climate, the British Isles must be treated as a single main unit, and that for economic purposes, 


\section{THE TEACHING OF GEOGRAPHY}

such as a general review of coal-fields, manufactures, imports, and exports, Scotland cannot well be separated from England and Wales.

Climate of Great Britain.-The general determining factors in the climate of the British Isles might well be taught before the separate treatment of the different regions is begun, on the ground that for this purpose the whole country is a single region. The class would then be in a position to understand the comparative wetness of the western portions, which would of necessity be mentioned in connection with Lancashire, Wales, and Ireland. Teachers should study Maps of summer and winter isotherms over these islands, and should notice how in winter the lines run almost due north and south. This topic might form part of the subject-matter of the systematizing lessons on climate at the end of the course, and Maps illustrating it might be constructed by the class. The Rainfall Maps bring out forcibly the effect of the mountains in catching the rainy winds. The nature of the cyclonic disturbances which come from the Atlantic should be understood and taught.* Teachers may find it an interesting occupation to follow the weather-charts published daily by the Meteorological Office, and to compare them day by day. The advance of cyclones will thus be noticed, and the actual direction of the wind at the place where the observer lives will be compared with the chart in order to see its relation to the general system of cyclonic circulation. In this way the observer will learn to distinguish by the direction of the wind whether a cyclonic disturbance is advancing on us or has passed,

* For an explanation of these the reader is referred to Mackinder, "Britain and the British Seas," pp. r54-r62. 
and whether its centre is passing to the north or south of us. The charts in a simplified form are published in the Daily Telegraph. Most of the papers only give the written account and forecast, which are not easily understood till the reader has formed an acquaintance with the charts themselves.

Imports and Exports.-Lessons on the imports of the British Isles serve rather as a revision of the World than of the Islands themselves. As regards our own country, they show what we do not produce, and are chiefly useful when contrasted with the exports. In a sense they are the culminating-point in the creation of the idea of international trade and of the interdependence of all parts of the World. Lessons on the exports are useful mainly as a revision of the chief industries. In this branch of the work a teacher is in a much more advantageous position if he has definite statistics* before him which are of a recent date, and contain the increase or decrease in the imports and exports over several decades. $\dagger$ It must be remembered that commercially Ireland is in quite a different position from Great Britain, being, except in the north-east, a country, not of manufactures, but of raw products.

Conclusion.-This chapter has avoided dealing with the subject-matter of the British Isles, except where it was thought advisable to introduce the reader to some topic with which the older Geography did not concern itself. Even here the object has rather been to show the nature of the topic than to give an adequate account

* See pp. 233-235 for a discussion of sources of information.

$\dagger$ Comparisons between year and year are often deceptive owing to the "trade-cycle," or tendency for years of good and bad trade to occur at more or less regular intervals, usually about ten years. 


\section{THE TEACHING OF GEOGRAPHY}

of it. In particular, the broader descriptive treatment of the physical structure to be found in modern works is utterly different from the cataloguing process of the old-fashioned textbooks, and the explanation of the climate is far more thorough and interesting. A reform in Geography teaching can only come from teachers studying some good books on the subjectmatter, and it is well for those who have not hitherto done so to begin with a book on the British Isles. There is always a fascination in discovering quite unexpected meanings and connections in well-known facts, and a good book on Great Britain may revolutionize a teacher's attitude towards Geography.

(For the purpose of stimulating interest, no better book can be recommended than Mackinder's "Britain and the British Seas" [Frowde, 7s. 6d. net]. It illustrates the new standpoint on the physical and climatic side. Amongst more incidental matters, the history of rivers and the account of the origin of political divisions maybe mentioned. In reading any book of this character, it should be remembered that many facts are mentioned only to illustrate principles, and need not be memorized; on the other hand, the book does not profess to supply information of a quasi-conventional kind. The everfluctuating commercial facts have, as a rule, to be sought elsewhere than in purely geographical works, though they cannot be neglected in school teaching.) 


\section{XIV}

\section{BOOKS AND APPARATUS}

THE aim of the following pages is to give references to a few books, with some indication of what can be found in them, rather than to give a long list. The use of books will also be considered, and hints will be given as to Maps and other apparatus. The chapter is intended for those who have not had an opportunity for making a special study of Geography.

\section{BOOKS FOR THE TEACHER.}

"Regions of the World," edited by H. J. Mackinder (Clarendon Press, I2 vols., 7s. 6d. net each).

Each region is worked out on regional principles, beginning with the chief physical facts, and tracing in turn the climate, products, and effects on human life. The various volumes are written by different authors. Mr. Mackinder's own contribution, "Britain and the British Seas," is a particularly good example of the regional method. In particular, it should be consulted for the climatic principles of the British Isles, for a working-out of sub-regions in a larger region, and for the account of the history of various rivers. It will put the teacher on the right lines, not only for the treatment of the British Isles, but for the general treat- 
ment of any region. It is not a reference-book to be consulted for detailed facts or statistics.

"The Senior Geography," by A. J. Herbertson (Frowde, 2s. 6d.).

A Geography of the World, worked out on regional principles. It is the best book for simplifying Geography by classifying the World into regions. The whole book may be read as an exemplification of the system of division which is put forward in its early pages.

"Regional Geographies," by Miss J. B. Reynolds (A. and C. Black, 2s. each).

Volumes on the British Isles, Europe, Asia, Africa and Australasia, and the Americas, are published. These are probably the best cheap textbooks for separate continents. The facts are well selected, and the diagrams and maps are useful. They are based on regional principles, and the whole point of view is that of the modern geographical school.

"The Descriptive Geographies," by F. D. and A. J.

Herbertson (A. and C. Black, 2s. 6d. each).

The volume dealing with the continent which is being taught is an indispensable possession for the teacher, who can use it $(a)$ to discover descriptive matter, (b) to find out what books of travel exist about different regions, out of which more descriptive matter can be obtained, and (c) to read facts from it to the class, which can then be asked to explain the causes of these facts.

"The World of To-day," by A. R. Hope Moncrieff. 6 vols. (Gresham Publishing Co.).

The school library should contain this work. Use- 
ful for description, but specially for the large number of pictures.

"The World's Commercial Products" (Pitman, Ios. 6d.).

A useful book for the school library, containing descriptions and illustrations of the mode of production of all the chief vegetable and mineral products of the World. It will provide the teacher with a large amount of matter and many illustrations.

"Child's World in Pictures," von Wyss (A. and C. Black, Is. 6d.).

An excellent book for the school to possess for its illustrations. Does for the youngest standards and within a more limited compass what the last two do on a bigger scale, and the pictures would make more appeal to the younger children.

"Man and his Work," by A. J. Herbertson (A. and C. Black, Is. 6d.).

The aim is to show the types of life to which the chief physical regions have naturally given rise. The reader will see the importance of this side of Geography from Chapter V. above. Very important as keeping the human side of Geography in the forefront.

"Man in Many Lands," by L. W. Lyde (A. and C. Black, 2s. 6d.).

Groups countries in regions with an economic unity, and deals with each country in the region in turn, showing the effect of climate and productions on occupations and life. It is the best short book for obtaining facts on the social life of different peoples, an aspect of Geography which is very necessary for descriptive 
purposes and is too much neglected in the textbooks which deal with other aspects; and in all cases it attempts to show a connection between such facts and the climate and productions.

“Lyde's Geographies: The World"(3s. 6d.). Better each continent separately (A. and C. Black, Is. 4d. each).

Owing to their small compass and moderate price, these are useful handbooks for a teacher to possess. They contain a good deal of information about towns, rivers, etc., which is quite of the right kind. The sequence of lessons ought not to be used by a teacher in elementary schools, as the books are intended as textbooks containing the matters to be memorized in secondary schools, leaving the descriptive matter to be supplied by the teacher. Teachers should only select a very few of the names which are mentioned.

"Man and his Markets," by L. W. Lyde (Macmillan, 2s.).

The point of view is, having taken the chief articles of necessity, to show the organization of industry which is required to produce and distribute each, including the growth of towns.

"The International Geography" (in 7 parts, or complete, Newnes, I2s.).

Useful as a reference-book for the facts about different countries. It is written by various writers, generally belonging to the country which is described, and considered from different points of view. The articles by W. M. Davies, Professor of Geology in - Harvard University, on North America and the United 
States, are particularly to be recommended as an exposition of the Regional Method, and form a good basis for a study of the North American Continent. Some of the earlier articles on general topics give points of view.

"Handbook of Commercial Geography," by G. G. Chisholm (Longmans, I5s.).

This is of use as a reference-book, especially the articles at the beginning as to the distribution and conditions required for various products, and the commercial tables at the end. The tables, it should be remembered, are always a few years old, and in the case of rapidly changing industries-e.g., the relative output of gold from different countries-should be verified, if possible, by the latest information. The tables which show changes for decennial periods are most useful.

"The Story of Geographical Discovery," by J. Jacobs (G. Newnes, Ltd., Is.).

This contains a short sketch of ancient and medieval knowledge of the World, and then describes the search for the Indies by various routes, the consequent discovery and settlement of America, and the more recent completion of our knowledge of the World by exploration in Africa and the South Seas.

"Geographical Diagrams," by H. J. Snape (A. and C. Black, Is. 4d.).

A series of diagrams illustrating specific pointse.g., rainfall, temperature, distribution of population, minerals, crops; a number of statistics, from which similar maps could be constructed, and a series of suggestive questions. 


\section{THE TEACHING OF GEOGRAPHY}

"Geographical Influences in American History," by

A. P. Brigham (Ginn and Co., Boston, 6s.).

It will be good for those who are interested in the historical side of Geography to read this. The history of North America is contained in a fairly short period of years, and, being largely a history of expansion, has been much influenced by geographical conditions. It is a useful continent with which to begin the study of Historical Geography.

"Our Neighbours" (a Series). French, German, Russian, etc., Life in Town and Country (G. Newnes, Ltd., 3s. 6d. each).

These contain a large amount of matter descriptive of life and customs in different countries which will colour the teacher's descriptions. Only a small portion is, of course, suitable to the interests of children. But they are valuable to give the teacher a point of view, sympathy, and descriptive matter with regard to life in civilized countries, without which the teaching loses all air of reality in the upper standards. The importance of some such book is emphasized in Chapter XII.

"The Statesman's Year-Book" (Macmillan, Ios. 6d.).

This can be found in most Free Libraries. It is useful for checking the statistics to be found in Commercial Geographies, etc., where the teacher suspects that there has been a considerable change in the course of a few years.

"Whitaker's Almanack" (Whitaker, 2s. 6d. edition).

Teachers who are at a loss for statistics as to trade, and are in a hurry, can often borrow this book when they have no time to find the "Statesman's Year-Book." Information may be found there on the gross imports 
and exports of the United Kingdom in different articles for the preceding year, as well as for those of various other countries under their respective headings. Whenever possible, however, it is best to use fuller statistics. It is, of course, a reference-book only; the articles on the different countries cannot be used as a textbook.

The number of Physiographical textbooks is very great. Teachers should on no account work through the contents of these books with a class in the order of the textbook, as the order in each school depends in the early stages on the phenomena which are to be observed near the school, while other phenomena should be dealt with as they arise in the regional series (see Chapter XI.). We may mention W. M. Davis's "Physical Geography" (Ginn and Co., 5s. 6d.) as the fullest, but with instances which are mainly taken from America; and A. J. Herbertson's "Outlines of Physiography" (Arnold, 4s. 6d.).

\section{BOOKS FOR CLASS.}

It is not intended to recommend any special books.

Textbooks. - Hitherto the textbook proper, out of which the class learn, has scarcely been used in elementary schools. It has been prejudiced by the old custom of secondary schools, where the class merely learned the textbook, and the teacher "heard" it with the book open, not needing to know it himself. Most so-called "geographical readers" are textbooks in disguise, and if we are to have textbooks, it would be better that they should be openly avowed. The chief difficulty is that they confine the teacher's lessons to the lines taken by the author. They might either be in the form of mere synopses for memorizing after the 


\section{THE TEACHING OF GEOGRAPHY}

lesson, or in a more connected form. The lesson would precede their use. The more purely they contain names and facts, the less likely is the teaching to do so. However, in view of the difficulty of hampering a right selection and treatment of matter, we think it is best at present to avoid a use of textbooks altogether.

Reading-Books.-The fault of most reading-books is that they aim at being textbooks - that is, they attempt to cover the whole ground of the lessons, and lend themselves to being read in class before the lesson, or even being taken as the basis of it ; the facts are memorized from them, and sometimes the teacher even "prepares" his lesson from them. There is, in short, not a single evil use to which a textbook can be put to which many readers do not equally lend themselves. The observance of the following principles would obviate most dangers :

I. Geographical readers should not be used to banish the true purpose of reading-lessons in the upper part of the school-viz., as an introduction to literature by fostering a love of reading. We sometimes hear of "literary" readers, a rather candid admission that Historical and Geographical readers are not literary. Books of travel are, however, a branch of literature, and to some boys from twelve to sixteen a peculiarly fascinating branch; hence literary geographical readers are possible. If, however, a teacher has any other object than to encourage reading books of travel, their use is illegitimate. The information can always be given by the teacher. If the idea is to secure more time for Geography, it should be done openly. The true place to speak more fully on this subject would be in a book dealing with the teaching of literature. 
2. The reading-book should therefore either be a connected story, dealing with some country that is being taken, or a book of descriptions. Whether it consist of the original work or works of a traveller or travellers, or of an abridged and simplified form of such works, or of a presentation of its contents in the compiler's own words, depends on the material accessible for the particular country and the standard for which it is intended. Some of the stories in Kipling's " Jungle Books," for instance, would lend themselves to reading or to adaptation. It need only deal with one of the countries which are being dealt with in the term, if, by so confining it, interest and literary treatment are encouraged.

\section{GENERAL LITERATURE WITH GEOGRAPHICAL BEARINGS.}

The scope here is almost unlimited. It has been already pointed out that the Bible picture of the life of the East is still true to-day, and that the literature of every nation breathes something of the special spirit of that nation which is useful for geographical purposes. We merely propose to mention a few examples from modern fiction or travel of books with obvious bearings on the teaching of the Geography of some country.

Scandinavia. - Björnstjerne Björnson, "A Happy Boy."

Alps.-Whymper, "Scrambles amongst the Alps." ITALY.-F. Marion Crawford's novels. Russia.-Ivan Turgenev, "Virgin Soil," etc. INDIA.-Almost anything by Kipling.

F. Marion Crawford, "Mr. Isaacs."

R. E. Forrest, "The Bond of Blood." 


\section{THE TEACHING OF GEOGRAPHY}

General Travel (especially China).-J. F. Fraser, "Round the World on a Wheel."

JAPAN.-Douglas Sladen, "A Japanese Marriage."

Clive Holland, "My Japanese Wife."

Central Asia.-Sven Hedin, various books of travel in Tibet and Central Asia.

Malay Isles.-Joseph Conrad, "Tales of Unrest." Palestine.-Rev. J. Kelman, "The Holy Land." EGypt.-E. W. Lane, "Manners and Customs of the Modern Egyptians."

Africa (N.).-Robert S. Hichens, "Garden of Allah."

A. E. W. Mason, "Four Feathers," etc.

Boyd Alexander, "From the Niger to the Nile." Africa (C.).--Stanley, "In Darkest Africa."

Mungo Park, "Life and Travels."

CANADA.-J. Fenimore Cooper, any of his novels.

E. Robins, "The Magnetic North."

U.S.A.-F. Norris, "The Pit," "The Octopus."

Winston Churchill, "The Crossing," etc.

Stevenson, "Across the Plains."

H. Dickson, "The Black Wolf's Breed" (backwoodsmen).

MAPS.

Ordnance Survey Maps.- - . Twenty-five inches to mile: plans of towns; every building marked; no contour lines, 2s. 6d. Such plans should be hung up in every town school.

2. Six inches to mile, Is.: contours marked; all roads and names of chief streets; solitary houses, etc.

3. One inch to mile, Is. each.

Bartholomew's $\frac{1}{2}$ inch to mile: coloured shading as well as contour lines. Best for teaching fairly large areas-e.g., a large county: Is. on paper; 2 s. on cloth. 
Exercises in Maps, etc.-In connection with this, we may consider some exercises in Maps which can be carried out in schools with advanced upper standards, higher elementary schools, etc.

Relief-Map Construction.- - I. Tracing out contours on cardboard, cutting out, and building up the Map by steps.

2. Constructing sections on cardboard across a district from contour Map, cutting them out, placing them in a vertical position in a box at correct distances apart, and filling in with clay or plasticine. Accuracy depends on the number of sections which are made.

INTERPRETATION OF MAPS.-I. Given a number of heights of places above sea-level on a Map, to trace the contours.

Following this, the probable directions of roads, railways, or canals could be traced on a contoured or shaded Map.

Again, the probable positions of streams could be inserted on such Maps.

2. Drawing sections to different scales across a Physical Map, contoured.

3. Constructing Weather Maps (Isobars or Isotherms) from data supplied. Also, given Isobars at any given date, to fix the direction of the wind.

Other Practical Work possible in School.I. Construction of temperature curve for the schoolyard (three readings per day, 9 a.m., 2 p.m., 4 p.m.). This might be done for the temperature in the sun as well as for that in the shade.

2. Preparation of a weekly rainfall chart.

3. Recording wind and weather. Direction of wind, 


\section{THE TEACHING OF GEOGRAPHY}

kind of sky, clouds, and general weather for the day. From this may be deduced a means of predicting roughly the local weather some hours in advance.

\section{PICTURES.}

These may be divided into wall-pictures which may be used in the actual course of the lesson; smaller pictures illustrating points in the teaching which may be put on the class-room wall to be viewed afterwards; and small views such as picture post-cards which can be handed to the children and used during the lesson.

Care should be taken to know exactly what purpose a picture is to serve, so that every part of the expense which is incurred should be directly making for the maximum of efficiency. The chief purposes are: (I) To supplement descriptions, as explained in Chapter VI., with the purpose of giving a general impression of scenery; (2) with the more scientific purpose of illustrating the kinds and origin of scenery; (3) to illustrate the characteristic vegetations of different regions; (4) to illustrate occupations; and (5) to give an idea of the life of peoples of different civilizations and nationalities, whether expressed in their customs, their buildings, or their costumes.

The same picture may illustrate several points, and will therefore often be useful both in the upper and lower parts of the school. Thus pictures of the second of the above class, intended primarily for use in the upper standards, will serve the more general purpose (I) in the lower standards. Again (3) and (5) can often be combined-e.g., in pictures of Japan.

Wall-pictures are required for most of the typical regions-e.g., Desert, Frozen North, Steppe, sub-Arctic 
Forest, Tropical Forest, often serving purpose (3) as well as (I). Pictures of some kind are needed, again, to give an idea of the characteristic vegetation of Australia, California, and the Pacific Islands. Under (5) pictures are most necessary for Oriental countries-e.g., Mohammedan lands, India, China, and Japan, though they are useful for European countries as well.

For the second purpose, which includes also the first (though wall-pictures are for this purpose also necessary), an excellent series is published by A. and C. Black at $6 \mathrm{~d}$. per half-dozen, illustrating types of mountains, uplands, and valleys, the formation and character of basins and lakes, the work of water and glaciers, etc. The photographs are well reproduced, and where physiographical work is taken up specially, valuable exercises for the higher standards may be set on them. They are also useful in flat districts to give an idea of the variety of mountains, as a single wall-picture may create a false impression by making the particular features of one mountain or kind of mountain appear to be a universal attribute.*

Lastly, it is highly valuable to form a habit of collecting all pictures that can be cut out of newspapers, magazines, advertisements, and all kinds of likely and unlikely sources, picture post-cards, etc., and classifying them under countries or purposes. The value of this collection entirely depends on the methodical way of keeping it, so that what is included can be found when it is required.

* There is far greater danger of this kind of error than is generally recognized. See Adams' " Exposition and Illustration in Teaching," pp. IIo, III. 


\section{N DEX}

Aber Falls, II6

Abergavenny, 223

Aberglaslyn Pass, 222

Abstract teaching, 7

Accuracy, 89

Adige, I2I

Adirondack Mountains, I Io

Adria, I2I

Africa, natural boundary, 54; regions, 58-59; grasslands, $5 \mathrm{I}$; civilization, 55 ; colonization, 8 ; teaching, 47, 54, I69, 192

Agriculture, origin, 68; varieties, I3, 78, I92 ; in England, 78, 132, I33-135, 208; in North America, 53,78 , 190 ; teaching, ı66, 169, 186, 192; agricultural life, 68,70

Aims, I-I6; conventional aim, 5 ; disciplinary aim, 6 ; true aim, 7-12

Alaska, 60

Alberta, 44, 6o

Alfred, 216

Algeria, 54

Alleghany Mountains, 194, 195

Alluvial soil, the origin of agriculture, 68

Alps, build, 28-29, 201-202; as a climatic barrier, 53; determining sites of towns, 197-198; teaching, 200-202

Altitude, ascertainment, 97 ; representation in maps, 97-98, IOr-102; effect on temperature, I57, I6I, I83

Altitude of Sun, teaching, I75. See also Sun (movements of)
Amazon River, I59; basin, 50, $62,85,159,191$

America (North) discovery, 233 ; regions, 5I-53, 59-62; unforested parts, $20,5 \mathrm{I}, 53$; rivers, 6I, I43-I45 ; climate, $156,{ }_{58}^{8}$; towns, I94-I95 ; teaching, 4647,48 , I4I-I 48 ; books on, 230234

America (South), regions, 5I, 62 ; deserts, I59, I9I ; people, 190 ; teaching, 47, r90-192

Amu River, 189

Analogy the normal mode of reasoning, 21-22

Andes, as climatic barrier, 5 ', 53, I9I

Anglesey, 90

Angola, $5^{8}$

Animals, children's love of, 40, 88

Anti-Trade Winds, 19, I52-153, I54, 226

Antwerp, 195

Appalachian Mountains, 194, 195

Arabia, deserts, 57, 159, 161 ; life, 47,57 ; teaching, I68

Arctic regions. See Polar Regions Argyll, 225

Arithmetic, 78, I72

Art, rise of, 69,72 ; teacher's attitude to, 203-4

Arts, rise of, 69

Asia, regions, 57-58, 168-1 70 ; climate, I5O-I5I ; civilization, 55,67 ; as illustrating climate, I60-I62 ; teaching, 47, I66-I73, I78-r79; choice of map, I03 
Asia Minor, climate, I60; teaching, 168

Assouan, dam of, 75

Assyria, $\mathrm{r} 88$

Atlantic Ocean, currents, I54-156; centre of trade, 72, 195

Atlases, 93, 104

Atmosphere, 46. See also Winds Australia, climate, I9-20 ; deserts, 20, 5 I, 63, I59; regions, 62.63 ; teaching, 47, 62, I92

Austria-Hungary, I98; teaching, 57, 197-198, 200

Ayrshire, 225

Babylon, 169, I 88

Backwoodsmen, 47, 59, 62, I47

Baffin Bay, 156

Baffinland, I08

Bala, 222

Balkan States, 55-56, 200; attitude to, 203

Baltic Sea, I93, rg6

Baltimore, I95

Bananas, 66

Bangor, position, 222 ; illustrations from, 82, 90

Bantus, 59

Bartholomew's Maps, 35, 96, I03, 220, 238

Bays, teaching of, 29, 82

Beaumaris Bay, 90

Beauty, rise of expression of, 69 , 72 ; children's appreciation of, 83

Bedford, 218

Beetroot, 56, 193

Belfast, I4I

Belgrade, 197

Benares, I87

Bench-marks, 97

Bends in streams, causes, Ir9-r20; movement of water round, $\mathrm{II}_{3}$; determining sites of towns, I2I, I99, 218 ; teaching, I24, I27-I 29

Bengal, 187, 188

Berlin, 193, 197, 199

Berwick-on-Tweed, 225

Berwyn Mountains, 222

Bible, use in illustrating the East, $57-58,68,168,169,237$; maps, to use with, 104

Bird's-eye views, 92, 93
Birmingham, I31, 137, 220

Black Country, I3I, I36; teaching, 2 I I

"Black Soil " area, 56

Boers, 59

Bohernia, 193, 197, 200

Books for teacher, 229-235, 237

238 ; for class, $235-237$

Boston (U.S.A.), 195

Bradford, 137

Brazil, sub-tropical, 5I, 62, I9I, I92; tropical, see Amazon Basin

Bread-fruit, 66

Brecon, 222, 223

Bremen, 194

Brenner Pass, I97

Breslau, I93

Brick-making, I36

Bristol, reasons for site, 2Io; trade, 196; gap, 210 ; teaching, I4I

British Columbia, climate, 44, 52, 60 ; rainfall, 160

British Empire, teaching of, 4344 ; responsibility for, 12 ; features of its rule, 76,187

British Isles, geological divisions, 207-209 ; climate, 56, I 54, I56, 225-227; when to teach, 4I-42, 46,48 ; standpoint in teaching, 25-26, I3I-1 32 ; teaching, I05, I30-I42, 207-228; divisions for teaching, 209-212; books for information, 228-230

Buda-Pesth, I99

Buddhism, I70

Buffalo, I09, 194

Buildings, teaching of, I4O, 203

Builth, II7

Burgundy, 204

Calcutta, 187

California, climate, 52, 60, 160 ; settlement, 79 ; Lower, 159

Cambrian Railway, 222

Cambridge, site of, 218, 223

Canada, natural divisions, 52,60 ; rainfall, I6o ; forests, 52, 6o, I60 ; settlement, $79, x_{47}$; teaching, 44,147 . See also Manitoba and British Columbia 


\section{THE TEACHING OF GEOGRAPHY}

Canadian Pacific Railway, I47

Canals, 77 ; in Germany, 193

Cañons, origin, 60, I18-119, I44

Canterbury, site of, 220

Cape Colony, 52, 59

Capes, unimportant, 29, 213

Capital, economics of, $73-77,78$; teaching, $74-75,77,192$

Capitals, reason for position, 198 I99

Carboniferous era, 208; in lessons on coal, 136

Cardiff, reasons for its importance, 223 ; nature of its trade, I3I. 223 ; physiographical instances near, II 8,120

Cardiganshire Hills, 222

Caribbean Sea, 155

Carnarvon, site of, 222

Carolina, I45

Carpathian Mountains, 197

Carrying power of rivers, II5-II6, II9; teaching, I24, I26-I27, I44

Cartier (Jacques), 62

Cascade Mountains, 160

Castles of Wales, teaching of, 222

Casual Labour, 77

Catskill Plateau, I Io, 194

Cause and effect, I7-20 ; complexity in Geography, 20.22 ; in Great Britain, 213-2I4

Caves, origin of, II 4 ; illustrations, 60, 145

Cawnpore, 187

Ceylon, I $7 \mathrm{I}$

Chalk Age, 208 ; area, 83, 2 II

Chalk, coloured (in teaching), Ioo

Champlain (Lake), r94

Character of nations, 66-73; in Europe, 205-206

Charts (weather), 226

Chatham, I4O

Chatham and South-Eastern Railway, 2 I9

Chelmsford, 218

Chepstow, 223

Chesapeake Bay, nature of coast on each side, rog, I45

Cheshire Gap, 210

Chesil Bank, I20

Chester, site, $2 \mathrm{I} 7$; river-bend, I2O

Cheviot Hills, I34
Chicago, 60, I10, I94

Chili, 52

Chiltern Hills, 208

China, climate, $5 \mathrm{I}, 5^{8}$; rivers, I88; agriculture, 58,68 ; when to teach, 47; teaching, 170 ; people. See Orientals

Churchill (American novelist), 147,238

Civil War (American), 59

Civilization, growth, 64-73; dependence on geographical influences, $185-186 ;$ regions divided according to, 53-55 : teaching of variety in, 23-24

Civilized countries, teaching of, $27 \cdot 28,193-206$

Classrooms, measurements of, 100

Clearness, distinguished from vividness, 87

Cleveland, I Io, I94

Climate, laws of, I8, I49-165; effect on primitive man, 66; effect on civilized man, 65-66, 142 ; effect on manufactures, 76 ; regions classified by, $50-63$; of British Isles, I54, 225-227, 229 ; of Europe, 55-57; of Asia, 57-58, I60-170, I85; of Siberia, 185; of Africa, 58-59; of North America, $59-62$; of South America, I9I-I92 ; of Australia, 19-20, 62-63; to be taught early, 34 ; standpoint in teaching, 166 ; matters to be taught in different standards, 35-36 ; teaching, 166-189, 226-227; deductive teaching, 62, I9I-I92; observational teaching, I72-177. See also Temperature, Rainfall, Winds, and Sun (movements of) Clouds, 37,167, I81

Clyde, 224

Coal, distribution in Great Britain, 208, 209; teaching of British coalfields, $\mathrm{r} 35-\mathrm{r} 37$; in Germany, 193 ; export of British, I96, 223; effect on manufac. tures, 70, 72, 76, 137

Coastal plains, 90,145

Coasts, types, I45; modelling, 90 ; features to teach, 29 
Cod fisheries, 156

Coffee, 2I, 62

Coinage, origin, 72 ; not wealth, 79

Colonial policy, British, Io; European, 8

Colonies (British). See British Empire

Colonization as illustrating economic principles, $27,74-75, \mathrm{I} 42$, I92-I 93

Colorado, I 8

Coloured chalk, roo

Columbus, $\mathrm{I}_{4} 6$

Commerce, origin, 69-70, 72 ; eco. nomics of, $76-77,79,227$; British, I95-196, 227 ; German, 193-I94; teaching of first notions, $137-138$; sources of statistics, $233-235$

Commercial Geography, teaching of, 30-31 ; books on, 233-235

Compass (points of), 36, 94-95, I77

Complexity of Geography, I3, 20-2I

Concentric order, 40-4I

Concrete teaching, 7, 12-13, 21

Condensation, $46,167, \mathrm{I} 8 \mathrm{I}$

Congo, I 59 ; basin, 5O, 58, I59

Consequent rivers, 224

Constantinople, 197, I99

Constellations, teaching of, $\mathrm{I}_{4}$, $24 \cdot 25$

Constitutions, teaching of varieties of, I4, 24-25

Continents, units for teaching 55 ; learning names of, 95

Contour lines, 97-98, I02; exercises in, 239

Contrast, use in teaching, 28,182

Conventional knowledge, attitude to, 5 ; in teaching British Isles, 212-2I3

Conway, valley, 222 ; town, 223

Cooper (Fennimore), ${ }_{4} 6$

Coral islands, 63

Cornwall, 2 ro

Corporate life, origin, 67

Cotswold Hills, 208

Cotton, conditions of growth, 38 ; of manufacture, 76,$197 ;$ in
America, 59 ; (in Lancashire), teaching of, 132, 136, 137; export from Hull, I95

Counties, origin, $215-219$; teaching, r05, 212.213; of Scotland, 225

County-towns, reason for sites, 217-218

Course, need of progressive, 3334 ; suggested, $44-48$

Crewe, reasons for position, 2 Io ; streams near, I 20

Cromer (Earl of), 70

Currents (Ocean), I7, I54-156, I57 ; teaching, I6r, I70, I83

Cycle of Trade, 227

Cyclonic disturbances, I53-I54, 226

Daily Telegraph weather charts, 227

Dairy farming, 135

Dakota, 44,60 , r 94

Danes in England, 2r6, 218

Danube, a trade-route, 197 ; basin not a unit, I99-200

Day and Night, teaching of, I7, 46, 94

Day (variations in length), cause, 37-38, I58, 162-165; effect on climate, 158,162 ; teaching, I77-I78, I79-180

Deccan, 169 ; teaching, 187

Deductive teaching, 62, I91-192, 2 I4

Dee, route into Wales, 222 ; physiographical instances from, I 8, I 20

Deer forests, I34, I 35

Definiteness, in teaching, 87, 129

Definitions, disuse of, $8 \mathrm{I}-82$

Delhi, 187

Deltas, cause, I20-I2I

Denmark, 72

Denudation, II3-II9, I2I, I43. I44 ; teaching, I23-I29

Deposition, II9, I2I ; teaching, I24, I25, I29, I44

Descriptions, subject-matter of, $40,45-46,82-83$; use in teaching, $83-84$; relation to pictures, $84-85$; use in teaching climate, 


\section{THE TEACHING OF GEOGRAPHY}

I67, I70-I72; means of preparing, 86-87; of Alps, 202 ; sources for, $87-88,230,237$

Deserts, cause and distribution, $5 \mathrm{I}, 57,59$, I 59 ; described, 85 ; teaching to Lower Standards, 40,$45 ;$ to Upper Standards, I69, I82, I9I

Detroit, I Io

Devonshire, 210: map-making of, 219

Diagram maps, 104

Diminishing returns, law of, 78

Direction, teaching idea of, 9495

Disciplinary aim, 6, 7

Discipline, rise of, 72

Dissected plateau, 144

Division of labour, 69

Dolgelly, 222

Dover, 219

Drave, River, 197

Drawing to scale, teaching, 97, 99-100

Drill in facts, $218-220$

Duluth, 194

Dundee, 225

Durham City, site of, 218 ; coalfield, I37, 2 I I

Dutch, 72 ; attitude to, 203, 205

Dyfi, River, 222

Earth, shape, 18; teaching of shape, $36,46,94$; as a planet, $37,94,167$; changes in surface, II2; motions, see Day and Night, and Seasons

Earthquakes, I70

East Anglia, I34; scenery, 83 ; former isolation, 216 ; heights, 208 ; teaching, 2II ; mapmaking, 2 I9

Economic Geography, early teaching, I32-1 $33, I_{42}$; should be historical, 62, 133, 137. See also Commercial Geography

Economics, relation of Geography to, $16,22 \cdot 23,65$; difficulty of teaching, I3, 23; taught through Geography, 73-80, I 32

Edgehill, 208

Edinburgh, I4I, 225
Egypt, climate, 5I, 57; due to Nile, 121, 188; British rule, 70, 75,76 ; teaching, 168,169

Elbe, 193, 197

Elementary Science, 36, I73, I8I

Elephant, 4I

Elevation, effect on temperature, I 57, I6I, I83

Ely, River, I20

Emden, I94

Emigrants, use of Geography to, 13; teaching concerning, 74 , I 42, I92-I93

Empire League, 107

England. See British Isles

Equator, position of Sun at, 37, I63-164, I68, I79-I80 : climate, I49-150, 158, 182; belt round, 50, 66, 159; in South America, I9I

Equinox, position of Sun at, 163 , I75, I77; winds at, I49, I 52

Erie, Lake, I09, 195

Erosion, II4-II9

Erz Gebirge, I97

Eskimos, 6o

Euphrates, agricultural value, 29, 68, 1 88; teaching, 168

Europe, division from Asia, 55 ; regions, 55-56; units for teaching, I99-200 ; towns of, I93I99; teaching, 48, I93-206; choice of map, I03

Evaporation, 46, 167, I81

Exercises, physiographical, I25I29 ; mapping, I04-105, I08Iro, 216-220, 226, 239; on climate, 239

Exeter, 2I7

Expeditions (school), 90, I22-I23

Exports, I96; teaching, 227

Falkland Islands, 44

Fall-line, I45

Fen Country, scenery, 82-83; drainage, 209; teaching, I4I, 2II ; as barrier, 216

Fife, 225

Figs, 56

Fiji Islands, 44

Firths, 82 ; origin, 224

Fiscal questions, 80 
Fisheries (American), ${ }_{5} 6$

Flax, 56

Fleet, I3I, 132, I36

Florida, Straits of, 156

Flow of stream, rate of, II2-II3 ; effect on carrying power, II5II6; teaching, I22, I23-I24, 125,126

Fogs, Newfoundland, I56 ; Japan, I56

Foreign policy, 9

Foreign trade, theory of, 79,80 ; of Great Britain, I32, I39, I4I, 227

Foreigners, attitude to, II, 203. 206

Forests, tropical, 50, 85-86, I59 ; in Asia, I68; in Africa, 59 ; in South America, 62, I9I ; teaching, 40 ; temperate, 56 ; subarctic, 52, 160 ; in Europe, 56 ; in Asia, 168, 185; in North America, 6o; absence explained, 20

Forth, 224, 225

France, origin, 198, 200 ; climate, 55 ; altitude to, 203, 204, 205

Freedom, rise of, 70-72

Frost, 37

Frozen North. See Polar Regions

Fruit, of Mediterranean region, 52,56

Fur trade, 147

Galloway, 225

Ganges, use, 30 ; basin, 68 ; teaching, 187

Genesis, 58, 68

Geneva, 120

Geology of Great Britain, 207-209

Germany, origin, 198 ; divisions, 200 ; climate, 56 ; reasons for greatness, 72-73; teaching, I93I94; attitude to, 203, 204, 205 ; schools, 74

Geysers, I45

Glamorgan coalfield, in Lower Standards, 131, 136 ; in Higher, 2II, 223

Glasgow, I4I

Glenmore, 225
Globes, use, 46, 94, 105; number needed, ro4 ; celestial, I76-18I

Gloucester, 217

Gobi, Desert of, 5I, I6o

Gold mines, 147 ; effect on population temporary, 79

"Golden Age," 66

Gorges, origin, 1 I8

Goring Gap, 214

Grading of streams, II6-II8, I45

Grampian Mountains, I36

Granite, II 4, 136

Grasslands, cause and distribution, 5I ; of Europe, 56; of Asia, 57 (see also Steppes); of Africa, 59; of North America, 53,$60 ;$ of South America, I9I

Great Basin, 52

Great Britain. See British Isles

Great Eastern Railway, 219

Great Northern Railway, 220

Great Ormes Head, 90

Great Western Railway, 2ro, 219, 220 ; in Wales, 222

Greece, climate, 55; contributions to civilizations, 7 I

Greeks, Ancient, 54, 71, 72

Greenland, $107,{ }_{56}$

Green Mountains, IIo

Grimsby, 140

Ground-plans, drawing of, roo

Guiana, I9I

Gulfs, 82

Gulf Stream, I54, I 55-156

Hamburg, I93-194, I95

Hampshire, 2II, 2I 2

Hansa League, I93

Hatteras, Cape, 156

Hay (Breconshire), 223 .

Heimatkunde. See Local Geography

Herbertson (A. J.), 68, 87, I45, I7I, I95, 200, 230, 23 I

Hereford, 218

Hiawatha, 146

Highlands of Scotland, I34, I35, 224,225

Hills. See Mountains

Himalayas as climatic barrier, 53 ; teaching, I6I, I86 


\section{THE TEACHING OF GEOGRAPHY}

Historical Geography of England, 2I6-2I8; of Wales, 220-223; of America, 234

History, 77-78, 82, I31, 221

Hoangho, 68, 12I, I88

Hogs, 60

Holland, 72. See also Low Countries

Holyhead, 222

Home Country. See British Isles

Home Geography. See Local Geography

Hop Gardens, 135

Horse Latitudes, I9

Hudson River, I09, I94, 195

Hull, I3I, I95-I96

Human side of Geography the chief, 2, 15, I8; scope of, 22-25

Humber, 195, 208

Hungary, $197,198,200$

Hunstanton Point, 208

Hunting life, 61, 66-67, I42, 146

Huron, Lake, I ro

Huxley, 3

Imagination, $83.84,86.87$, I 35

Imaginary lines on Maps, Ioo

Imperial responsibilities, I2

Imports, distribution of, 138,196 ; teaching, 227

Increasing and diminishing returns, 78

India, characteristics, 58 ; climate, $47,5 \mathrm{I}$; British rule in, 76 ; map of, I04; teaching, I69, 186-187

Indians. See under (I) Orientals ; (2) Red Indians

Indian Ocean, currents, 155

Indo-Chinese Peninsula, 58

Indus, delta of, $\mathrm{I} 20$; teaching, ${ }^{\mathrm{P}} \mathrm{r} 87$

Industrial system, 78, I33

Industries. See Manufactures, Agriculture, etc.

Industry, how to teach, 13, 205

Infant Schools, adoption of methods from, $83,89,95$, I 34

Institutions, growth of, 67-73 ; teaching of diverse, I4, 24-25, 26

interest as an aim, 14, 16
International Trade, 80, 138, I39,

14I, 227 ; statistics of, 233-235

Inventiveness, conditions of, $7 \mathrm{I}$

Investments, 78

Ipswich, 217

Iran, plateau of, 57, I 68

Ireland, rainfall, 226 ; industries, 227 ; teaching, I4I, 223

Iron, in England, I37; in Germany, I93; in America, 194 ; in Sweden, I96

Irrigation, 169,188

Islands, 29

Isobars, making, 239

Isotherms, 226; making, 239

Italy, climate, 54,55 ; contributions to civilization, $7 \mathbf{1}$; a unity, 200 ; attitude to, 203, 204, 205

Japan, climate, 51 , 156 ; characteristics, $5^{8}$; teaching, I6I, I70, I83; people, see Orientals

Job, Book of, 168

Jungle, teaching in Standard I., $40,4 \mathrm{I}, 45,85,88$; in Higher Standards, I69, I 86

Juras, 197

Jurassic Escarpment, 208, 210

Kalahari Desert, 5 I, 59, I59

Kamschatka, I55

Kansas, 44

Kent, 2II, 2I6 ; map-making, 2 I9 towns, 220

Kentucky, I 45

Kingston-on-Thames, II4

Kipling, R., 88, 237

“ Known to Unknown," 40

Korea, 58

Kuro Shiwo, I56

Labour, 75-77

Labrador, 60, 155

Lace industry, 195

Lake District, I4I, 209-210

Lakes, deltas in, 120; of England, 213 ; of St. Lawrence, I09, 194 Lampeter, 223

Lanarkshire, 225

Lancashire coal, 79 ; towns, 131 ; industry, I97; climate of, 76, 226 ; teaching, I36, 2 II 
Lancaster, $2 \mathrm{I} 7$

Land, economic conception of, 74,76 ; rise of property in, 69, 74

La Plata, I9I

Latitude and longitude, I06-I09

League of the Empire, IO7

Leeds, 137

Leicester, 217

Leicestershire heights, 208

Lemons, 56

Lewes, 218

Limestone, II4, II7, I45

Literature, rise of, 72 ; relation of Geography to, 236-238

Liverpool, 138, I95; reasons for position, 2 Io

Llanberis Pass, 222

Llandovery, 222

Llangollen, Vale of, 9I, II8

Llanidloes, 222, 223

Local Geography, 25 ; for modelling, 88-92; for drawing plans, 99-I00 ; for physiography, III129

London, reason for position, 138 , 223 ; growth, I99; trade, I3I, I96; teaching, 46, 138-140

London and North-Western Railway, 210, 220; in Wales, 222

Longfellow, 146

Loops of rivers, 120,144

Lothians, 225

Low Countries, 56, 200; attitude to, 203, 205

Lubeck, I93

Lucknow, I87

Lumbering, 147

Luton, 215

Luxury, rise of, 70

Machinery, origin of, 70

Machynlleth, 222

Mackenzie River, I45

Mackinder, H. J., 63, I54, 224, 226, 228, 229

Madrid, 199

Magdeburg, 193

Maine, 44, 60

Maize, 6o, 147, 194

Malay Archipelago, 50, 58, I59; teaching, I79, 183
Mammoth Caves, 6o, I45

Manchester, I3I, I37, I96

Manchuria, 52

Manitoba, 44, 60, 78, I94

Manufactures, origin, 70 ; economics, 76-77; localization, 133 , I96 ; teaching, I32-I33, I35I38, I4I, 2I4-2I5

Maps, how to draw deductions from, I7; use compared with accounts, 35 ; choice of, I03I04, 220, 238; map-making by class, 104-105, 108-110, 218220, 226 ; projections, 105-108 ; puzzle-maps, 219; Climatic maps, 226; Ordnance Survey, $97-98$, 102, 238 ; exercises on, 239 ; teaching, $35,40,46,88-$ 93, 95-103, I35

Markets in foreign countries, 9, 193-194, 195 ; determining manufactures, 76

Marlborough Downs, 208

Mauritius, 44

Mawddach, 222

Measurements, teaching, 99-100

Mediterranean Sea, not a barrier, 54 ; region round, $52,55-56,59$; civilization, 7I ; rainfall, 160

Medway, 220

Menai Straits, 90

Mental discipline, 6,7

Mercator's projection, I06-108

Merthyr Tydvil, II7

Mesopotamia, 57

Meteorology, I49-I54, I57-I60 ; meteorological reports, 154,226

Mexico, Gulf of, 53, I55, 195

Mexico, climate, I58, I 59

Michigan, 60

Middlesbrough, I96

Midland Railway, 219, 220

Midlands, 134 ; scenery, 83 ; division into counties, 216 ; mapmaking, 219, 220; teaching, 2 II

Milan, I98

Milwaukee, I Io

Minerals, $I 7,74$; teaching, 185

Minnesota, 44, 60, I94

Minoan civilization, $7 \mathbf{I}$

Mississippi, 29, I43-144, I45 ; carrying power, II5; delta, I20 ; 
basin, I47; facilities for trade, I95

Modelling, 46, 88-92, 99

Mohammedans, 54,75 ; in India, I86 ; teaching, I68. See Orientals

Mohawk River, I09, I94

Money, nature of, 79

Monsoons, I9, 39, I50-I5I, I62 ; countries influenced by, $5 \mathrm{I}, 58$, I6I, I66, I69-I70; teaching, I69, I 7I, I82-I 83

Montreal, I94

Moon, 37, 46, I67

Moral instruction, 205-206

Moral qualities of nations, 66-72, 205-206

Moravian Gap, 197

Morocco, 54

Moscow, 198

Mound-fortresses in England, 217

Mountains, effect on rainfall, 159 I60 ; on climate, 20r; as barriers, 20I ; of Great Britain, 208-209; modelling, 89, 91; teaching, 28,83

Mulberry, 56

Mycenæan civilization, $7 \mathrm{I}$

Names, limiting number that have to be taught, I, 5, 28-29, 3I, 42, $46,95,130,14 I$; in Great Britain, 212-213 ; in Wales, 221

Nant Ffrancon Yass, 222

National characteristics, 205-206

Natural Agents as a factor in production, 74,76

Nature-study, 36, II I , 125, I73

Naval supremacy, Io, 72

Navy, 131, 132, 136

Neath River, II7

Nebraska, 44

Netherlands, 56, 200; attitude to, 203, 205

Nevada, 79

New Brunswisk, 44

Newcastle, 136, I37

New England, 147,156

Newfoundland, 155

New Orleans, II 5

New York, rog-I to, 194-195

New Zealand, 63
Newspapers, attitude to, 7, I4; weather forecasts in, 227

Niagara, 60, II6-II7, I45; as a barrier, 195

Nile, 29, 68, II9, I88; delta, I20

Nineveh, 169

Nomads, 57,67

Norfolk, 2 I6

Normandy, 204

Northampton, 217

North Pole. See Polar Regions

North Sea, I93 ; civilization, 72-73

Northumberland, 137, 211

Norway, 72, 157; attitude to, 203, 205. See also Scandinavia

Norwich, 217

Nottingham, 195, 218

Nova Scotia, 44

Novels, use of, 88

Oats, 56

Object-lessons, 36, r35-136

Observational work, I72-178, I81

Oceania, 63

Oceans, teaching of, 95

Ochill Hills, 225

Oder, 193

Oldham (Yule), ro8

Old Sarum, 2 I8

Ontario (Lake), Io9, I95

Opium traffic, II

Oranges, 56

Ordnance Survey Maps, 97-99, I02, 238

Oregon, 44, 52, 60, 160

Orientals, characteristics, 54,70 ; attitude of Europeans to, 9, II, 24 ; pictures of, $24 \mathrm{I}$

Originality, rise of, $7 \mathrm{I}$

Ouse Basin, 2 I I

Oxford, 2I $4,215,218$

Pacific Ocean, currents, 154-156

Palestine, choice of map, I04; teaching, 168

Pamir plateau, 168

Paris, 198, 199

"Parks" (American), 60

Passes, importance, 28, 76, 20I ; of North Wales, 222

Pastoral life, 57, 59, 60, 67-68; teaching, 166,168 
Patriarchal institutions, 57, 67

Patriotism, teaching, 206

Peaks, unimportant, 28, 201, $2 \mathrm{I} 3$

Penarth, I20

Penmaenmawr, 90

Pennines, 209, 210

Persia, 47, 168, 169

Perth, 225

Philadelphia, 195

Phœenicians, 54,70

Physical Geography of countries, content of, 28-30. See also Physiography

Physiography, subsidiary to human side, 3, 4, I5; subject matter, III-I2I; illustrated by North America, 60-6I, I4I, I43I45; for Standard I., 9395 ; for Standard II, III, I2I-I25; for Upper Standards, 125-129: books on, 235. See also Climate

Pictures, use of, $84-86$; bad kinds, 92 ; selection of, $86,202,240-$ $24 \mathrm{I}$

Pigs, 60

Pilgrim Fathers, 62

Plains, 28,82 ; scenery, 83

Planets. See Solar System

Plans, drawing, 99-10o

Plasticene. See Modelling

Plateaux, characteristics, 52 ; when to teach, I70; teaching, $28,58,82,16 \mathrm{r}$; dissected, $\mathrm{I}_{44}$; of Africa, 192

Plymouth, I4O

Po, delta of, I20

Polar Regions, characteristics, 52, 60 ; description, 85 ; variation of temperature, $\mathrm{I}_{58}$; atmospheric pressure, I5I ; position of Sun, 164, 168, I79; representation on Mercator, I07; currents, 156 ; teaching in Standard I., $40,45,83,95$; in Upper Standards, I68

Pole Star, I 76, I 78

Political Economy. See Economics

Political Institutions, rise, 67, 6972 ; effect on industry, $75-76$
Political questions, bearing of Geography on, 8-12, 80

Pontsarn, I I7

Pontypridd, 223

Portmadoc, 222

Ports, specialized trade of, 196 ; teaching, I32, I38-139, I4O

Portsmouth, I 40

Post-cards (picture), use in teaching, 24I

Potteries, 42, 2I5 ; in Germany, I93

Potholes, II 7

Pressure, atmospheric, I5I-I 53

Prices, 80

Primitive Man, 66

Productions. See Vegetation, Minerals

Progressive course, need of, 33-34

Projections of maps, 105-108

Property, rise of, 69

Prophecy, safety of, 2I

Provence, 204

Prussia, 198

Puffin Island, 90

Puget Sound, 158

Puzzle Maps, 219

Quantitative work, 122, I25-129

Railways, 77 ; teaching, I05, I40, I4I, 2I9-220 ; in America, r47; in Siberia, I86; in Great Britain, 2IO-2II ; in Wales, 222

Rain, 37

Rainfall, I7, I56-160, I62 ; regions classified by, $50-52,53,55-63$; effect on Man, 67; of Australia, I9, I92; of Asia, I68-169; of South America, I9I-I92 ; maps, 226 ; exercises on, 239 ; teaching, $161,168,169,183$

Raleigh, Walter, 62

Ranching, 60, I47

Rapids, II7, I2I, I25, I45

Reading (Berks), 2I4, 2 I 5,218

Reading-books, 235, 236-237

Red Indians, 47, 6I, 67, I42, I45, I96

Regional Geography, 49-63; of British Isles, 132, 24I, 207; of 


\section{THE TEACHING OF GEOGRAPHY}

Asia, I84; of Siberia, 185-186; of India, 186-187; of Europe, I99-200; application to teaching, 184-r89; books on, 230232

Relief Maps, 93 ; making, 239

Religions (teaching of), in India, I87; in Asia, I89. See also Mohammedanism and Buddhism

Revision lessons, 44, I67, I70, I87-I89; on British Isles, 225228

Rhine, basin not a unit, 30, I99

Rhuddlan, 223

Rice, 58 ; teaching, 186

Rivers, life history, II2-I2I ; direction, 224: varieties, I43, I88-I89; use, 76, I88-I 89,216 ; in rainless lands, 6I, II8, 143I44; of England, 213; of Wales, 22I-223 ; of Scotland, 224; of Asia, 188-189; of Siberia, I85; of India, I86187; of North America, 6r, 143-1 45 ; determining the site of towns, I98-199, 217-218, 222 ; children's ideas of, I2I-I22; modelling, 89, 9r; basins not units for teaching, 30, I99-200 ; teaching, 29, 46, 83, 121-129, I 88- I 89

Rocky Mountains, 5I, 52, 53, 60

Roads, badness of Mediæval, 216 ; determination of site, 219-220, 222

Rochester, 220

Romans, 54, 7I

Rome, I99

Rote-learning, avoidance of, 2 I2216

Rotundity of the Earth. See Shape of Earth

Rousseau, I74

Ruabon, 222

Russia, origin, I98; expansion, 57, 186 ; in Europe, regions, 52,56 ; attitude to, 203, 204, 205 ; in Asia, see Siberia, Turkestan, Steppes, Tundras.

Rye, 56
Sahara, 5I, 57, 59, I59 ; as barrier, 54

Sailors, qualities of, $7 \mathrm{I}$

St. Lawrence, 52, 60, I09, I45; facilities for commerce, 195

St. Petersburg, I99

Salisbury, 218

Saloniki, I97

Sandstone, II4

Sand-trays. See Modelling

Saracens, 54

Savages, 62, 66

Savannahs, 62 ; teaching, I9I

Saxony, r93, I97

Scale-drawing, 97, 99-100

Scandinavia, 56, 72, 200

Scenery, pictures of, 240 . See also Descriptions

Schenectady, I94

Scotland, regions, 224 ; teaching, 224-225, 226

Scripture, teaching, 104

Sea, teaching of, 82

Seafaring life, effect, 7 I

Seasons, changes, 17 ; facts, 162 I65; teaching, 37-38, 46-47, I7I, I72, I73-I8I

Sediment. See Carrying-power of Rivers and Deposition

Semmering Pass, I97

Severn, basin, 208, 2II ; as route, into Wales, 222

Shadings of maps, 97-98, IOI-IO2, I05

Shadows, used to find altitude of Sun, I75, I77

Shape of Earth, I8 ; teaching, 36, 46,94

Sheep-farming, I34-r35

Sheffield, I37, I95

Shrewsbury, 218

Siberia, 52; climate, I58, I60; rivers, I86, I89; teaching, I68, $183,185-186$

Sidlaw Hills, 225

Sierra Leone, 44

Sierra Nevada, I6o

"Sights," how to teach, I40, 203

Sikiang River, 188

Silesia, I93

Silver, 79

Slate industry, 136 
Slavery, origin, 69

Slave-States, U.S.A., 59, 147

Snow, 37

Snowdon, I02, 262

Social institutions, 66-73, 23 I, 234

Socialism, 74

Sociology, relation of Geography to, 16, 64.65

Soil, 18

Solar Sytems, 37, 46, I67

Somerset, 2 Io

Soudan, 51,58

Sounds, 82

South Africa, 59 ; teaching, 192

Southampton, I96

South-Eastern Railway, 2 I9

Spain, coasts, 29: climate, 54, 55 ; people, 75 ; a unity, 200 ; attitude to, 203, 205; rainfall, 260

Specialization of industries, 69-70, 72,132

Spencer (Herbert), 5, 4I

Springs, 37 ; hot, I 45

Staffordshire. See Potteries and Black Country

Standard I., 40, 45-46, 8I-95

Standard II., 46, 99-I03, III, I2I125, I3 I-I37

Standard III., 46-47, I38-I48, I67, I72-I78, I8I

Standard IV., 47, I66-1 73, I78-I89

Standard V., 47-48, 190-193, 207228

Standard VI., 48, I93-206

Standard VII., 48

State, origin, 67

Statistics, use, 227 ; books of, 233235

Steel, 137, I95

Steppes, point of view, $5 \mathrm{I}, 67$, I66; effect of climate on, 40, 47 . I6I ; teaching, 57, 83, 168, 184

Stevenson, R. L., 60

Stirling, 225

Stories, 88

Stour (Kent), 219-220

Strathclyde, 225

Strathmore, 224

Straw, manufacture, 215

Structure, how to teach, 28
Subsequent rivers, 224

Suffolk, 2 I6

Sugar, 5I. See Beetroot

Suggestiveness in teaching, ${ }_{5}$

Sun, movements, $37,46,163-165$; teaching, I67, I68-169, I73-181

Sunderland, 196

Sunset, description, 84

Superior, Lake, I Io

Surface of Earth, changes on, II2

Surveying, 97

Sussex, 2II, 2I6

Swansea, 222

Sweden, 72. See also Scandinavia

Swindon, 2II

Switzerland, 72, 200 ; attitude to, 203

Symond's Yat, I20

Syr River, 189

Syria, 168

Szechuan, I88

Tablelands, 28, 52, 58, 82

Taff, II 8, 223

Taff's Watt Gorge, II8

Tariff Reform, I0, 80

Tarim River, 189

Tasmania, I92

Taxation, effect on industry, 75-76

Tay, 224, 225

Tea, 2I, 38, 58, I 70

Temperate regions, $51-52$, I 52-I 54 , I59; position of Sun in, I64

Temperature, I7, I57-I58, I62 ; variations, I $57-158, \mathrm{I} 68, \mathrm{I} 80$, 183,185 ; teaching, 39, I6I, I69, I74-I80, I83, I85 ; types, 50-52 $55-63$; effect on productions 38 ; on winds, 39 , I49-I $5 \mathrm{I}, 180$, 183 ; on Man, 66 ; of Australia, I9; of Asia, I68-I70, I83, I85 ; exercises on, 239

Tendencies, I3, 62

Terraces, river, I 19

Texas, 44,60

Text-books, use, 235

Thames, basin, II8, 208, 2II ; carrying power, II4; towns on, $2 I_{4}$; marshes, 216

Thar Desert, I59, I69

Tibet, $52,5^{8}$; teaching, I6I, I83 


\section{THE TEACHING OF GEOGRAPHY}

Timber, 196

Tobacco, 59

Towns, origin, 69 ; kinds, 3I, I3I ; reasons for position, 76 , I92, 193-199, 203, 214, 217-218, 222223; how to teacn, 3I, 193-r99, 2I 4 ; not too many, 42, 2I3; of Great Britain, I3I, I37-I4I, I95-I96, 2I7-218; of Wales, 222, 223

Towy, 222

Trade (see Commerce), traderoutes, 76 ; trade-cycle, 227

Trade-Winds, I9, 39, I49-I 5I, I62; belt of, 5I ; teaching, I69, I82183, I9I-I92

Transport, economics, 76-77 ; teaching, I32, 133

Trans-Siberian Railway, 186

Transvaal, 59

Travel, use of books of, 230,236 , 237-238

Trent, basin, 208, 21I ; mapmaking, 219

Trobwll, II3

Tropical forests, distribution, 50, I 59 ; described, 85-86; African, 59; South American, 62 ; teaching, I68, I9I ; in Standard I., 40,83

Tropical regions, effect on Man, 66 ; products, 38

Tropics of Cancer and Capricorn, position of Sun at, I62-I64; teaching of, 169,180 ; pressure and winds, I49, I5I, I59; deserts, $5 \mathrm{I}, 59$, I59; teaching of last two divisions, I8I-I82, I9I, I92

Tundras, 168

Tunis, 54

Turin, I98

Turk, former misgovernment, 76 , I68, I69

Turkestan, 68, I6I, see also Steppes ; rainfall of, 160

Turkey, 47, 55

Tyne ports, 196

\section{Ulster, 223}

Underground streams, II4

Unemployment, 77
United States, regions, $51,52,53$, $59-62,79$; point of view, 73,75 , teaching, 44, 147 ; towns, I94I95

Universities, Geography in, 2

Uplands, 52; of Great Britain, I $35,210,224$

Usk, 222

Valleys, formation of, II7-II8

Vancouver Island, 34, I55

Vegetation, 18 ; of regional types, 50-52; of continents, $55-63$; pictures, 240 ; teaching, 185

Victoria, I92

Vienna, I97-198, 199

Vikings, life, 72

Vine, 56

Virgil, 66

Vividness explained, 87 ; need of, 135

Volcanoes, I70, I83

Wages, 80

Wales, mountains, $135,209,222$; slate, I36; South, coalfield, I3r, I36, 2II, 223; teaching, 2IO, 220-223 ; rainfall, 226

Wall-maps, I03-I04, 220

Wall-pictures, 240-24I

Wars, causes of, 9 ; popular attitude to, II

Warwick, 218

Wash, basin, 208, 2 I I

Washington (State), 44, 52, 60, I6o

Water, work of, 46, 6I, II2-I29, I45; water-power, 76

Waterfalls, I I6-II7, I29, I45

Weald, 2II, 216; as determining roads, 219

Wealth, nature of, 79

Weather, forecasts and maps, I 54, 226; making of maps, 239 ; forecasting in school, 240

Weathering, I 12

Welshpool, 222, 223

Weser, I94

West Indies, 5I, 59, 62, I56

Wheat, conditions of growth, 38 ; in Europe, 56 ; in England, 78 , 134 ; in Siberia, I68, 185; in 
North America, 44, 6o, 147, 194; teaching, 168,185

White Mountains, 194

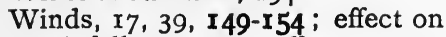
rainfall, I 59-160; effect on tem. perature, I $55, \mathrm{I} 57, \mathrm{I} 58$; effect on separate regions, $50-52$; of Australia, I9, I92; of South America, I9I; how to forecast weather from, 226; exercises on, 239 ; teaching, I6I, I67, I69, I72, I8I-183, I88, I9I-r92

Wolds, 208

Woollen manufacture in Lower Standards, 132, 136, 137 ; in Upper Standards, 145,197

Worcester, 2 I8
Wrexham, 223

Writing, invention of, 69

Wye, as example of Physiography, II 7, I 20 ; as route into Wales, 222 ; not industrial, 223

Yakutsk, 158

Yangtse, 68, r88

Yarmouth, I 40

Yellowstone River, 143; Park, I45

York, 218

Yorkshire, I3I, I36, I95, r97 ; teaching, $2 \mathrm{II}$; reasons for size, 215,216

Zambesi, 58

THE END 
AIR. 


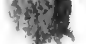

4 




\section{DAY USE}

RETURN TO DESK FROM WHICH BORROWED

\section{LOAN DEPT.}

This book is due on the last date stamped below, or on the date to which renewed.

Renewed books are subject to immediate recall.

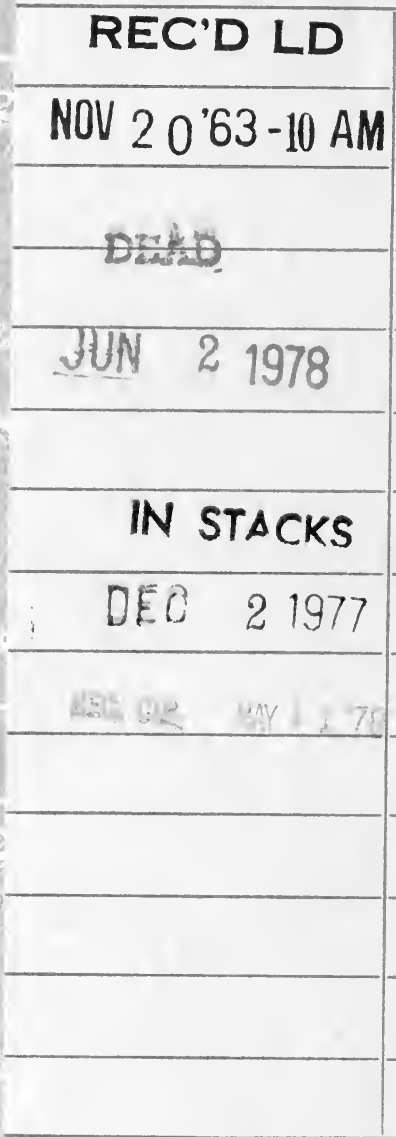


